\title{
Preliminary Models for Viscosity, \\ Thermal Conductivity, and Surface Tension of Pure Fluid Constituents of Selected Diesel Surrogate Fuels
}

\author{
Marcia L. Huber
}

This publication is available free of charge from: https://doi.org/10.6028/NIST.TN.1949

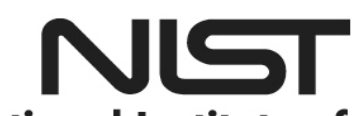

National Institute of Standards and Technology U.S. Department of Commerce 


\title{
Preliminary Models for Viscosity, Thermal Conductivity, and Surface Tension of Pure Fluid Constituents of Selected Diesel Surrogate Fuels
}

\author{
Marcia L. Huber \\ Applied Chemicals and Materials Division \\ Material Measurement Laboratory
}

This publication is available free of charge from:

https://doi.org/10.6028/NIST.TN.1949

January 2017

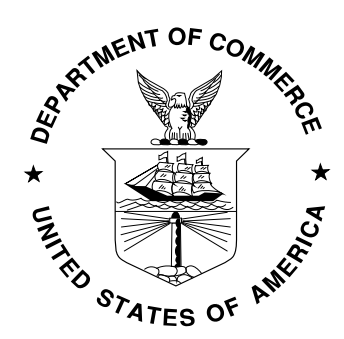

U.S. Department of Commerce

Penny Pritzker, Secretary

National Institute of Standards and Technology Kent Rochford, Acting NIST Director and Under Secretary of Commerce for Standards and Technology 
Certain commercial entities, equipment, or materials may be identified in this document in order to describe an experimental procedure or concept adequately. Such identification is not intended to imply recommendation or endorsement by the National Institute of Standards and Technology, nor is it intended to imply that the entities, materials, or equipment are necessarily the best available for the purpose.

National Institute of Standards and Technology Technical Note 1949

Natl. Inst. Stand. Technol. Tech. Note 1949, 62 pages (January 2017) CODEN: NTNOEF

This publication is available free of charge from:

https://doi.org/10.6028/NIST.TN.1949 


\begin{abstract}
We describe preliminary models for the viscosity, thermal conductivity, and surface tension for pure fluids that are constituents of four surrogate fuels for ultralow-sulfur diesel fuels developed under the auspices of the Coordinating Research Council (CRC). These fluids do not presently have published reference fluid quality models in the open literature, so we provide here preliminary models based on available data as an interim measure to allow calculations of these properties for both the pure fluids and the four surrogate mixtures. Comparisons with selected experimental pure-fluid data are given, and text files compatible with the NIST REFPROP computer program are included as supplementary material. We also present tabulations of the viscosity, thermal conductivity, and surface tension along the bubble point for four surrogate fuels.
\end{abstract}

\title{
Keywords
}

diesel fuel; REFPROP; surface tension; surrogate; thermal conductivity; viscosity. 


\section{Table of Contents}

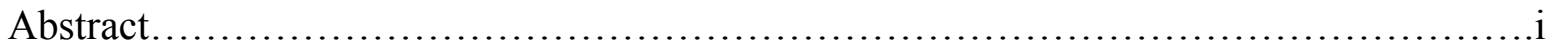

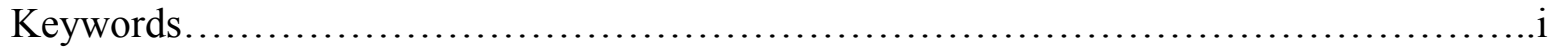

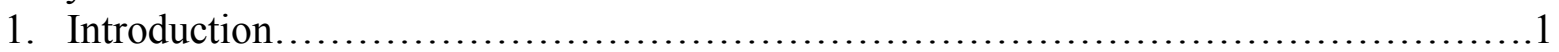

2. Pure Fluid Viscosity Model..................................................... 2

3. Pure Fluid Thermal Conductivity Model.......................................4

4. Pure Fluid Surface Tension Model................................................ 5

5. Application to the Surrogate Constituent Fluids...................................... 5

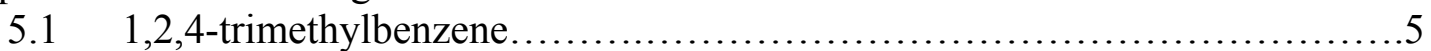

$5.2 \quad 1,3,5$-triisopropylbenzene......................................... 14

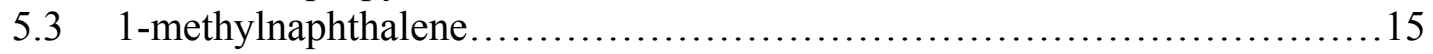

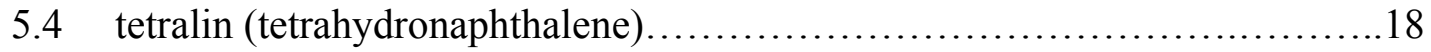

5.5 n-butyl cyclohexane.................................................

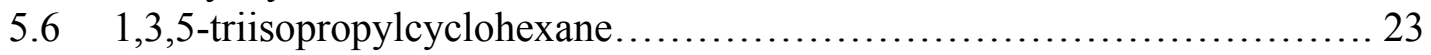

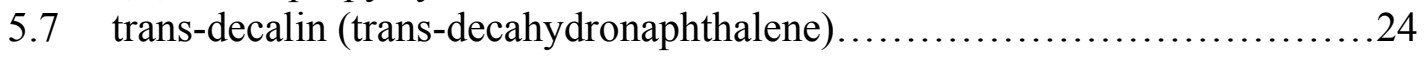

5.8 perhydrophenanthrene (tetradecahydrophenanthrene) $\ldots \ldots \ldots \ldots \ldots \ldots \ldots \ldots . .27$

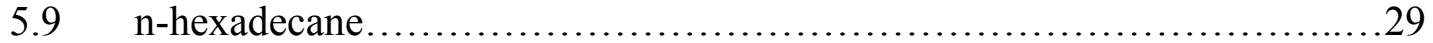

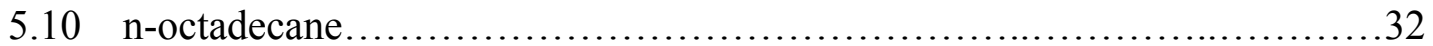

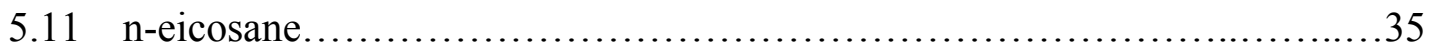

5.12 2-methylheptadecane............................................ 38

$5.132,2,4,4,6,8,8$-heptamethylnonane (isohexadecane).......................40

6. Application to the Surrogate Mixtures......................................... 41

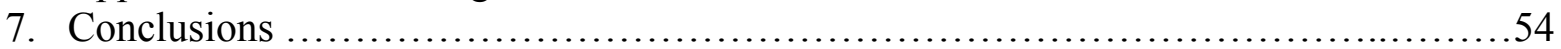

8. Acknowledgements....................................................... 54

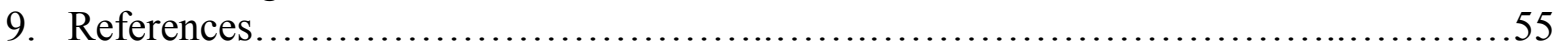

10. Appendix: fluid (.FLD) and (.MIX) text files for use with REFPROP.................62 


\section{Introduction}

Diesel fuels are complex mixtures that contain hundreds of individual chemical compounds. Modelling the thermophysical properties of such a mixture is often done by creating a simpler representation of the fuel, called a surrogate mixture, containing far fewer compounds (typically less than a dozen) that represents selected properties of the actual real fuel. Mueller et al. (1-3) developed four surrogate mixtures that were designed to reproduce the ignition characteristics (derived cetane number), volatility, density, and carbon bond types of actual ultralow sulfur diesel fuels. The surrogates ranged from a simple 4-component mixture to a 9component mixture. The compositions of these surrogates $(2,3)$ are shown in Table 1 . Details on the properties of these surrogates were presented by Mueller et al. (2, 3); however, the viscosity, thermal conductivity, and surface tension of the surrogate models were not given. In this work, we present the details of the surrogates and data used to develop correlations for the viscosity, thermal conductivity, and surface tension of the pure fluids constituents of the four surrogates, and these properties for the 4 surrogate mixtures computed along the bubble point. We also provide text files that can be used with the REFPROP computer program (4) to compute these properties. 
Table 1. Compositions of the surrogate fuels (2)

\begin{tabular}{|c|c|c|c|c|}
\hline fluid & $\begin{array}{l}\text { V0a surrogate } \\
\text { mole fraction }\end{array}$ & $\begin{array}{l}\text { V0b surrogate } \\
\text { mole fraction }\end{array}$ & $\begin{array}{l}\text { V1 surrogate } \\
\text { mole fraction }\end{array}$ & $\begin{array}{l}\text { V2 surrogate } \\
\text { mole fraction }\end{array}$ \\
\hline$n$-hexadecane & 0.278 & - & 0.027 & - \\
\hline$n$-octadecane & - & 0.235 & 0.202 & 0.108 \\
\hline$n$-eicosane & - & - & - & 0.008 \\
\hline isohexadecane & 0.363 & 0.270 & 0.292 & - \\
\hline 2-methylheptadecane & - & - & - & 0.073 \\
\hline$n$-butylcyclohexane & - & - & 0.051 & 0.191 \\
\hline 1,3,5-triisopropylcyclohexane & - & - & - & 0.110 \\
\hline trans-decalin & 0.148 & - & 0.055 & - \\
\hline Perhydrophenanthrene & - & - & - & 0.060 \\
\hline 1,2,4-trimethylbenzene & - & 0.125 & 0.075 & - \\
\hline 1,3,5-triisopropylbenzene & - & - & - & 0.147 \\
\hline tetralin & - & 0.209 & 0.154 & 0.164 \\
\hline 1-methylnaphthalene & 0.211 & 0.161 & 0.144 & 0.139 \\
\hline
\end{tabular}

The NIST REFPROP computer program (4) provides models for the thermophysical properties of commonly used industrial fluids, including refrigerants, natural gas fluids, cryogens, alcohols, and other fluids. The goal is to provide high-accuracy models that can represent the thermophysical properties of the fluids to within their experimental uncertainty. For some fluids, lack of experimental data prevents this goal from being achieved. As a result, we provide here some models (considered preliminary) that can be used to compute thermophysical properties in REFPROP until more data and better models become available. A previous publication (5) described the extended corresponding states model for viscosity and thermal conductivity implemented in REFPROP, which is based on the earlier publications by Ely and Hanley $(6,7)$. This method is also discussed in additional publications (8-12); here we will present the coefficients and comparisons with data; the reader is referred to earlier publications for details on the methodology.

\section{Pure Fluid Viscosity Model}

The viscosity of a pure fluid is represented as a sum of a dilute gas and a residual contribution. Only the residual contribution is treated via corresponding states:

$$
\eta(T, \rho)=\eta^{*}(T)+\Delta \eta(T, \rho)=\eta^{*}(T)+\Delta \eta_{0}\left(T_{0}, \rho_{0}\right) F_{\eta}(T, \rho),
$$

where the superscript $*$ denotes a dilute gas value, and the subscript 0 denotes a reference fluid value. The viscosity of the reference fluid is evaluated at a conformal temperature and density $T_{0}$ and $\rho_{0}$ given by

$$
T_{0}=T / f
$$

and

$$
\rho_{0}=\rho h
$$


The quantities $f$ and $h$ are called equivalent substance reducing ratios, and relate the reference fluid to the fluid of interest using a ratio of critical parameters (denoted by the subscript c) and functions of temperature and density known as shape factors $\theta$ and $\Phi$,

$$
f=\frac{T_{\mathrm{c}}}{T_{\mathrm{c} 0}} \theta
$$

and

$$
h=\frac{\rho_{\mathrm{c} 0}}{\rho_{\mathrm{c}}} \phi .
$$

The shape factors can be considered functions of both temperature and density. In this work, we generally have available accurate formulations for the thermodynamic properties of the fluids, either in terms of a Helmholtz free energy equation or a PVT equation of state (EOS), and we use a form of the "exact" shape factor method. It is a requirement in this method to first determine the thermodynamic shape factors.

The dilute gas viscosity in Eq. (1) is found by Chapman-Enskog theory (13)

$$
\eta^{*}(T)=\frac{5 \sqrt{m k_{\mathrm{B}} T}}{16 \pi \sigma^{2} \Omega^{(2,2)}},
$$

where the dilute gas viscosity is $\eta^{*}, m$ is the molecular mass, $k_{\mathrm{B}}$ is the Boltzmann constant, and $T$ is the absolute temperature. We will further assume that a Lennard-Jones 12-6 potential applies, and use the Lennard-Jones collision diameter for $\sigma$. Neufeld et al. (14) gave the following empirical correlation for the calculation of the collision integral $\Omega^{(2,2)}$

$$
\Omega^{(2,2)}=1.16145\left(T^{*}\right)^{-0.14874}+0.52487 \mathrm{e}^{-0.77320 T^{*}}+2.16178 \mathrm{e}^{-2.43787 T^{*}},
$$

with the dimensionless temperature $T^{*}=k_{\mathrm{B}} T / \varepsilon$, and $\varepsilon$ the minimum of the Lennard-Jones pairpotential energy. The range of validity of this empirical correlation is $0.3<T^{*}<100$.

The factor $F_{\eta}$ in Eq. (1) is found using the expression

$$
F_{\eta}=f^{1 / 2} h^{-2 / 3}\left[\frac{M}{M_{0}}\right]^{1 / 2},
$$

where $M$ is the molar mass of the fluid and $M_{0}$ is the molar mass of the reference fluid. The model as developed to this point is predictive, and does not use any information on the viscosity of the fluid (except for the dilute-gas contribution that requires Lennard-Jones $\varepsilon$ and $\sigma$ ). The functions $f$ and $h$ are found from thermodynamic data. In order to improve the representation of the viscosity, an empirical correction factor may be used if there are experimental viscosity data available. We then evaluate Eq. (1) at $\rho_{0, \mathrm{v}}$ instead of $\rho_{0}$, where (12)

$$
\rho_{0, v}(T, \rho)=\rho_{0}(T, \rho) \psi\left(\rho_{\mathrm{r}}\right),
$$


and $\psi$ is a polynomial in reduced density $\rho_{\mathrm{r}}=\rho / \rho_{\mathrm{c}}$ of the form

$$
\psi\left(\rho_{\mathrm{r}}\right)=\sum_{k=0}^{n} c_{k} \rho_{\mathrm{r}}^{\mathrm{k}}
$$

where the coefficients $c_{k}$ are constants found from fitting the experimental viscosity data. As indicated in Eq. (1), in order to evaluate the viscosity of a particular fluid, the value of the residual viscosity of a reference fluid is required. It is not necessary to use the same reference fluid for all fluids. However, when using the model in a predictive mode, it is best to select the reference fluid that is most similar in chemical nature to the fluid of interest. The reference fluid should also have a very accurate equation of state and viscosity surface. When using pure fluid experimental viscosity to essentially "correct" the viscosity, the choice of reference fluid is not as important since an empirical correction factor determined from data is applied as in Eqs. (9-10).

\section{Pure Fluid Thermal Conductivity Model}

We start with the procedure of Ely and Hanley (7) and represent the thermal conductivity of a fluid as the sum of translational (from collisions between molecules) and internal (due to internal motions of the molecule) modes of energy transfer,

$$
\lambda(T, \rho)=\lambda^{\text {int }}(T)+\lambda^{\text {trans }}(T, \rho) .
$$

The translational contribution may be further divided into a dilute-gas contribution (denoted here by a superscript *) that is a function only of temperature, a residual contribution, and a critical enhancement,

$$
\lambda^{\text {trans }}(T, \rho)=\lambda^{*}(T)+\lambda^{\mathrm{r}}(T, \rho)+\lambda^{\text {crit }}(T, \rho) .
$$

leading to the following expression for the thermal conductivity

$$
\lambda(T, \rho)=\lambda^{\text {int }}(T)+\lambda^{*}(T)+\lambda^{\mathrm{r}}(T, \rho)+\lambda^{\text {crit }}(T, \rho) .
$$

We use an Eucken correlation for the internal contribution

$$
\lambda^{\mathrm{int}}(T)=\frac{f_{\mathrm{int}} \eta^{*}}{M}\left[C_{p}^{*}-\frac{5}{2} R\right],
$$

where $C_{p} *$ is the ideal-gas heat capacity in $\mathrm{J} /(\mathrm{mol} \cdot \mathrm{K}), R$ is the molar gas constant (15) (8.314 4598 $\mathrm{J} /(\mathrm{mol} \cdot \mathrm{K})), \eta^{*}$ is the dilute-gas viscosity $(\mu \mathrm{Pa} \cdot \mathrm{s})$ as given in Eq. $(6), f_{\text {int }}$ is set to $1.32 \times 10^{-3}$, and $\lambda$ is in $\mathrm{W} /(\mathrm{m} \cdot \mathrm{K})$. If sufficient dilute-gas thermal conductivity data are available, $f_{\text {int }}$ is fit to a polynomial in temperature,

$$
f_{\text {int }}=a_{0}+a_{1} T \text {. }
$$

For the dilute-gas translational contribution (in $\mathrm{W} /(\mathrm{m} \cdot \mathrm{K})$ ), we use 


$$
\lambda^{*}(T)=\frac{15 \times 10^{-3} R \eta^{*}}{4 M},
$$

where the dilute gas viscosity, $\eta^{*}$, is from Eq. (6). The residual contribution is found using extended corresponding states:

$$
\lambda^{\mathrm{r}}(T, \rho)=\lambda_{0}^{\mathrm{r}}\left(T_{0}, \rho_{0}\right) F_{\lambda},
$$

with

$$
F_{\lambda}=f^{1 / 2} h^{-2 / 3}\left[\frac{M_{0}}{M}\right]^{1 / 2} .
$$

In order to improve the representation of the thermal conductivity, an empirical correction factor may be used if there are experimental thermal conductivity data available. We then evaluate Eq. (17) at $\rho_{0, \mathrm{k}}$ instead of $\rho_{0}$, where (11)

$$
\rho_{0, k}(T, \rho)=\rho_{0}(T, \rho) \chi\left(\rho_{\mathrm{r}}\right),
$$

and $\chi$ is a polynomial in reduced density $\rho_{\mathrm{r}}=\rho / \rho_{\mathrm{c}}$ of the form

$$
\chi\left(\rho_{\mathrm{r}}\right)=\sum_{k=0}^{n} b_{k} \rho_{\mathrm{r}}^{\mathrm{k}},
$$

where the coefficients $b_{k}$ are found from fitting the experimental thermal conductivity data.

The critical contribution is computed using a simplified crossover model developed by Olchowy and Sengers (16), and later generalized (17) so that it may be used knowing only $T_{\mathrm{c}}, \rho_{\mathrm{c}}$, $p_{c}$, the acentric factor $\omega$, and the molar mass of the component. Details of the equations can be found in Ref. (17); we report only the coefficients here.

\section{Pure Fluid Surface Tension Model}

We fit surface tension data to a commonly used equation that has been used successfully for other fluids in the REFPROP program (18):

$$
\sigma(T)=\sum_{i=0}^{k-1} \sigma_{i}\left(1-\frac{T}{T_{\mathrm{c}}}\right)^{n_{i}},
$$

where $\sigma_{i}$ and $n_{i}$ are coefficients obtained from fitting data and $T_{\mathrm{c}}$ is the critical temperature.

\section{Application to the Surrogate Constituent Fluids}

\section{$5.1 \quad$ 1,2,4-trimethylbenzene}

As mentioned above, it is first necessary to have a representation of the PVT properties of a fluid available before a transport model can be constructed. For 1,2,4-trimethylbenzene, we use a preliminary Helmholtz-energy equation of state developed using the NIST (ThermoData Engine) 
TDE software tool (19) to provide density. The equation of state is implemented in the REFPROP text file included in Supplementary materials. There were no viscosity data found for the gas phase, so we estimated the Lennard-Jones parameters using the method of Chung et al. (20); these are given in Table 2 along with the critical parameters. The critical parameters are consistent with the equation of state as generated by TDE (19). For the liquid phase, the viscosity data of Zambrano et al. (21) were used to obtain the coefficients in Table 3, with toluene as a reference fluid. For toluene, the equation of state, viscosity surface, and thermal conductivity surface are given by references (22-24) respectively. Data up to $50 \mathrm{MPa}$ were used in the fit; the upper pressure limit on the equation of state. Two different measurement techniques were used in Zambrano's studies; a vibrating wire method and a falling body method. Zambrano et al. (21) give an estimated uncertainty of $1.5 \%$ for the vibrating wire measurements, and $4.0 \%-4.9 \%$ for the falling body method. The sample was $99.7 \%$ pure. Figure 1 shows the percentage deviations between the predictions of the model and the viscosity data of Zambrano et al. (21) at pressures up to $50 \mathrm{MPa}$. Here we define percentage deviation as $100\left(X_{\text {exp }}-X_{\text {cal }}\right) / X_{\text {cal }}$ where $\mathrm{X}$ is any property of interest and the subscripts exp and cal denote experimental values and calculated values respectively. The deviations are within $4 \%$. As mentioned earlier, there are no gas-phase viscosity data available and the method of Chung was used for Lennard-Jones parameters. Although Chung et al. (20) gives an estimated uncertainty of $1.5 \%$ for viscosity of their method, our experience indicates that the uncertainty of the viscosity of the low-pressure gas using this method is more likely on the order of $10 \%$. When uncertainty is discussed in this document, it is the expanded uncertainty with a coverage factor of two, that is approximately a $95 \%$ confidence interval. 
Table 2. Critical parameters and Lennard-Jones parameters of the pure fluids

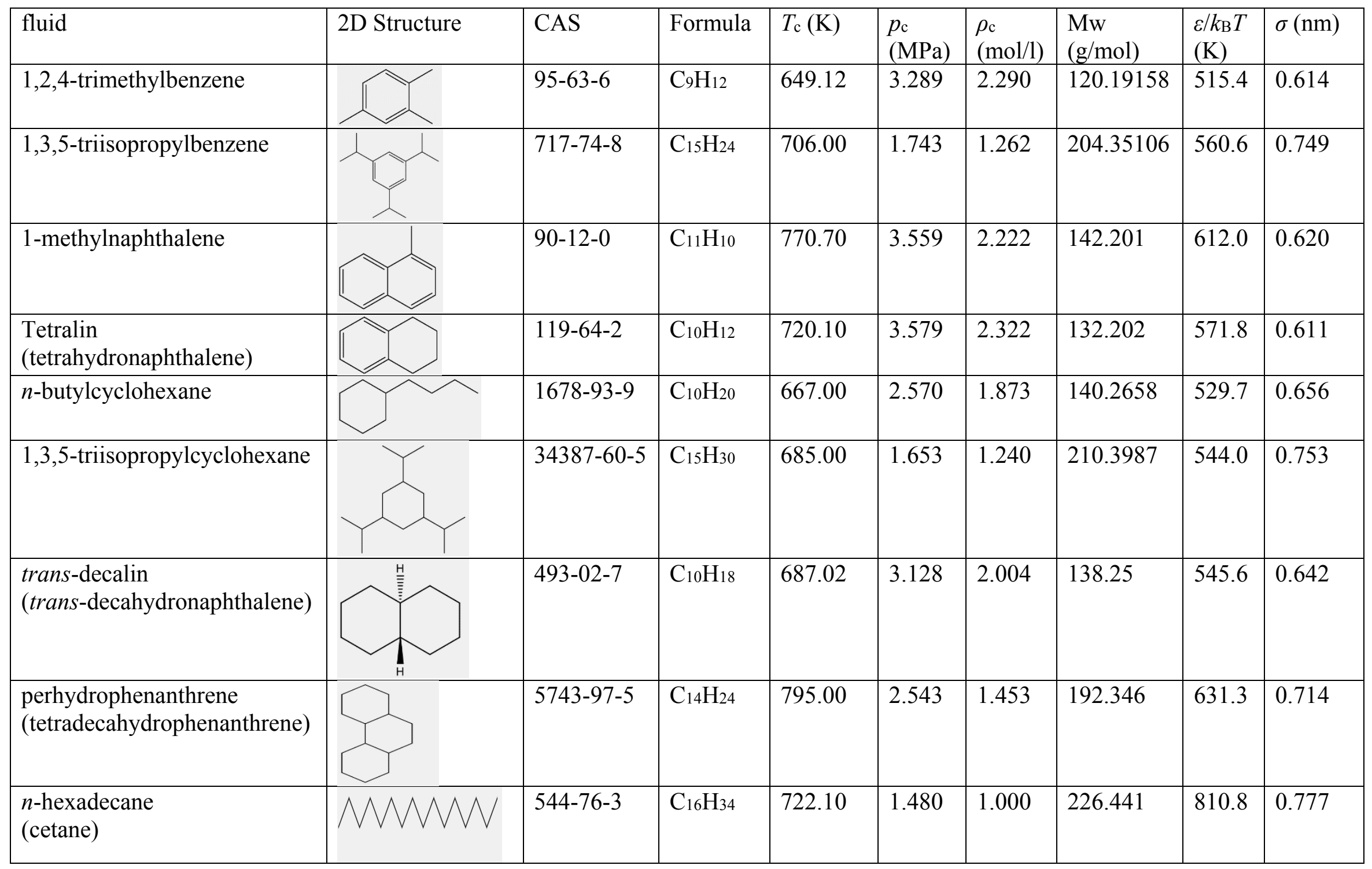




\begin{tabular}{|c|c|c|c|c|c|c|c|c|}
\hline$n$-octadecane & $593-45-3$ & $\mathrm{C}_{18} \mathrm{H}_{38}$ & 748.17 & 1.335 & 0.851 & 254.49432 & 495.8 & 0.9693 \\
\hline$n$-eicosane & $112-95-8$ & $\mathrm{C}_{20} \mathrm{H}_{42}$ & 771.38 & 1.198 & 0.758 & 282.54748 & 506.4 & 1.0166 \\
\hline 2-methylheptadecane & $1560-89-0$ & $\mathrm{C}_{18} \mathrm{H}_{38}$ & 735.90 & 1.325 & 0.873 & 254.49432 & 495.8 & 0.9693 \\
\hline $\begin{array}{l}2,2,4,4,6,8,8- \\
\text { heptamethylnonane } \\
\text { (isohexadecane) }\end{array}$ & $4390-04-9$ & $\mathrm{C}_{16} \mathrm{H}_{34}$ & 691.90 & 1.527 & 1.045 & 226.441 & 484.0 & 0.9195 \\
\hline
\end{tabular}


Table 3. Coefficients for the residual viscosity, Eq. (10)

\begin{tabular}{|l|l|l|l|l|}
\hline Fluid & Ref fluid & $c_{0}$ & $c_{1}$ & $c_{2}$ \\
\hline $1,2,4$-trimethylbenzene & toluene & 1.05079 & $-2.04689 \times 10^{-2}$ & 0 \\
\hline $1,3,5$-triisopropylbenzene & $n$-dodecane & 0.910009 & $4.04269 \times 10^{-2}$ & 0 \\
\hline 1 -methylnaphthalene & $n$-dodecane & 1.28631 & -0.276013 & $5.96372 \times 10^{-2}$ \\
\hline tetralin & $n$-dodecane & 1.19682 & -0.188106 & $4.22595 \times 10^{-2}$ \\
\hline$n$-butylcyclohexane & $n$-dodecane & 1.890620 & -0.592088 & 0.101177 \\
\hline $1,3,5$-triisopropylcyclohexane & $n$-dodecane & 2.30414 & -0.913555 & 0.1629890 \\
\hline trans-decalin & $n$-octane & 0.922666 & $9.77294 \times 10^{-2}$ & $-1.77959 \times 10^{-2}$ \\
\hline perhydrophenanthrene & propane & 1.60622 & -0.391015 & $6.72735 \times 10^{-2}$ \\
\hline$n$-hexadecane & $n$-dodecane & 0.7089890 & 0.193475 & $-3.26736 \times 10^{-2}$ \\
\hline$n$-octadecane & $n$-dodecane & 0.754491 & 0.174577 & $-3.11008 \times 10^{-2}$ \\
\hline$n$-eicosane & $n$-dodecane & 0.19691 & 0.513560 & $-8.26291 \times 10^{-2}$ \\
\hline 2 -methylheptadecane & $n$-dodecane & 1.14146 & $-4.3467 \times 10^{-2}$ & 0 \\
\hline $2,2,4,4,6,8,8$-heptamethylnonane & $n$-octane & 0.438645 & 0.409351 & $-6.83895 \times 10^{-2}$ \\
\hline
\end{tabular}

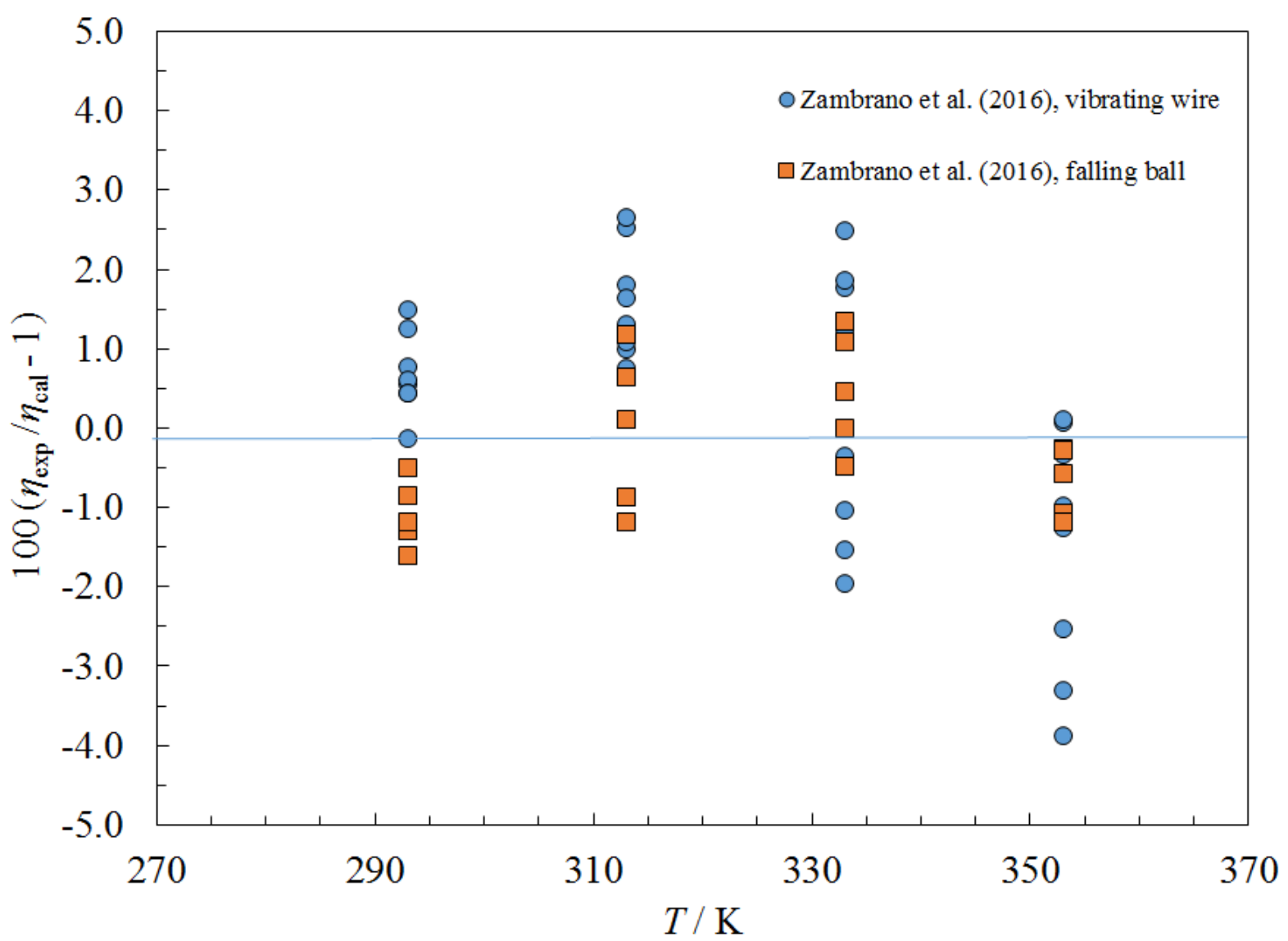

Figure 1. Percentage deviations between the model and the experimental viscosity data for 1,2,4-trimethylbenzene. 
For thermal conductivity, there were no experimental data available for the gas phase for 1,2,4-trimethylbenzene. There are data for a similar aromatic fluid, o-xylene, and using a coefficient of $1.32 \times 10^{-3}$ for $f_{i n t}$ in Eq. (14) as recommended by Ely and Hanley (7) results in atmospheric gas-phase thermal conductivities within $10 \%$, so we adopted this same value for 1,2,4-trimethylbenzene. Liquid-phase data of Watanabe and Kato (25), Bachmann (26), Rastorguev and Pugach (27), and Mukhamedzyanov and Usmanov (28) were used to obtain the coefficients in Table 4. Parameters for the critical enhancement term are given in Table 5, these were obtained by the predictive method of Perkins et al. (17) since critical-region data were unavailable for regression. In fact, we have used the predictive methods of Perkins et al. (17) for all of the fluids in this study to obtain the coefficients in Table 5. The liquid phase data ranged from $257 \mathrm{~K}$ to $433 \mathrm{~K}$ but are all at atmospheric pressure. Compressed liquid data are unavailable. Figure 2 shows deviations between the model and the experimental liquid phase thermal conductivity data; agreement is within $3 \%$.

Table 4. Coefficients for the dilute gas and residual thermal conductivity, Eq. (15), Eq. (20)

\begin{tabular}{|l|l|l|l|l|l|}
\hline Fluid & Ref fluid & $a_{0}$ & $a_{1}$ & $b_{0}$ & $b_{1}$ \\
\hline $1,2,4$-trimethylbenzene & toluene & $1.32 \times 10^{-3}$ & 0 & 0.990229 & $1.824820 \times 10^{-2}$ \\
\hline $1,3,5$-triisopropylbenzene & $n$-dodecane & $1.32 \times 10^{-3}$ & 0 & 0.828581 & $2.843380 \times 10^{-2}$ \\
\hline 1 -methylnaphthalene & $n$-dodecane & $1.32 \times 10^{-3}$ & 0 & 0.248975 & 0.17313 \\
\hline tetralin & $n$-dodecane & $1.32 \times 10^{-3}$ & 0 & 0.616641 & $5.10625 \times 10^{-2}$ \\
\hline$n$-butylcyclohexane & $n$-dodecane & $1.32 \times 10^{-3}$ & 0 & 0.50285 & 0.104913 \\
\hline $1,3,5$-triisopropylcyclohexane & $n$-dodecane & $1.32 \times 10^{-3}$ & 0 & 0.825035 & $3.2034 \times 10^{-2}$ \\
\hline trans-decalin & $n$-octane & $1.32 \times 10^{-3}$ & 0 & 0.831643 & $2.85909 \times 10^{-2}$ \\
\hline perhydrophenanthrene & propane & $1.32 \times 10^{-3}$ & 0 & 1.09 & 0 \\
\hline$n$-hexadecane & $n$-dodecane & $-3.76198 \times 10^{-4}$ & $2.51009 \times 10^{-6}$ & 1.21684 & $-3.54131 \times 10^{-2}$ \\
\hline$n$-octadecane & $n$-dodecane & $-1.64777 \times 10^{-4}$ & $2.27706 \times 10^{-6}$ & 1.31598 & $-5.06388 \times 10^{-2}$ \\
\hline$n$-eicosane & $n$-dodecane & $1.32 \times 10^{-3}$ & 0 & 1.12883 & $4.94959 \times 10^{-3}$ \\
\hline 2 -methylheptadecane & $n$-dodecane & $1.32 \times 10^{-3}$ & 0 & 1.11057 & $7.99217 \times 10^{-4}$ \\
\hline $2,2,4,4,6,8,8$-heptamethylnonane & $n$-octane & $1.32 \times 10^{-3}$ & 0 & 0.957608 & $3.47277 \times 10^{-2}$ \\
\hline
\end{tabular}


Table 5. Coefficients for the critical enhancement of thermal conductivity

\begin{tabular}{|l|l|l|l|}
\hline Fluid & $\bar{\Gamma}_{0}$ & $\xi_{0}(\mathrm{~m})$ & $\bar{q}_{D}^{-1}(\mathrm{~m})$ \\
\hline 1,2,4-trimethylbenzene & 0.060 & $0.243 \times 10^{-9}$ & $0.751 \times 10^{-9}$ \\
\hline 1,3,5-triisopropylbenzene & 0.054 & $0.289 \times 10^{-9}$ & $0.921 \times 10^{-9}$ \\
\hline 1 -methylnaphthalene & 0.055 & $0.249 \times 10^{-9}$ & $0.759 \times 10^{-9}$ \\
\hline tetralin & 0.057 & $0.247 \times 10^{-9}$ & $0.748 \times 10^{-9}$ \\
\hline$n$-butylcyclohexane & 0.054 & $0.269 \times 10^{-9}$ & $0.805 \times 10^{-9}$ \\
\hline $1,3,5$-triisopropylcyclohexane & 0.058 & $0.275 \times 10^{-9}$ & $0.927 \times 10^{-9}$ \\
\hline trans-decalin & 0.060 & $0.262 \times 10^{-9}$ & $0.786 \times 10^{-9}$ \\
\hline perhydrophenanthrene & 0.060 & $0.282 \times 10^{-9}$ & $0.878 \times 10^{-9}$ \\
\hline$n$-hexadecane & 0.063 & $0.291 \times 10^{-9}$ & $0.998 \times 10^{-9}$ \\
\hline$n$-octadecane & 0.066 & $0.302 \times 10^{-9}$ & $1.054 \times 10^{-9}$ \\
\hline$n$-eicosane & 0.066 & $0.310 \times 10^{-9}$ & $1.097 \times 10^{-9}$ \\
\hline 2-methylheptadecane & 0.066 & $0.297 \times 10^{-9}$ & $1.045 \times 10^{-9}$ \\
\hline $2,2,4,4,6,8,8-$ heptamethylnonane & 0.060 & $0.302 \times 10^{-9}$ & $0.983 \times 10^{-9}$ \\
\hline
\end{tabular}

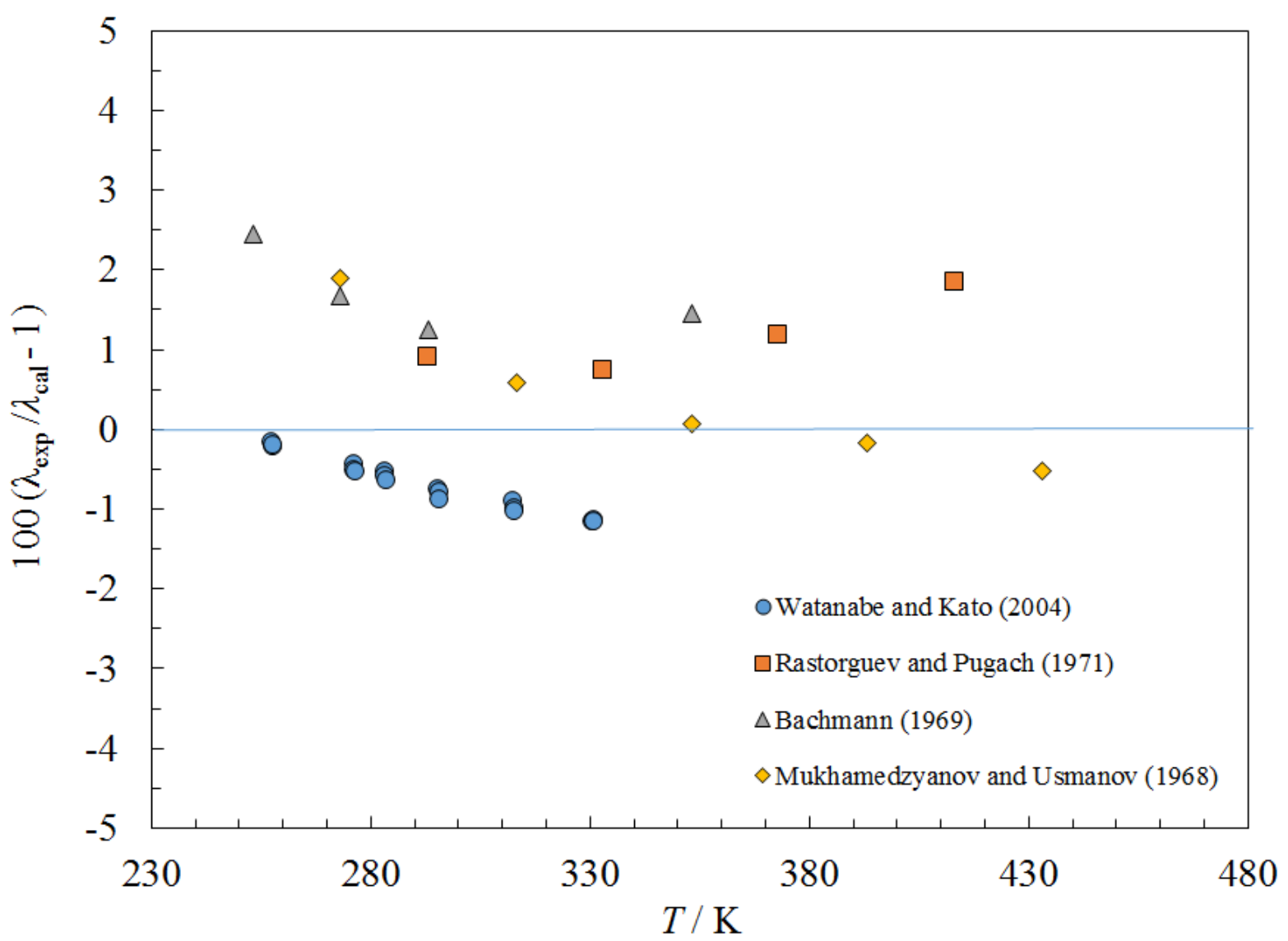

Figure 2. Percentage deviations between the model and the experimental thermal conductivity data for 1,2,4-trimethylbenzene. 
Finally, for surface tension, we fit the experimental data in references (29-36) to the functional form of Eq. (21); the coefficients are presented in Table 6 with the critical temperature as given in Table 2. Figure 3 shows the deviations between the correlation and the data. Deviations are within the estimated experimental uncertainty of $1 \%$ and cover $293 \mathrm{~K}<\mathrm{T}<313 \mathrm{~K}$.

Table 6. Coefficients for the surface tension

\begin{tabular}{|l|l|l|}
\hline Fluid & $\sigma_{0}$ & $n_{0}$ \\
\hline $1,2,4$-trimethylbenzene & 0.063359 & 1.25726 \\
\hline $1,3,5$-triisopropylbenzene & 0.0621645 & 1.36768 \\
\hline 1-methylnaphthalene & 0.0643111 & 1.08315 \\
\hline tetralin & 0.0639142 & 1.22821 \\
\hline$n$-butylcyclohexane & 0.0797228 & 1.88799 \\
\hline $1,3,5$-triisopropylcyclohexane & 0.0540756 & 1.13934 \\
\hline trans-decalin & 0.062032 & 1.31232 \\
\hline perhydrophenanthrene & 0.0602276 & 1.2188 \\
\hline$n$-hexadecane & 0.0568196 & 1.3815 \\
\hline$n$-octadecane & 0.0588982 & 1.45556 \\
\hline$n$-eicosane & 0.0580481 & 1.42901 \\
\hline 2-methylheptadecane & 0.0568885 & 1.37472 \\
\hline 2,2,4,4,6,8,8-heptamethylnonane & 0.0476977 & 1.2296 \\
\hline
\end{tabular}




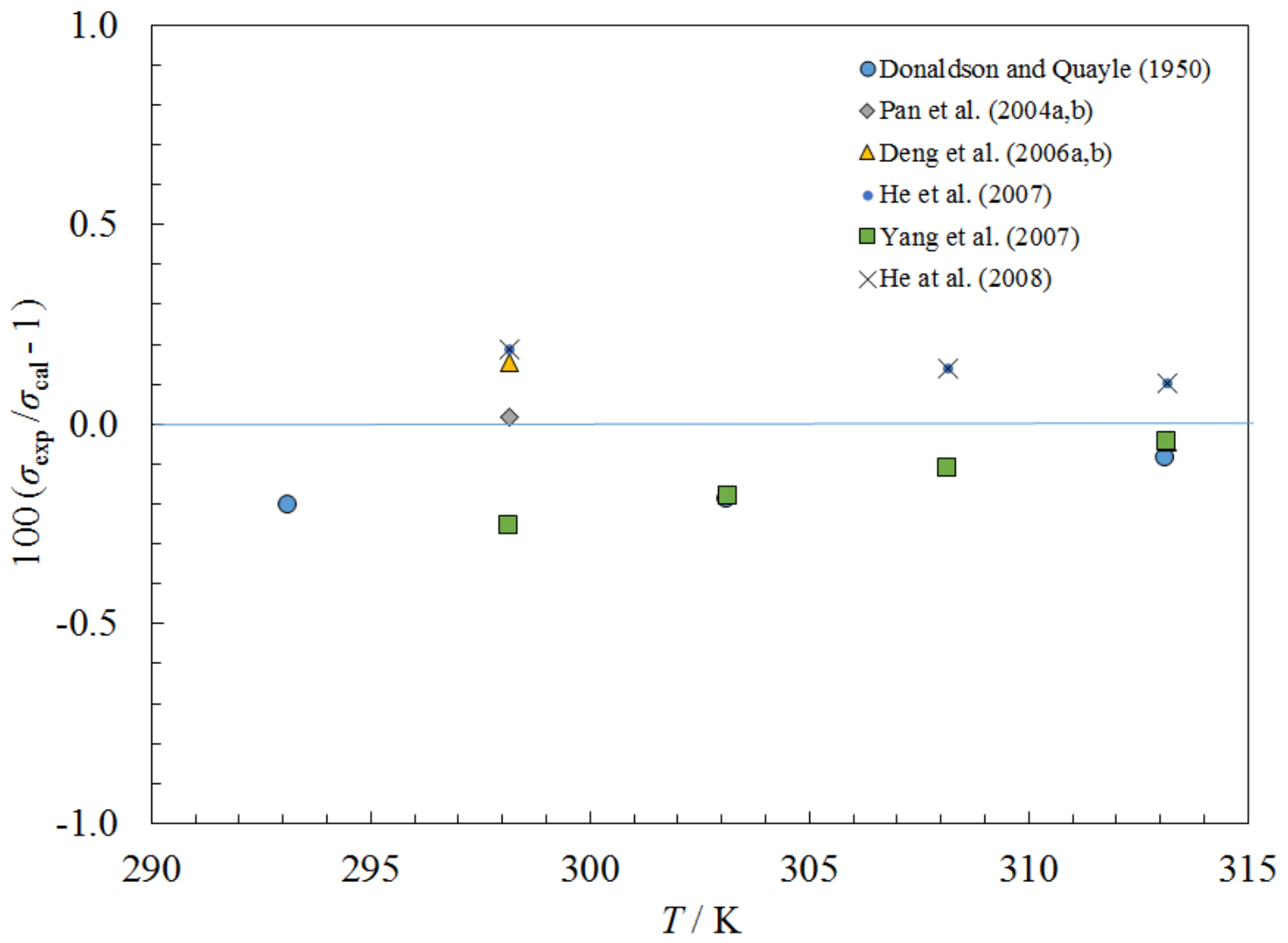

Figure 3. Percentage deviations between the model and the experimental surface tension data for 1,2,4-trimethylbenzene. 


\section{$5.2 \quad 1,3,5$-triisopropyllbenzene}

The experimental data for this fluid are extremely limited. A Helmholtz equation of state was generated with the equation of state development tool in the NIST TDE software (19). The equation of state is implemented in the REFPROP text file included in Supplementary materials, and was used to provide density in the formulations for viscosity and thermal conductivity. No data were available for viscosity in the gas phase, therefore we used the method of Chung et al. (20) to estimate Lennard-Jones (LJ) parameters; these are given in Table 2 along with the critical parameters. The critical parameters are consistent with the equation of state as generated by TDE (19). Only one very limited set of data for the liquid-phase viscosity was found (37); all points are at atmospheric pressure. Initially, we tried using toluene as a reference fluid since it is an aromatic, and was used successfully for 1,2,4-trimethylbenzene. However, better results were found with dodecane as a reference fluid so we adopted $n$-dodecane as the reference fluid and obtained the coefficients given in Table 3. The equation of state for the reference fluid dodecane and the correlations for viscosity and thermal conductivity can be found in refs. $(38,39)$. Figure 4 shows the percentage deviations between the viscosity data and the model. Deviations are within $5 \%$.

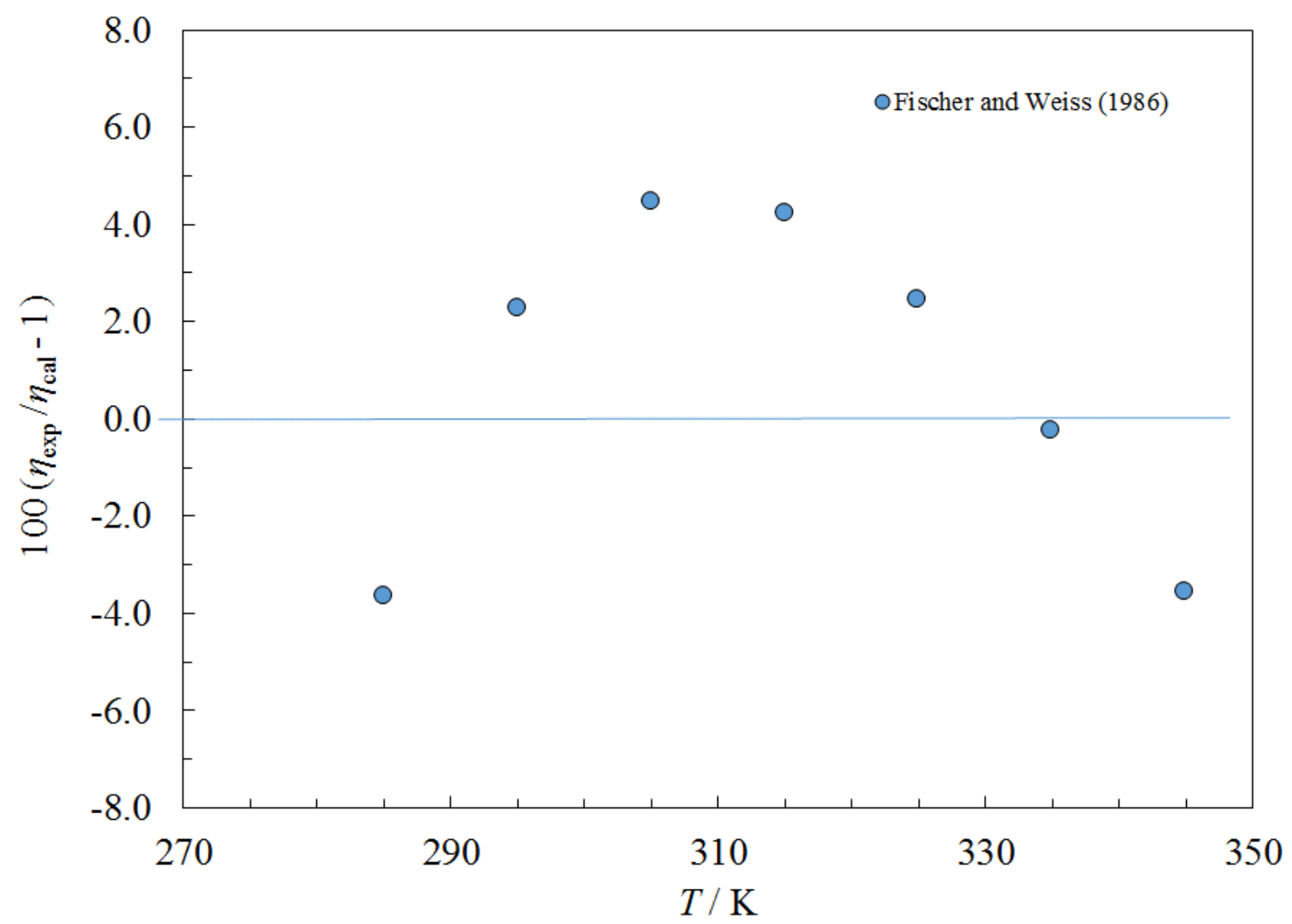

Figure 4. Percentage deviations between the model and the experimental viscosity data for 1,3,5triisopropylbenzene.

No data were available for the thermal conductivity of 1,3,5-triisopropylbenzene. For the gas phase, similar to 1,2,4-trimethylbenzene, we adopted $1.32 \times 10^{-3}$ for $f_{\text {int }}$ in Eq. (14). For the liquid phase, we used the Sastri-Rao method as implemented in the NIST TDE database software 
(19) to predict values that were then used to obtain the coefficients in Table 4. This method has an estimated uncertainty on the order of $20 \%$ for this fluid (19).

No data were found for the surface tension; we fit recommended values based on predictions from a molecular structure-based method (BYU-Parachor) in the DIPPR DIADEM computer program (40) that have an estimated uncertainty of $5 \%$.

\subsection{1-methylnaphthalene}

A preliminary Helmholtz equation of state for 1-methylnaphthalene (41) with critical parameters as given in Table 2 was used to provide density. The equation of state is implemented in the REFPROP text file included in Supplementary materials. No data for viscosity in the gas phase were available, therefore we used the method of Chung et al. (20) to estimate LJ parameters; these are given in Table 2 along with the critical parameters. The critical parameters are consistent with the equation of state. We obtained the coefficients in Table 3 by fitting the liquid-phase viscosity data of several sources (42-48) at pressures up to $50 \mathrm{MPa}$, the upper limit of the equation of state. The reference fluid was $n$-dodecane. Deviations between the model and the experimental data are shown in Figure 5. As seen in Figure 5, with the exception of the data of Canet et al. (48) and Baylaucq et al. (46), most deviations are within $3 \%$ over the temperature range $273 \mathrm{~K}<T<$ $503 \mathrm{~K}$. The measurements of Canet et al. (48) and Baylaucq et al.(46) are from the same laboratory and were obtained with a falling-body viscometer and the authors give an estimated uncertainty of $2 \%$. The measurements of Byers and Williams (44) were made in an Ubbelohde viscometer with an estimated uncertainty of $0.5 \%$ and cover a very wide temperature range, but are limited to atmospheric pressure. The measurements of Caudwell et al. (45) were made with a vibrating wire apparatus with an estimated uncertainty of $2 \%$ and cover a wide temperature range $(298 \mathrm{~K}<T<$ $473 \mathrm{~K}$ ) at pressures up to $200 \mathrm{MPa}$ and are consistent with Byers and Williams (44). Caudwell et al. (45) note in their work that the falling-body apparatus used in the measurements of Canet et al. (48) and Baylaucq et al. (46) also show larger differences from their work for other fluids such $\mathrm{m}$-xylene and decane. Considering this, our estimated uncertainty for the liquid-phase viscosity at pressures to $50 \mathrm{MPa}$ for temperatures from $293 \mathrm{~K}$ to $503 \mathrm{~K}$ is $3 \%$. 


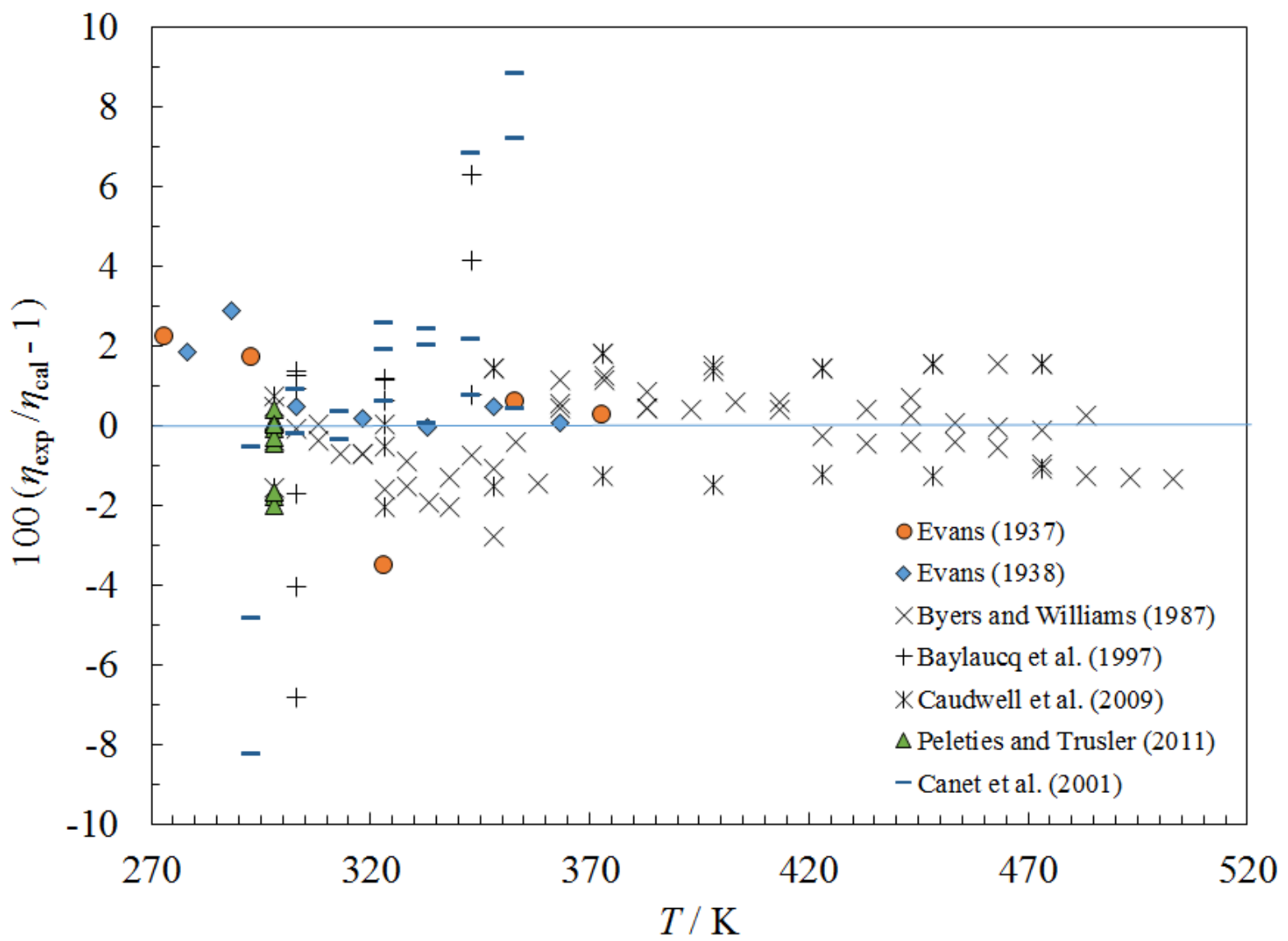

Figure 5. Percentage deviations between the model and the experimental viscosity data for 1methylnaphthalene.

No data were available for thermal conductivity of the gas phase; we adopted $1.32 \times 10^{-3}$ for $f_{\text {int }}$ in Eq. (14). Only one set of data was found for liquid-phase thermal conductivity (49) that covered the temperature range $298 \mathrm{~K}$ to $622 \mathrm{~K}$ at pressures up to $14 \mathrm{MPa}$. These measurements were made in a transient hot-wire apparatus, and no indication of sample purity was given. The resulting coefficients are given in Table 4. Figure 6 shows the deviations of the model and the data. For temperatures below $500 \mathrm{~K}$, the estimated uncertainty of the correlation is $5 \%$ at pressures to $14 \mathrm{MPa}$. 


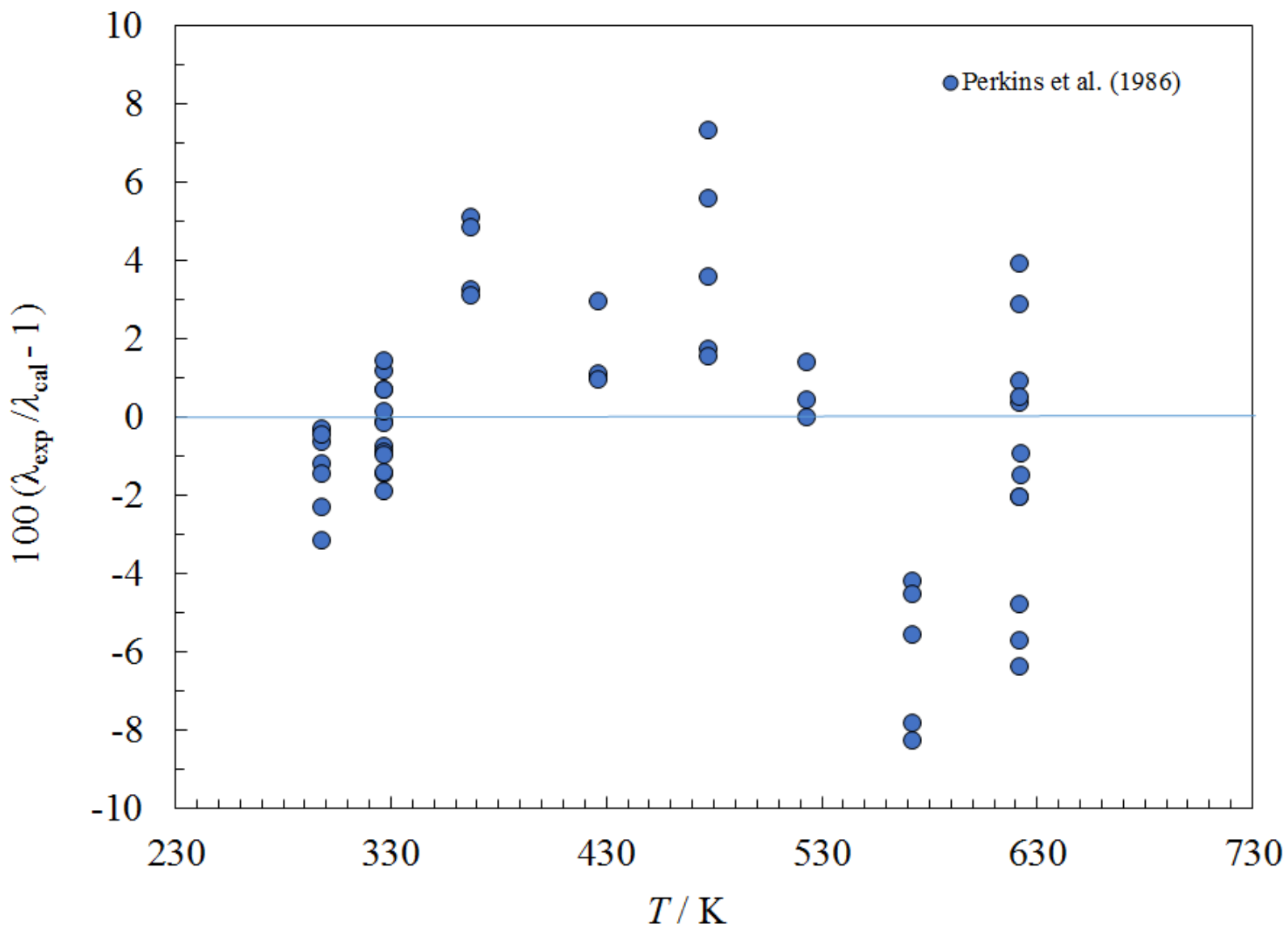

Figure 6. Percentage deviations between the model and the experimental thermal conductivity data for 1-methylnaphthalene.

Surface tension data from three sources (50-52) were found; however, there is a large amount of scatter in the data from the three sources as indicated in the deviation plot, Figure 7 , and we estimate the uncertainty as $5 \%$. The surface tension coefficients are given in Table 6 . 


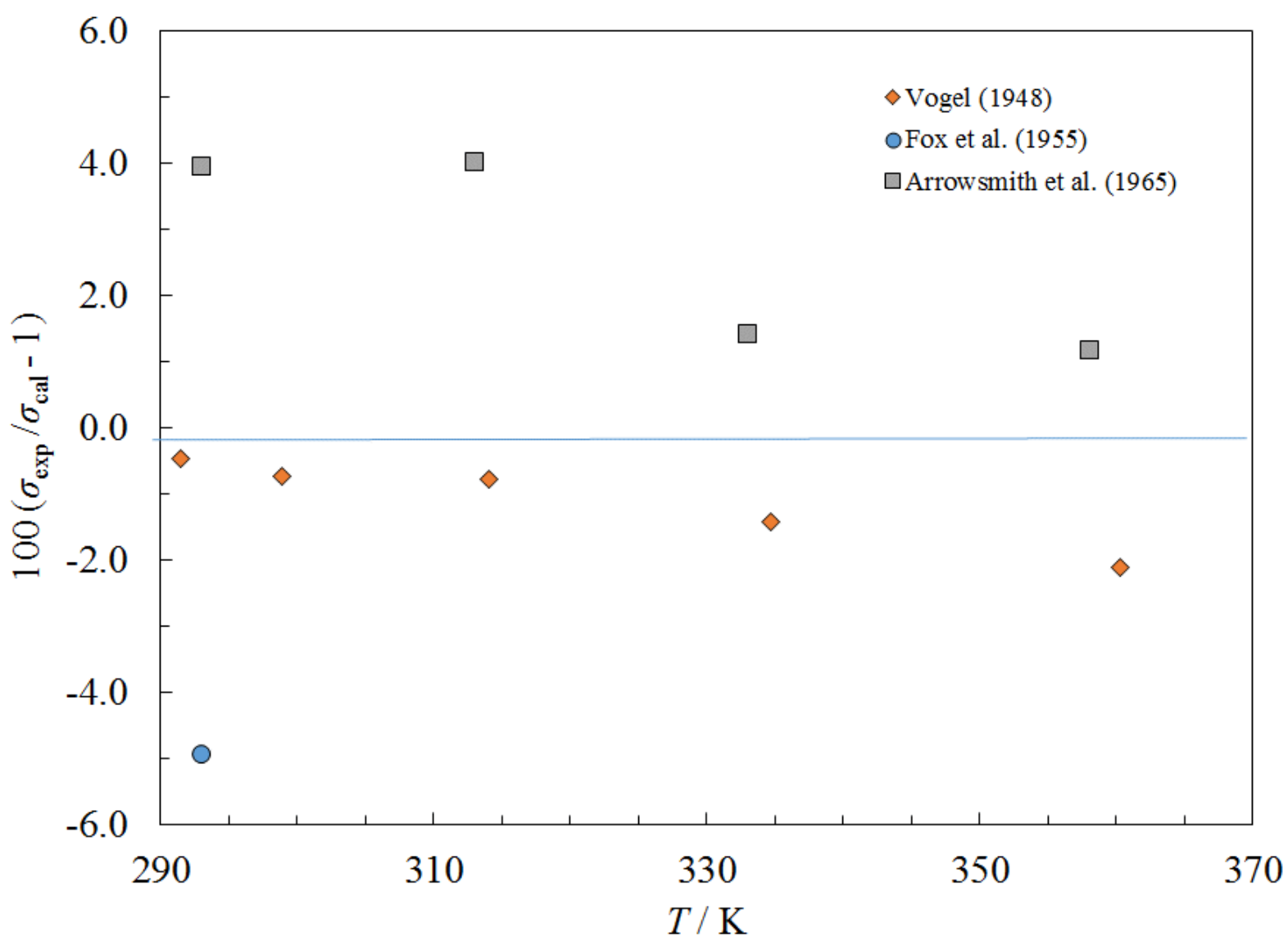

Figure 7. Percentage deviations between the model and the experimental surface tension data for 1-methylnaphthalene.

\section{4 tetralin (tetrahydronaphthalene)}

A preliminary Helmholtz equation of state for tetralin (tetrahydronaphthalene) (53) with critical parameters as given in Table 2 was used to provide density. The equation of state is implemented in the REFPROP text file included in Supplementary materials. Gas-phase viscosity data were unavailable, so the method of Chung et al. (20) was used to estimate LJ parameters. Liquid-phase viscosity data from three sources (43-45) were used to determine the coefficients in Table 3 (these sources also were used for 1-methylnaphthalene), with $n$-dodecane as a reference fluid. The deviations are given in Figure 8. Data are shown up to $50 \mathrm{MPa}$, the upper pressure limit of the equation of state, and cover $273 \mathrm{~K}$ to $458 \mathrm{~K}$. The model agrees with the data to within about $3 \%$, similar to what was found for 1-methylnaphthalene. 


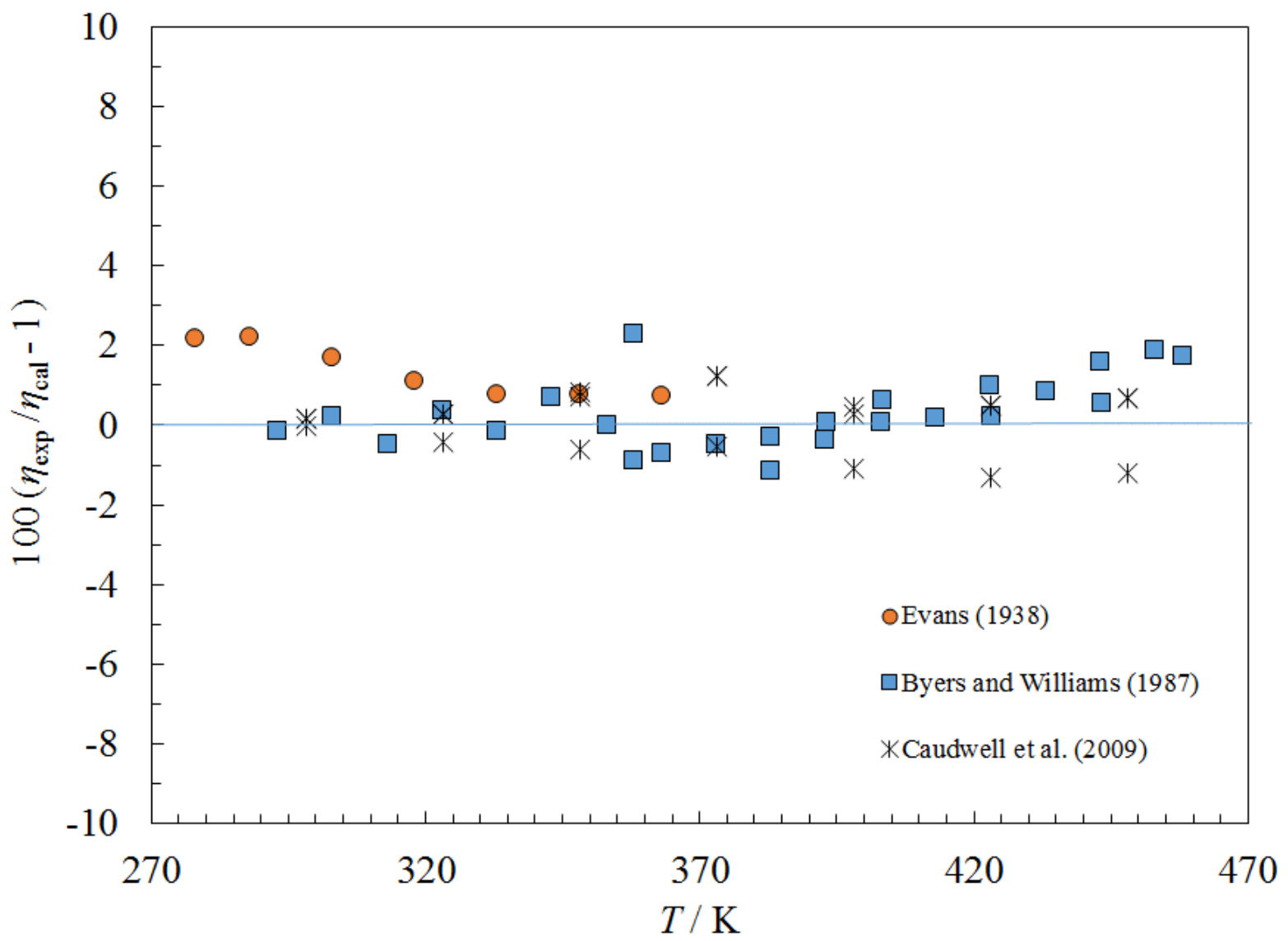

Figure 8. Percentage deviations between the model and the experimental viscosity data for tetralin.

No data were available for thermal conductivity of the gas phase; we adopted $1.32 \times 10^{-3}$ for $f_{\text {int }}$ in Eq. (14). The liquid-phase thermal conductivity data of Perkins et al. (49) that range from $303 \mathrm{~K}$ to $676 \mathrm{~K}$ at pressures to $14 \mathrm{MPa}$ were used to obtain the coefficients in Table 4 and the deviations are shown in Figure 9. Agreement for temperatures less than $600 \mathrm{~K}$ is within $4 \%$. The $676 \mathrm{~K}$ isotherm has much larger deviations than the other isotherms. The critical temperature is $720.1 \mathrm{~K}$, and it is possible that the critical enhancement model is contributing too strongly in this region, or that there may be some decomposition occurring at the highest temperatures. 


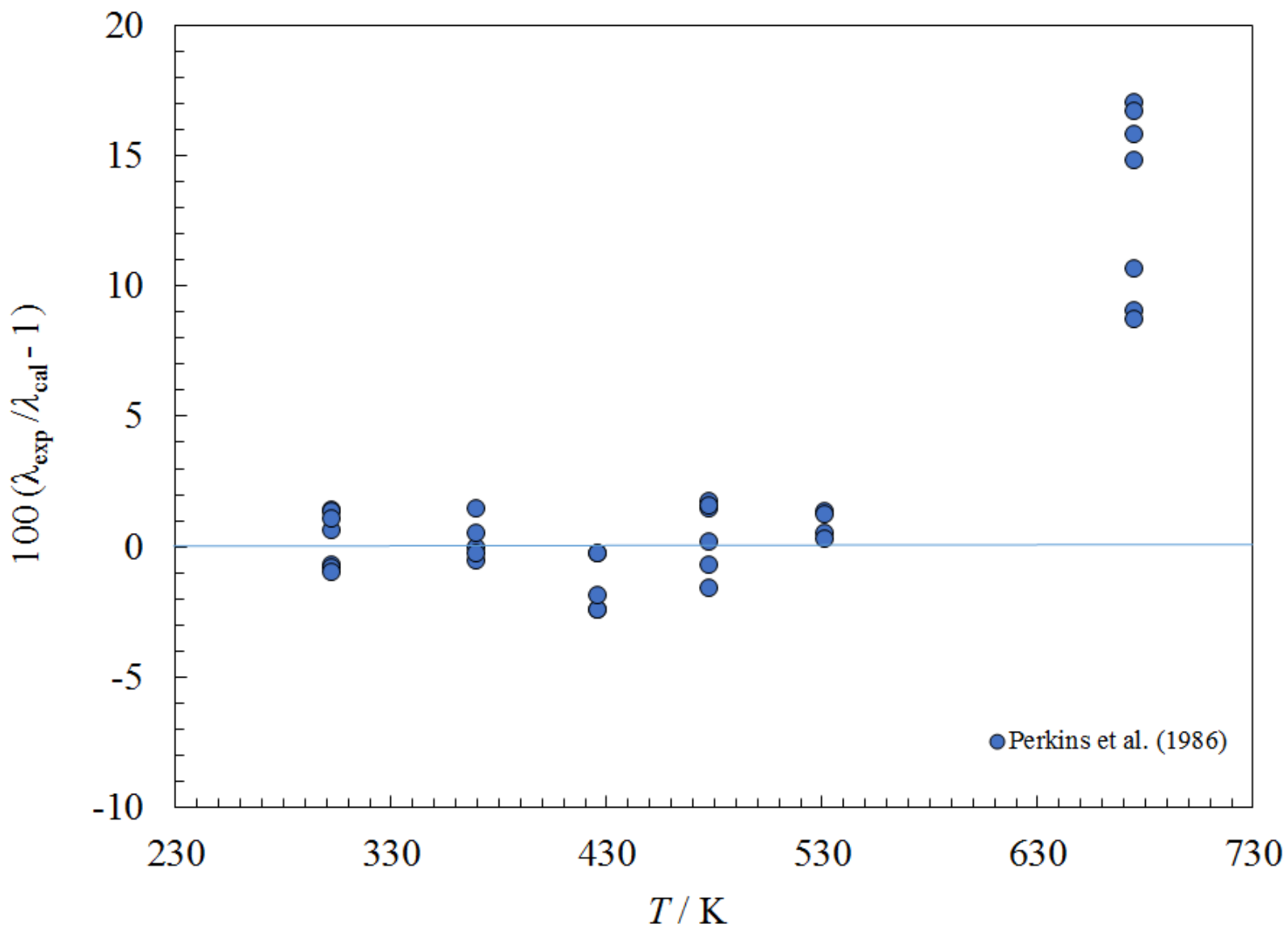

Figure 9. Percentage deviations between the model and the experimental thermal conductivity data for tetralin.

Surface tension data from $(54,55)$ were used to obtain the coefficients in Table 6 , and Figure 10 shows the deviations between the data and the model. Agreement is within the estimated uncertainty of the data, $1 \%$ over the temperature range $273 \mathrm{~K}$ to $373 \mathrm{~K}$. 


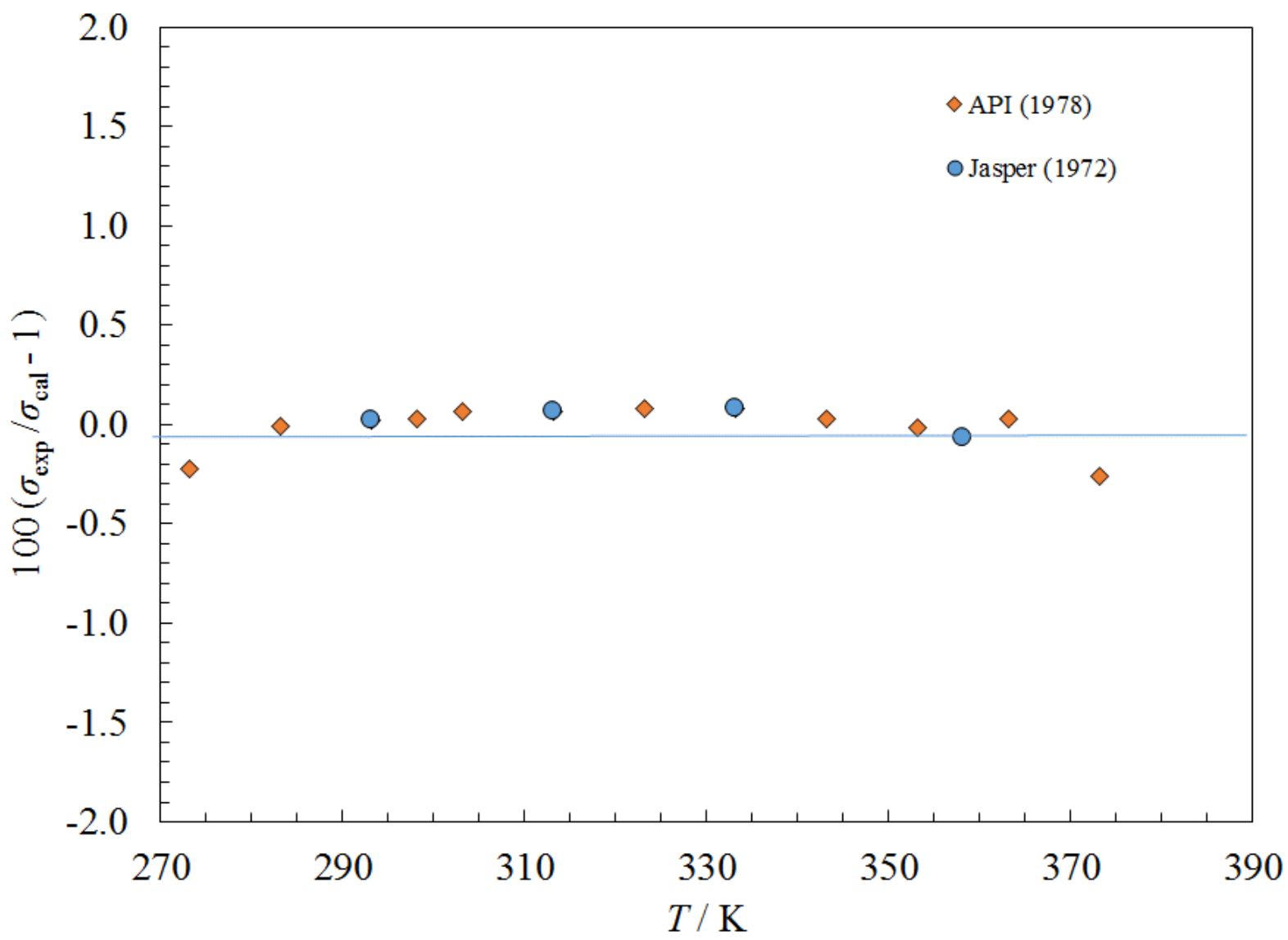

Figure 10. Percentage deviations between the model and the experimental surface tension data for tetralin.

\section{$5.5 n$-butyl cyclohexane}

A preliminary Helmholtz equation of state for $n$-butyl cyclohexane (56) with critical parameters as given in Table 2 was used to provide density. The equation of state is implemented in the REFPROP text file included in Supplementary materials. Gas-phase viscosity data were unavailable, so the method of Chung et al. (20) was used to estimate LJ parameters. Very limited liquid-phase viscosity data covering $293 \mathrm{~K}$ to $343 \mathrm{~K}$, all at atmospheric pressure (57-60) were used to determine the coefficients in Table 3, deviations are given in Figure 11 and are within $1 \%$. 


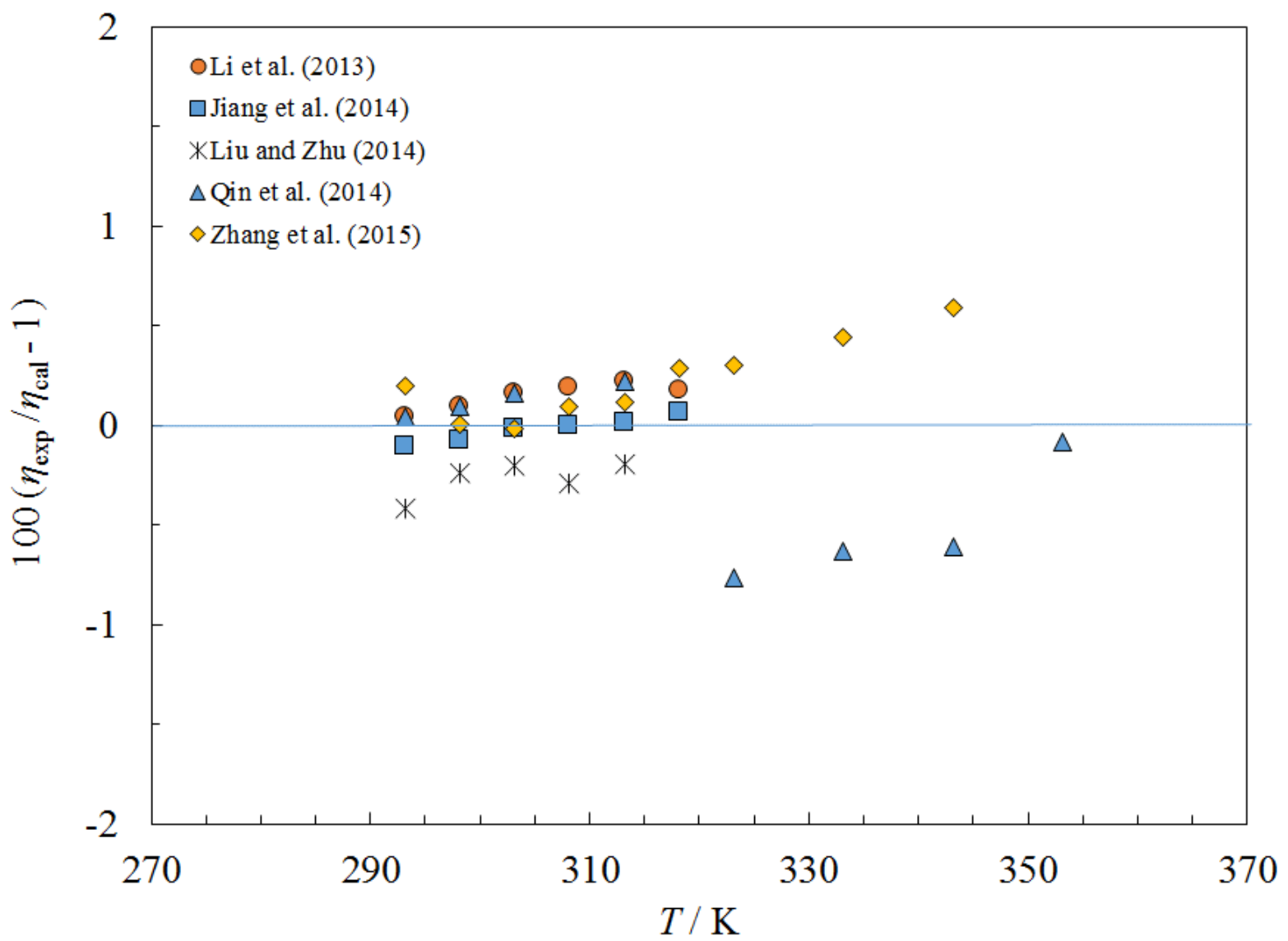

Figure 11. Percentage deviations between the model and the experimental viscosity data for $n$ butyl cyclohexane.

Experimental data were not found for gas and liquid-phase thermal conductivity. We used $1.32 \times 10^{-3}$ for $f_{\text {int }}$ in Eq. (14) and estimated the thermal conductivity coefficients in Table 4 based on analysis of the thermal conductivities of very similar compounds, $n$-propylcyclohexane and methylcyclohexane, for which there are experimental data (61). The estimated uncertainty for the liquid phase is on the order of $20 \%$.

Only one, very limited data set for surface tension was found. The data of Zhang et al. (60) was fit to obtain the coefficients for surface tension in Table 6. Deviations with the data are shown in Figure 12 and for the temperature range $293 \mathrm{~K}$ to $308 \mathrm{~K}$ are within the uncertainty of the data, $1 \%$. 


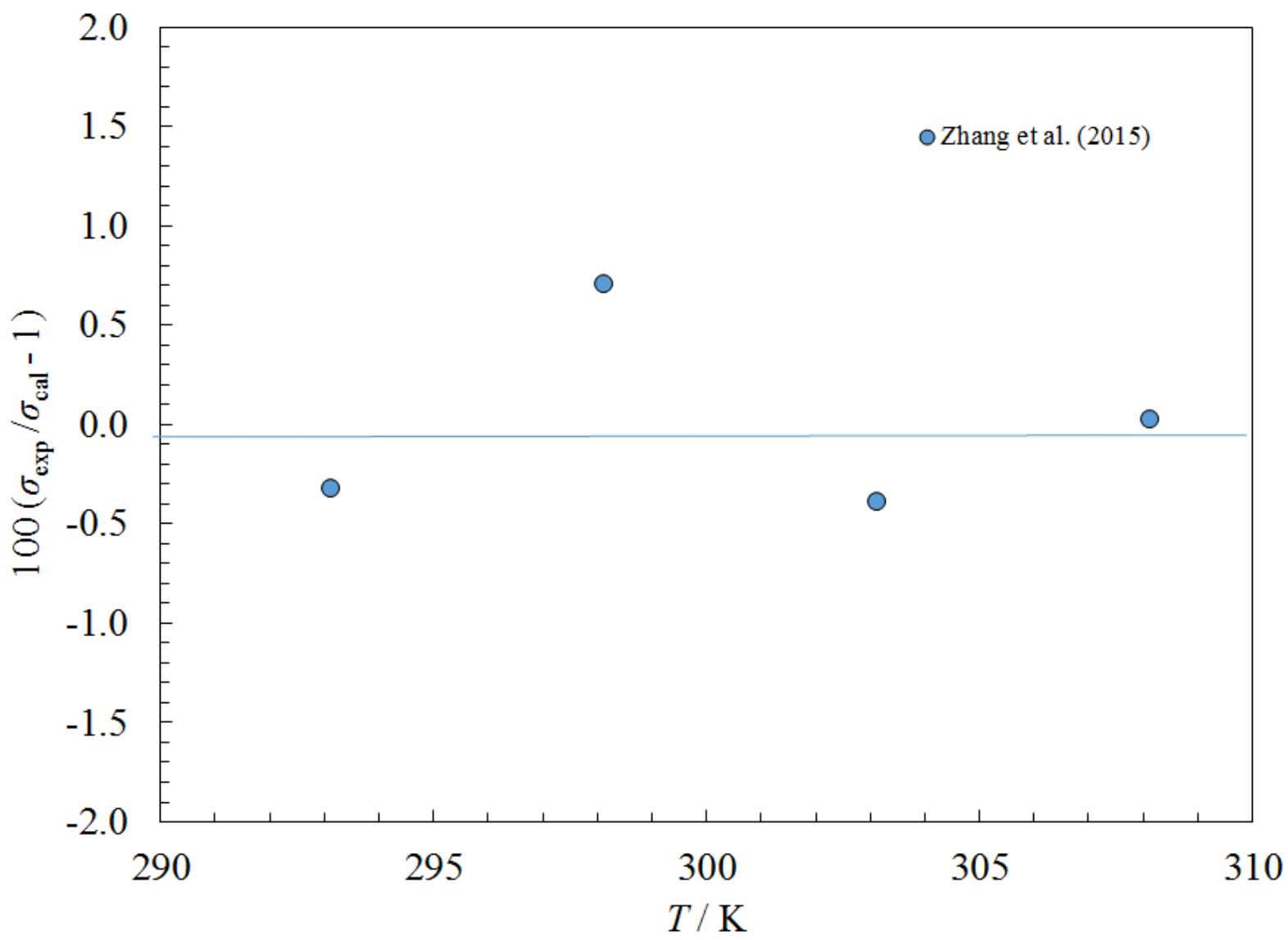

Figure 12. Percentage deviations between the model and the experimental surface tension data for $n$-butyl cyclohexane.

\subsection{1,3,5-triisopropylcyclohexane}

A Helmholtz equation of state (41) was developed and used to provide density and critical parameters. The equation of state is implemented in the REFPROP text file included in Supplementary materials. Gas-phase viscosity data were unavailable, so the method of Chung et al. (20) was used to estimate LJ parameters. Liquid-phase viscosity measurements (62) at atmospheric pressure from $293 \mathrm{~K}$ to $373 \mathrm{~K}$ were used to obtain the parameters in Table 3. Figure 13 shows deviation plots for the viscosity data. Although the deviations are within about $1 \%$, the measurements are extremely limited and we estimate the uncertainty of the liquid phase viscosity at pressures to $20 \mathrm{MPa}$ (the limit of the EOS) to be on the order of $5 \%$.

There were no experimental thermal conductivity data available for gas or liquid phases. We used $1.32 \times 10^{-3}$ for $f_{\text {int }}$ in Eq. (14), and for the liquid phase, and used the Sastri-Rao method as implemented in the NIST TDE database software (19) to predict values that were then fitted to obtain the coefficients in Table 4. This method has an estimated uncertainty on the order of $20 \%$. No data were available for the surface tension; we predicted values based on molecular structure with the model recommended (BYU-Parachor) in the DIPPR DIADEM computer program (40) that has an estimated uncertainty of $10 \%$ and fit the predicted data to obtain the parameters in Table 6 . 


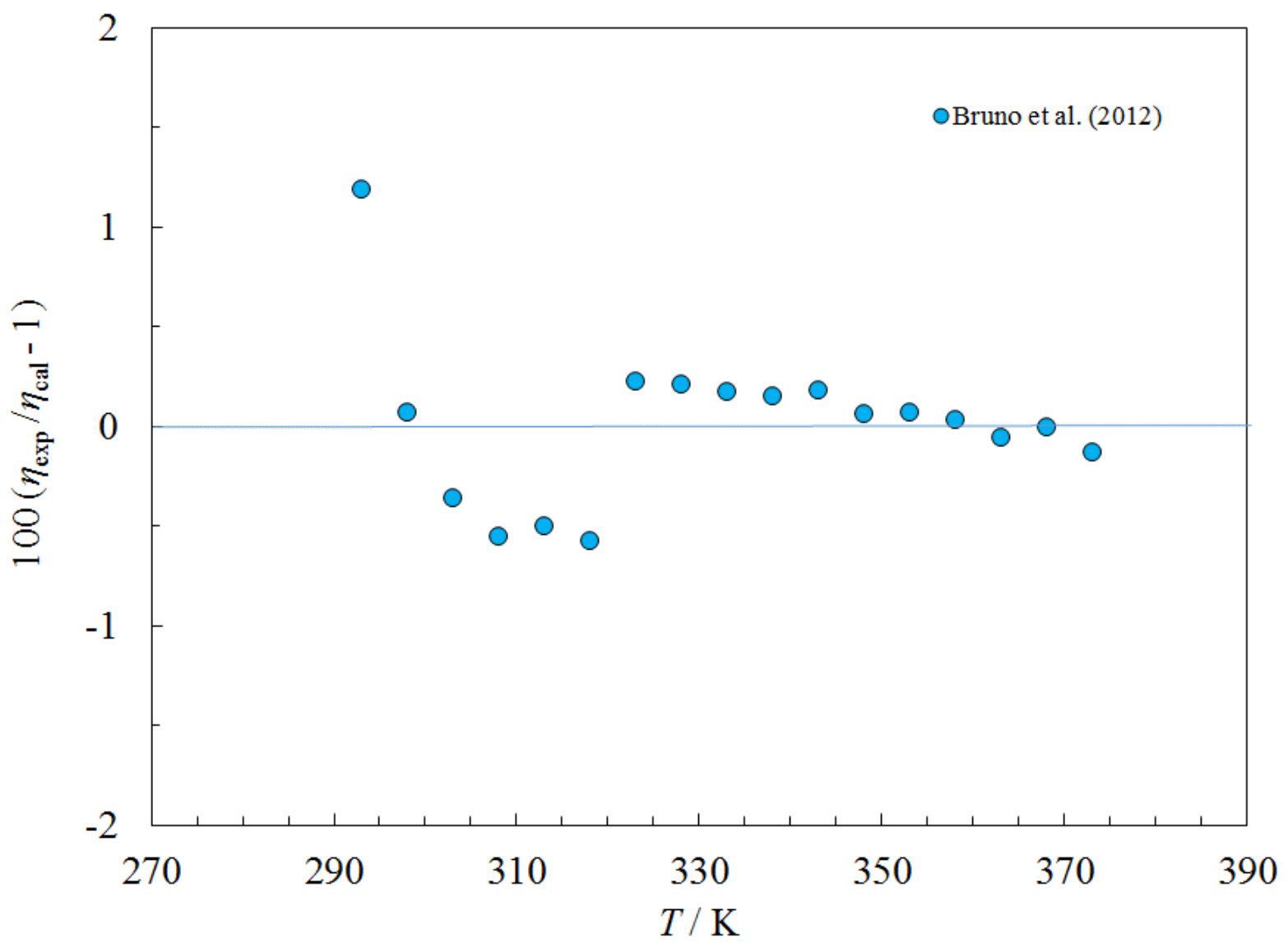

Figure 13. Percentage deviations between the model and the experimental viscosity data for 1,3,5-triisopropylcyclohexane

\section{7 trans-decalin (trans-decahydronaphthalene)}

A preliminary Helmholtz equation of state for trans-decalin (trans-decahydronaphthalene) (63) with critical parameters as given in Table 2 was used to provide density. The equation of state is implemented in the REFPROP text file included in Supplementary materials. Gas-phase viscosity data were unavailable so the method of Chung et al. (20) was used to estimate LJ parameters. We fit the liquid-phase data of Seyer and Leslie (64) along the saturation boundary from $243 \mathrm{~K}$ to $453 \mathrm{~K}$ along with the data of Zeberg-Mikkelson et al.(65). Seyer and Leslie (64) measured both cis- and trans-decalin in an Ostwald-type viscometer. Zeberg-Mikkelson also measured both isomers, in a falling-body viscometer with data extending to $100 \mathrm{MPa}$ but we fit only data to $50 \mathrm{MPa}$, the upper limit of the EOS. Dodecane, propane, and toluene were investigated as reference fluids but had difficulty representing the high-pressure data. We found $n$-octane gave better results and selected n-octane as the best reference fluid for transdecalin. For $n$-octane we used the formulations of Span and Wagner (66), Huber et al. (67) and Huber and Perkins (68) for the EOS, viscosity, and thermal conductivity respectively. Deviations from the experimental data up to $50 \mathrm{MPa}$ are shown in Figure 14. Along the saturation boundary in the liquid phase at temperatures above $273 \mathrm{~K}$, the uncertainty is $2 \%$, at pressures to $50 \mathrm{MPa}$ it rises to approximately $5 \%$. 


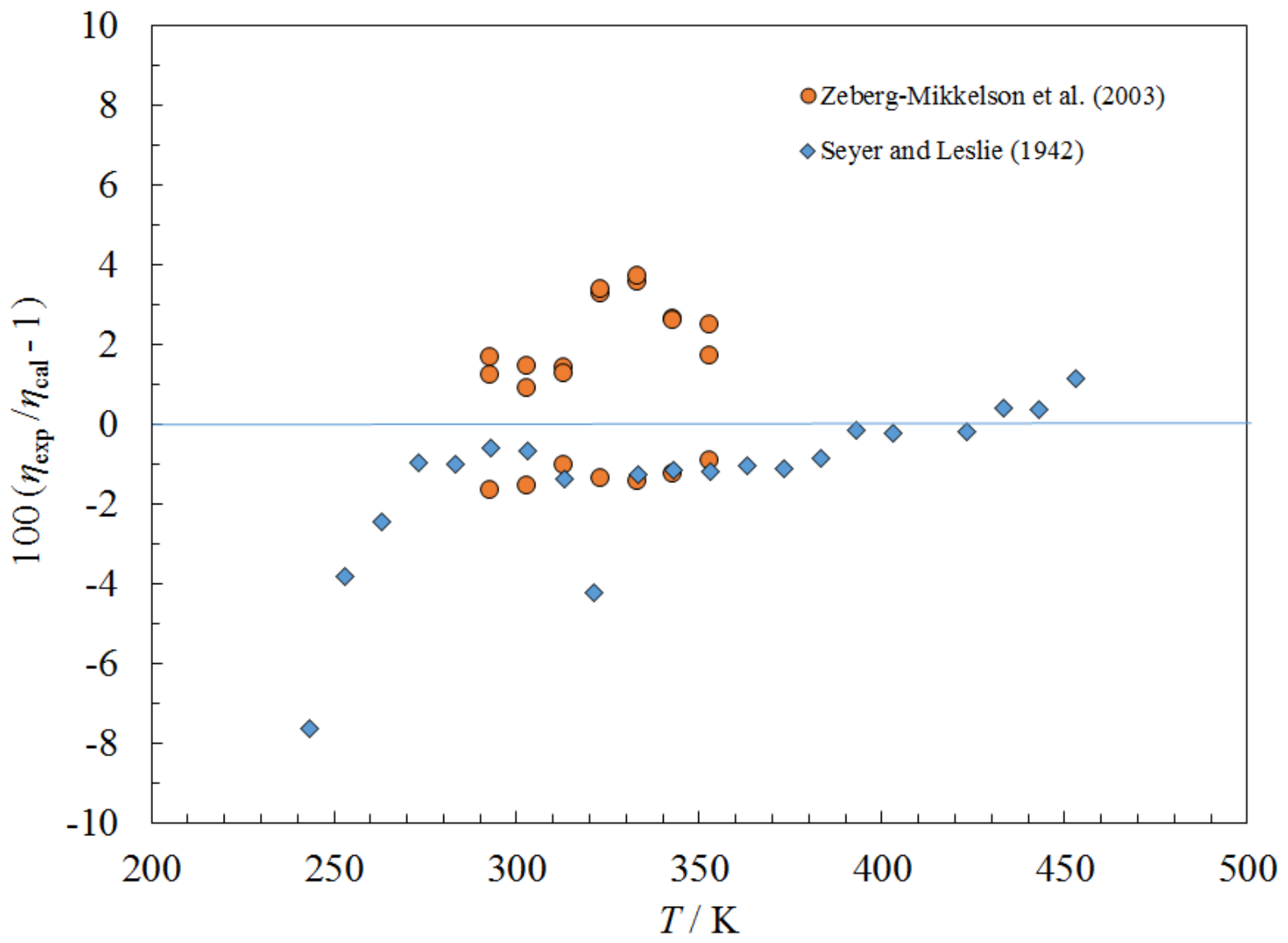

Figure 14. Percentage deviations between the model and the experimental viscosity data for trans-decalin.

Data for vapor-phase thermal conductivity were unavailable, so we used $1.32 \times 10^{-3}$ for $f_{\text {int }}$ in Eq. (14). The only pure trans-decalin thermal conductivity data are those of Frezzotti et al. (69), who measured both the cis and trans isomers and found the liquid thermal conductivity of the isomers differed by 2-3\%, with the trans isomer having the larger values. Perkins et al. $(49,70)$ measured a mixed isomer sample; we adjusted the Perkins et al. data upward by $3 \%$ and obtained the coefficients in Table 4. Deviations with the original experimental data are shown in Figure 15. Frezzotti et al. (69) made measurements in a steady-state coaxial cylinders apparatus and they are significantly higher than the data of Perkins et al. $(49,70)$; this could be due to convection. Also shown are the data of Briggs (71) for mixed isomers. Briggs is interesting for comparison since in his work he measured several fluids for which there are reference correlations and high quality data to compare with. For example, the data of Briggs for benzene are $2 \%$ to $9 \%$ higher than the reference correlation (72), for toluene are $2 \%$ to $15 \%$ higher than Ref. (24), for methylcyclohexane are $2 \%$ to $9 \%$ higher than reference $(61)$, for heptane are $0.5 \%$ to $5 \%$ higher than reference (73), and for ortho-xylene are $4 \%$ to $13 \%$ higher than the reference correlation (74). The deviations are always high, and become worse as the temperature increases. Briggs's apparatus was a concentric cylinder apparatus and may also have been affected by convection, leading to values of thermal conductivity that are systematically too high. For trans-decalin, the 
values of Briggs (71) are also systematically higher than the correlation by $5 \%$ to $15 \%$, which is consistent with other fluids.

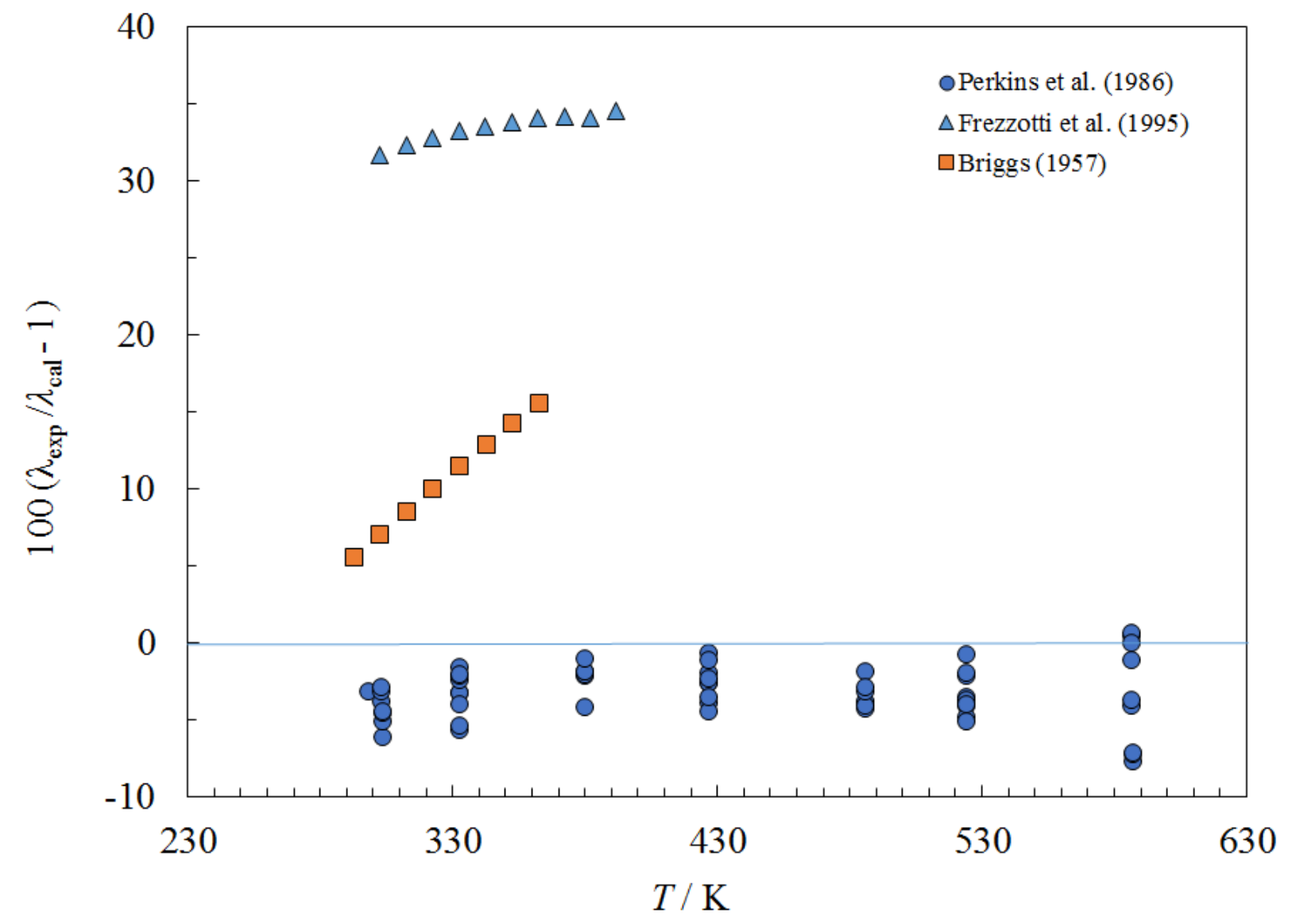

Figure 15. Percentage deviations between the model and the experimental thermal conductivity data for trans-decalin.

The surface tension data of Seyer and Davenport (75) covering $243 \mathrm{~K}$ to $453 \mathrm{~K}$ were fit to obtain the coefficients in Table 6, and deviations from the experimental data are shown in Figure 16. The estimated uncertainty is $2 \%$. 


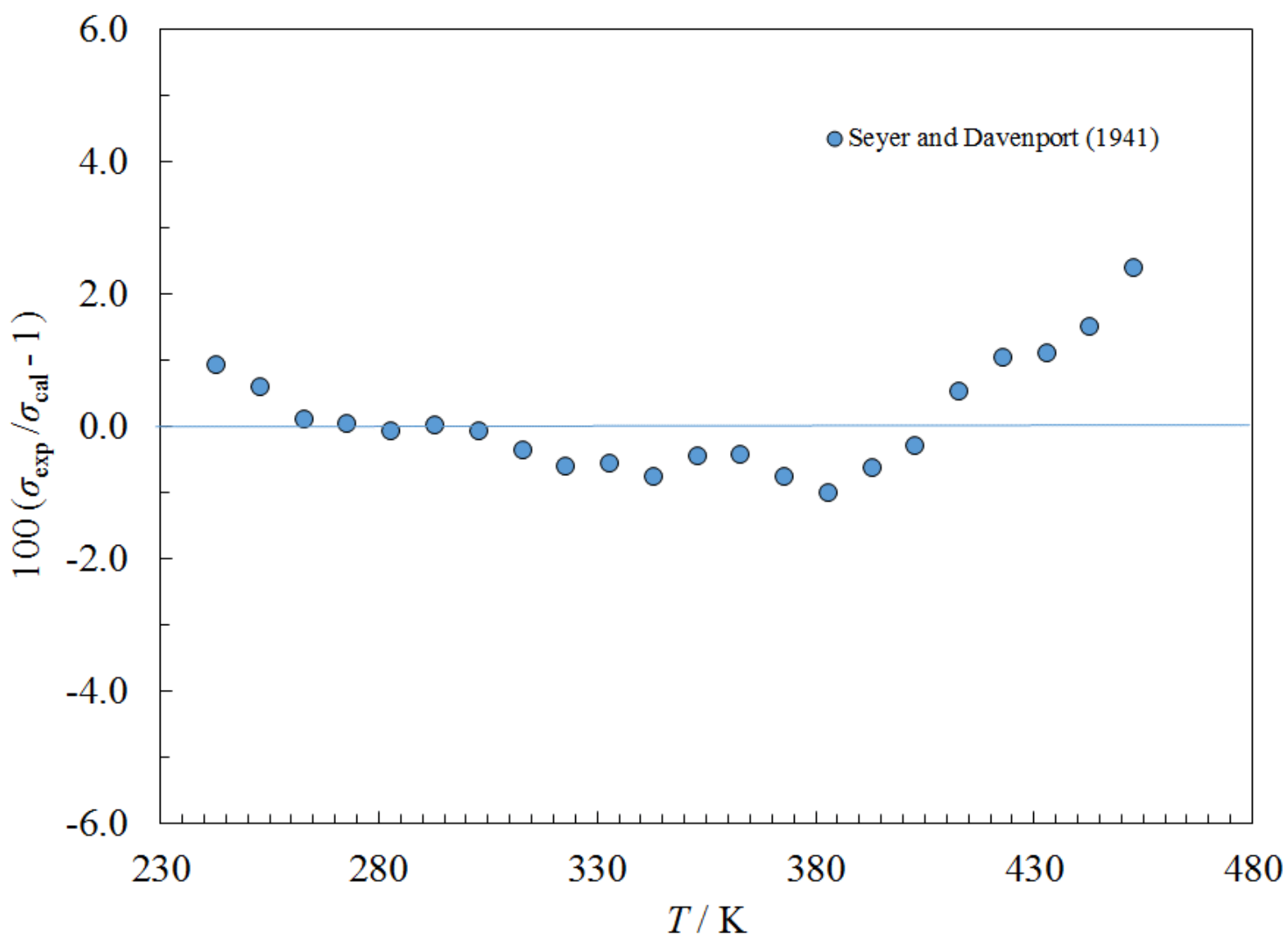

Figure 16. Percentage deviations between the model and the experimental surface tension data for trans-decalin.

\section{8 perhydrophenanthrene (tetradecahydrophenanthrene)}

The experimental data for this fluid are extremely limited. A Helmholtz equation of state was generated with the equation of state development tool in the NIST TDE software (19). The equation of state is implemented in the REFPROP text file included in Supplementary materials, and was used to provide density in the formulations for viscosity and thermal conductivity. Gasphase viscosity data were unavailable, so the method of Chung et al. (20) was used to estimate LJ parameters. We found the best results for correlating the liquid-phase viscosity were obtained with propane as a reference fluid. The equation of state, viscosity, and thermal conductivity formulations for the propane reference fluid are in refs. (76-78). Very limited liquid viscosity data, all at atmospheric pressure (79-81) over the temperature range $273 \mathrm{~K}$ to $513 \mathrm{~K}$ were fit to obtain the coefficients in Table 3, and a deviation plot is given in Figure 17. We estimate the uncertainty for the viscosity at atmospheric pressure to be $5 \%$. 


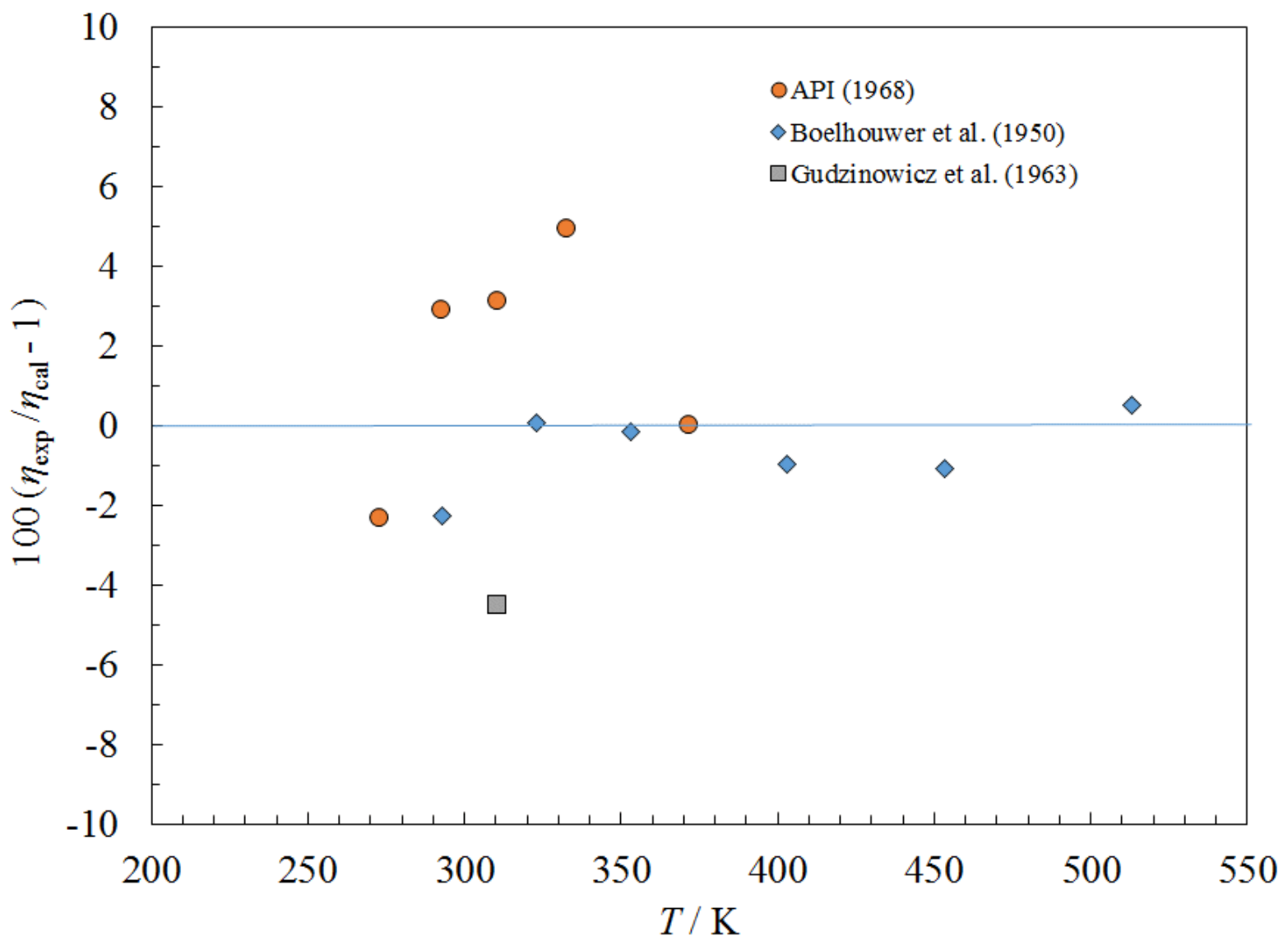

Figure 17. Percentage deviations between the model and the experimental viscosity data for perhydrophenanthrene.

The only thermal conductivity data found were liquid-phase data of Briggs (71) discussed earlier that are known to be systematically high. We used $1.32 \times 10^{-3}$ for $f_{\text {int }}$ in Eq, (14) and adjusted a single coefficient $b_{0}$ so that Briggs data are systematically high by $8 \%$ to $10 \%$. A deviation plot is given in Figure 18. Given the lack of reliable data, we conservatively estimate the uncertainty of the liquid-phase thermal conductivity to be $20 \%$. 


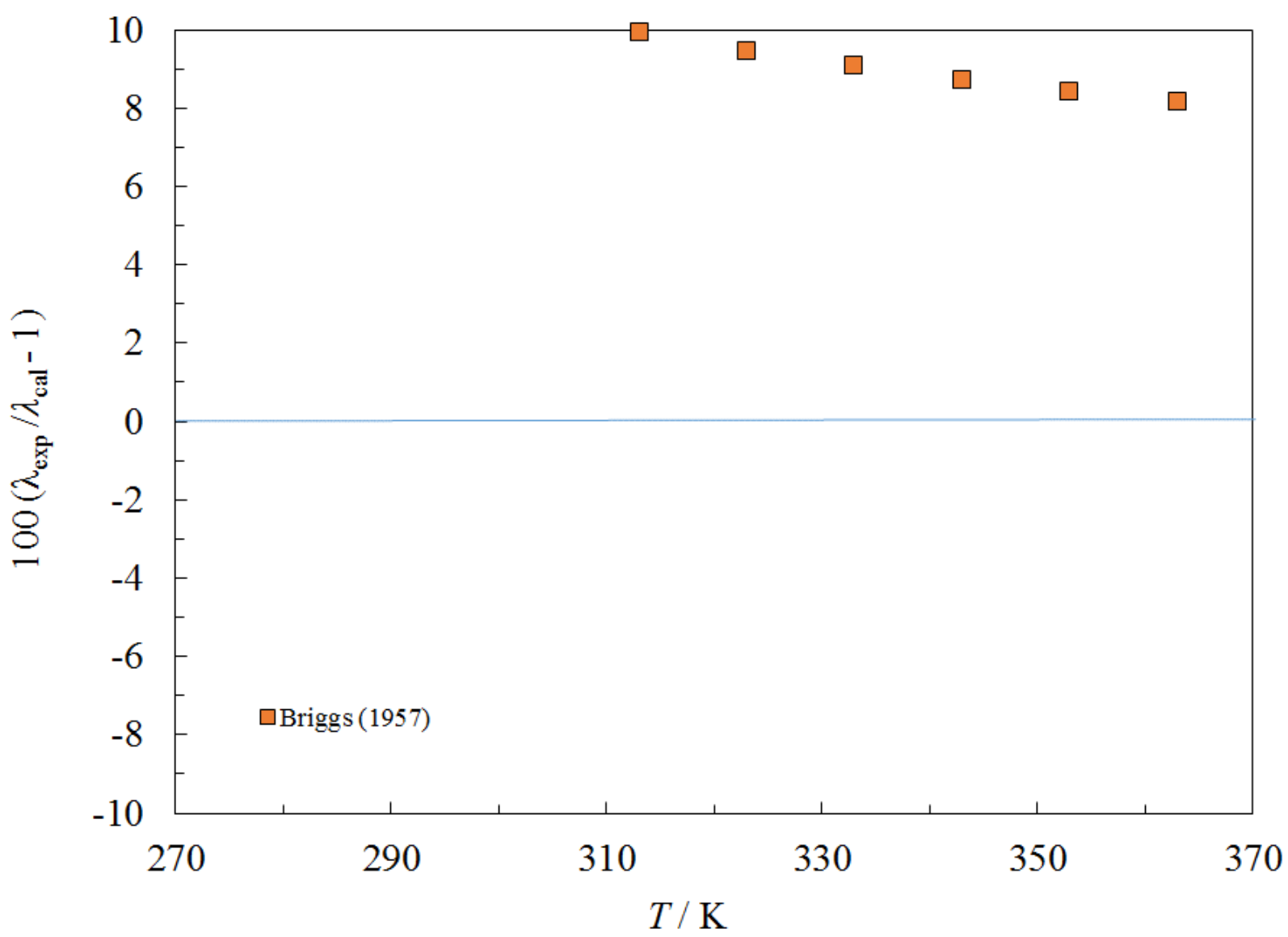

Figure 18. Percentage deviations between the model and the experimental thermal conductivity data for perhydrophenanthrene.

No data were found the surface tension. We predicted values based on molecular structure with the model recommended (BYU-Parachor) in the DIPPR DIADEM computer program (40) that have an estimated uncertainty of $10 \%$ and fit these predicted values to obtain the coefficients in Table 6.

\section{$5.9 \quad n$-hexadecane}

A new Helmholtz equation of state for $n$-hexadecane (63) with critical parameters as given in Table 2 was used to provide density. The equation of state is implemented in the REFPROP text file included in Supplementary materials. Lennard-Jones parameters were obtained by fitting the gas-phase viscosity data of Lusternik and Zdanov (82). The estimated uncertainty for the viscosity in the gas phase based on comparisons with experimental data of Lusternik and Zdanov (82) is 10 $\%$. Coefficients for the liquid-phase viscosity were obtained by fitting the data from (83-87) over $298 \mathrm{~K}$ to $533 \mathrm{~K}$ at pressures up to $100 \mathrm{MPa}$ and are given in Table 3. Deviations are shown in Figure 19. The estimated uncertainty for liquid-phase viscosity for temperatures from $293 \mathrm{~K}$ to $533 \mathrm{~K}$ is $5 \%$ for pressures to $100 \mathrm{MPa}$. 


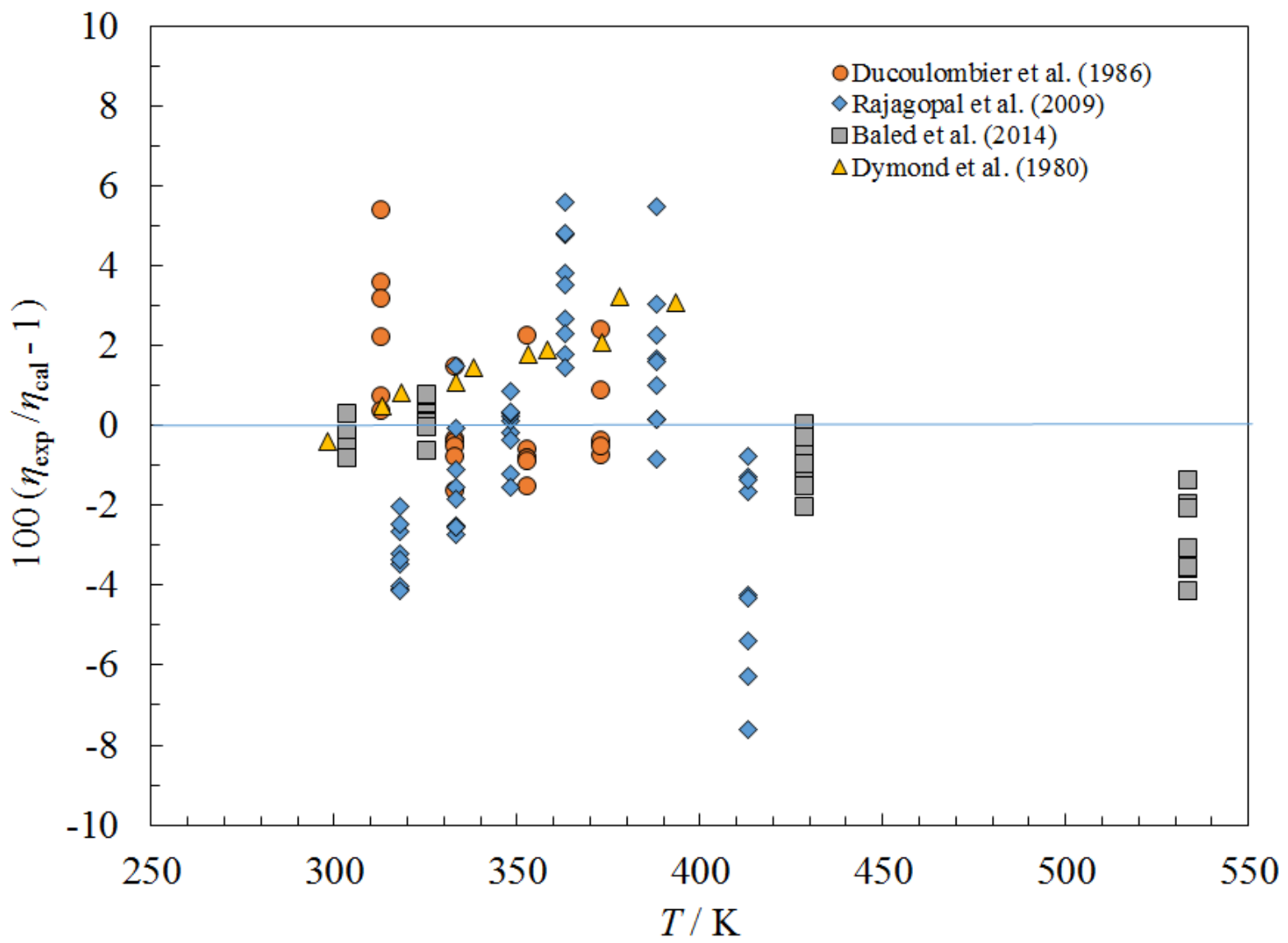

Figure 19. Percentage deviations between the model and the experimental viscosity data for $n$ hexadecane.

The dilute-gas thermal conductivity data of references (88-90) were fit to obtain the coefficients in Table 2, with an estimated uncertainty in the gas phase of $5 \%$. The liquid-phase data of references $(90,91)$ from $303 \mathrm{~K}$ to $693 \mathrm{~K}$ that extend to $50 \mathrm{MPa}$ were used to obtain the coefficients in Table 4, and deviations are shown in Figure 20. The two data sets do not agree with each other to within their authors' estimated uncertainties. Mukhamedzyanov et al. (91) used a steady-state hot-wire apparatus with an uncertainty of approximately 2-3\%, while Mustafaev (90) used a concentric-cylinder apparatus, with an estimated uncertainty of $3 \%$. Due to these unexplained discrepancies, we estimate the uncertainty for the thermal conductivity of the liquid phase from $300 \mathrm{~K}$ to $650 \mathrm{~K}$ at pressures to $50 \mathrm{MPa}$ to be $5 \%$. 


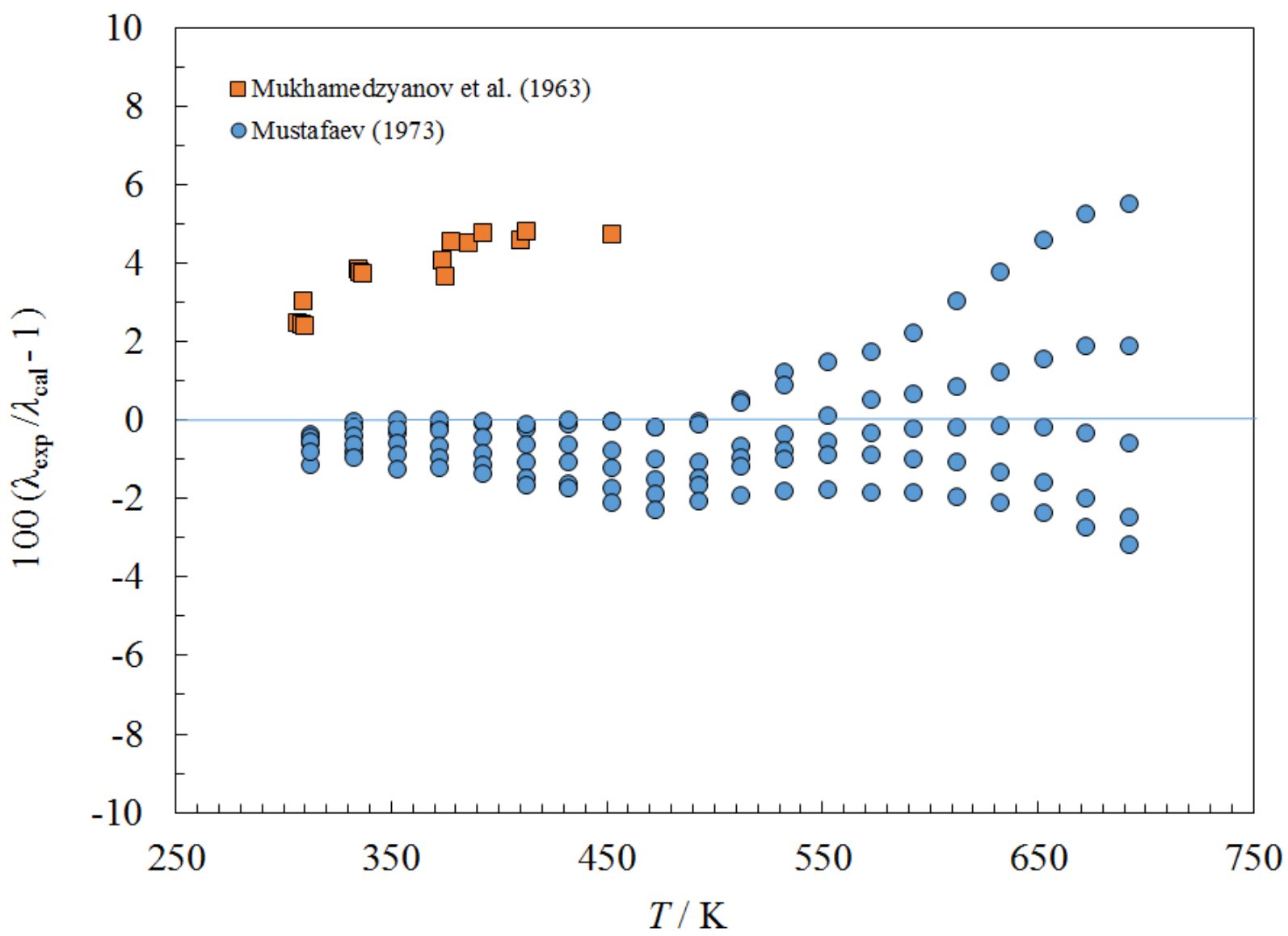

Figure 20. Percentage deviations between the model and the experimental thermal conductivity data for $n$-hexadecane.

The surface tension data from four sources (92-95) were fit to give the coefficients in Table 6 , and the deviation plot is shown in Figure 21. The estimated uncertainty is $2 \%$. 


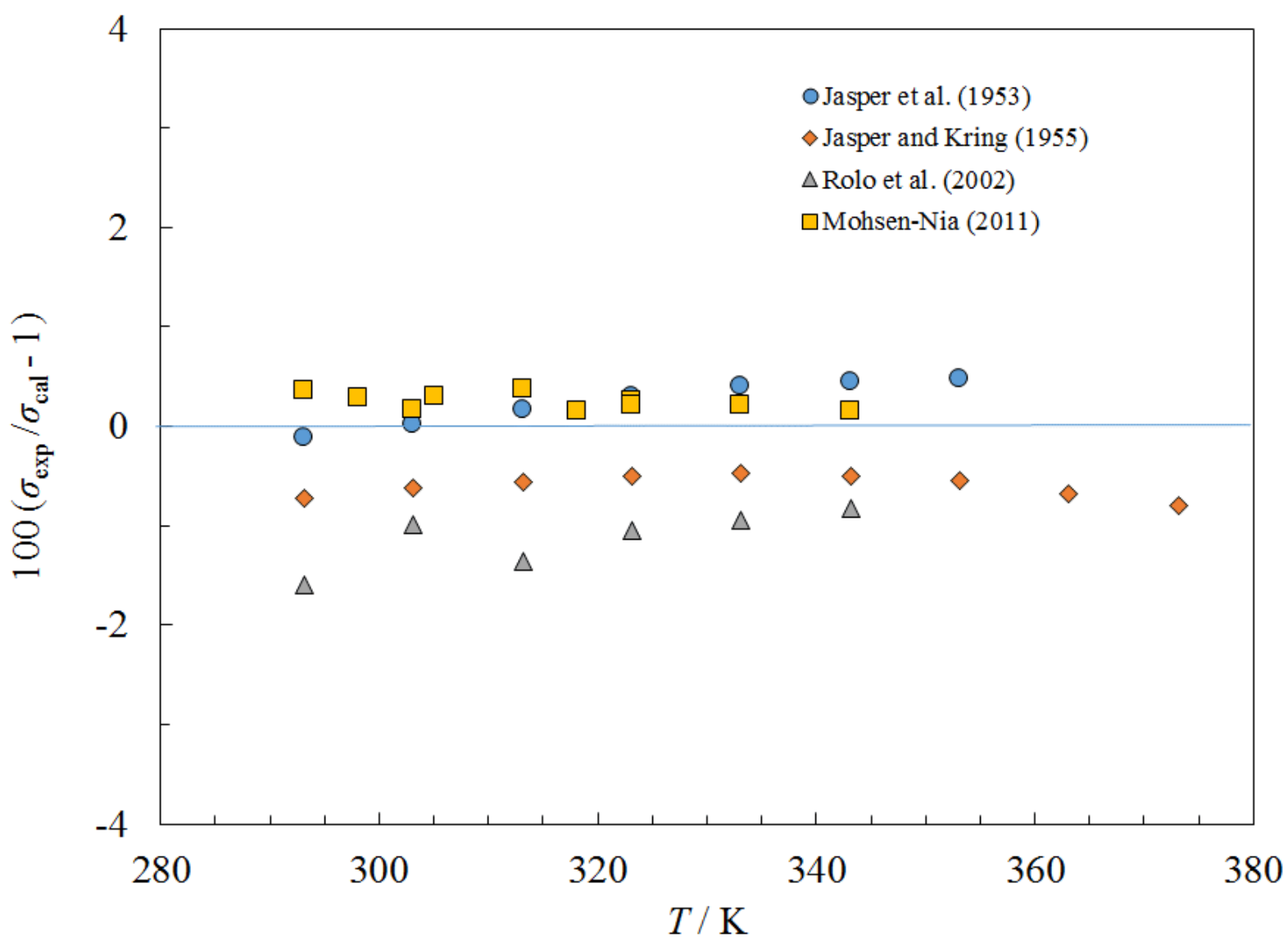

Figure 21. Percentage deviations between the model and the experimental surface tension data for $n$-hexadecane.

\section{$5.10 \quad n$-octadecane}

A Helmholtz equation of state for $n$-octadecane (96) with critical parameters as given in Table 2 was used to provide density. The equation of state is implemented in the REFPROP text file included in Supplementary materials. Lennard-Jones parameters were estimated with a new method developed especially for long-chain alkanes (97). The liquid-phase viscosity data of references $(85,87,98)$ were used to provide the coefficients in Table 3 , and a deviation plot for data up to $100 \mathrm{MPa}$ is shown in Figure 22. The estimated uncertainty of the correlation is $3 \%$ for the liquid viscosity over the range $303 \mathrm{~K}$ to $453 \mathrm{~K}$ at pressures to $100 \mathrm{MPa}$. The Caudwell et al. data (98) were obtained in a vibrating wire apparatus with an uncertainty of $2 \%$ and extend to 92 $\mathrm{MPa}$, and Golubev (87) cover the saturated liquid using a capillary viscometer. Baled et al. (85) used a rolling ball viscometer with an estimated uncertainty of $1.1 \%$ to $4.8 \%$ for their measurements. 


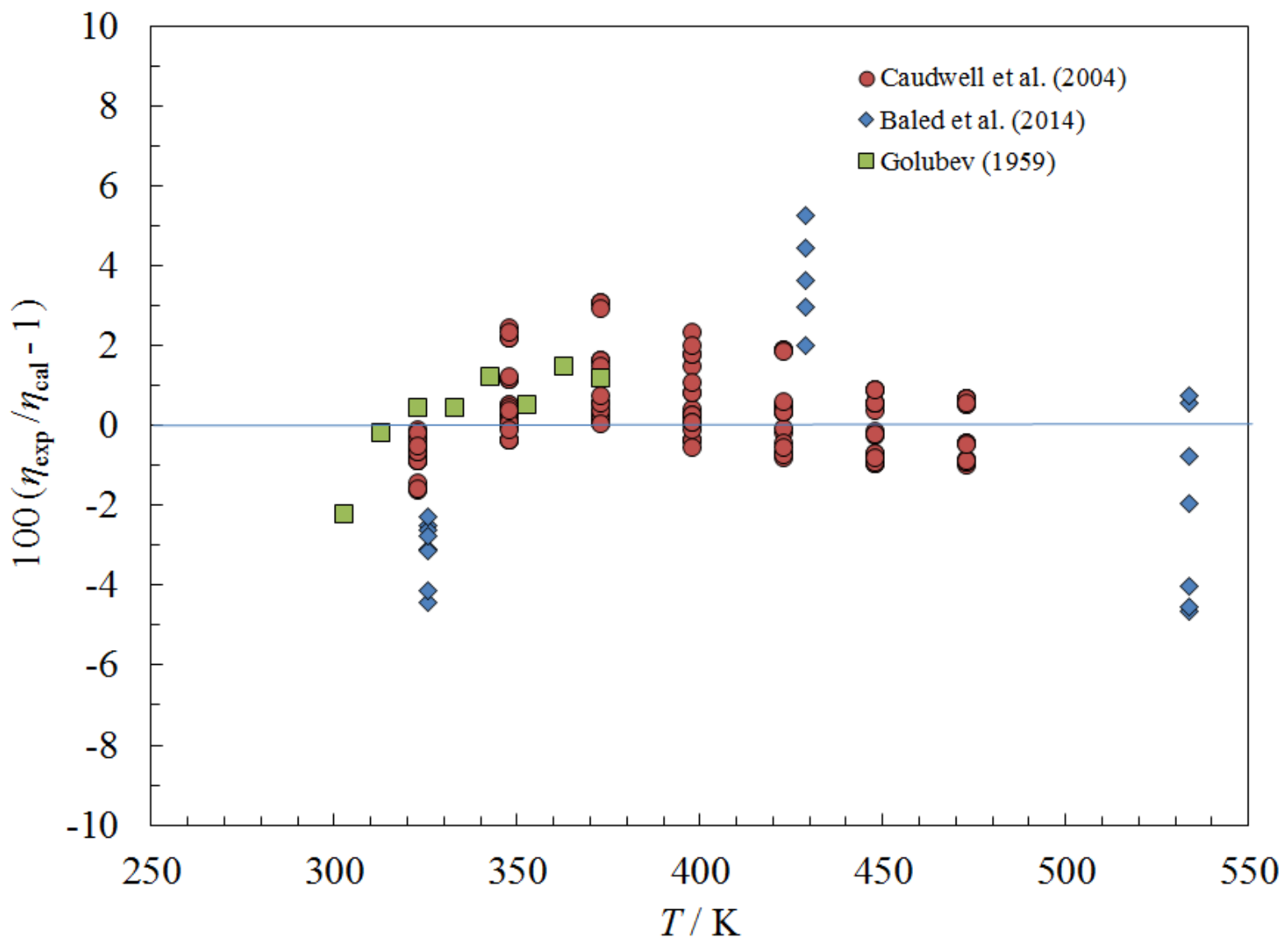

Figure 22. Percentage deviations between the model and the experimental viscosity data for $n$ octadecane.

The dilute-gas thermal conductivity data of Tarzimanov and Mashirov $(88,89)$ were used to obtain the dilute-gas coefficients in Table 4, and the liquid-phase data, extending to $50 \mathrm{MPa}$, of references $(90,99)$ were used to obtain the coefficients in Table 4 . A deviation plot is shown in Figure 23. We estimate the uncertainty of the correlation at pressures to $50 \mathrm{MPa}$ to be $4 \%$ for the temperature range from $313 \mathrm{~K}$ to $650 \mathrm{~K}$. The two data sets $(90,99)$ were both made in a concentric cylinder apparatus with an estimated uncertainty of $3 \%$; it is unknown why they do not agree to within their experimental uncertainties. 


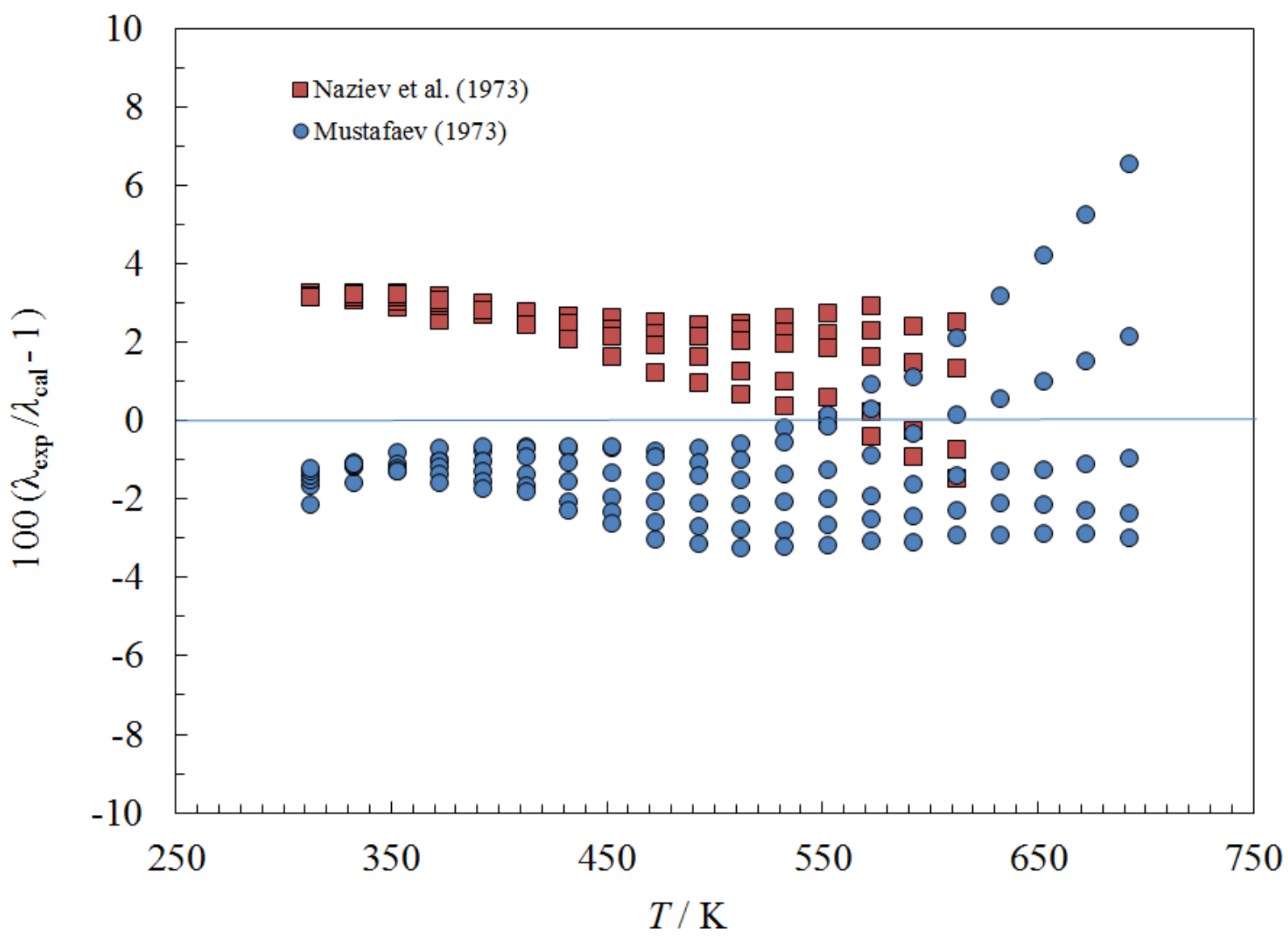

Figure 23. Percentage deviations between the model and the experimental thermal conductivity data for $n$-octadecane.

Two sets of surface tension data from Jasper and coworkers $(92,93)$ were used to obtain the coefficients in Table 6 and the deviation plot in Figure 24. The estimated uncertainty of the correlation is $1 \%$. 


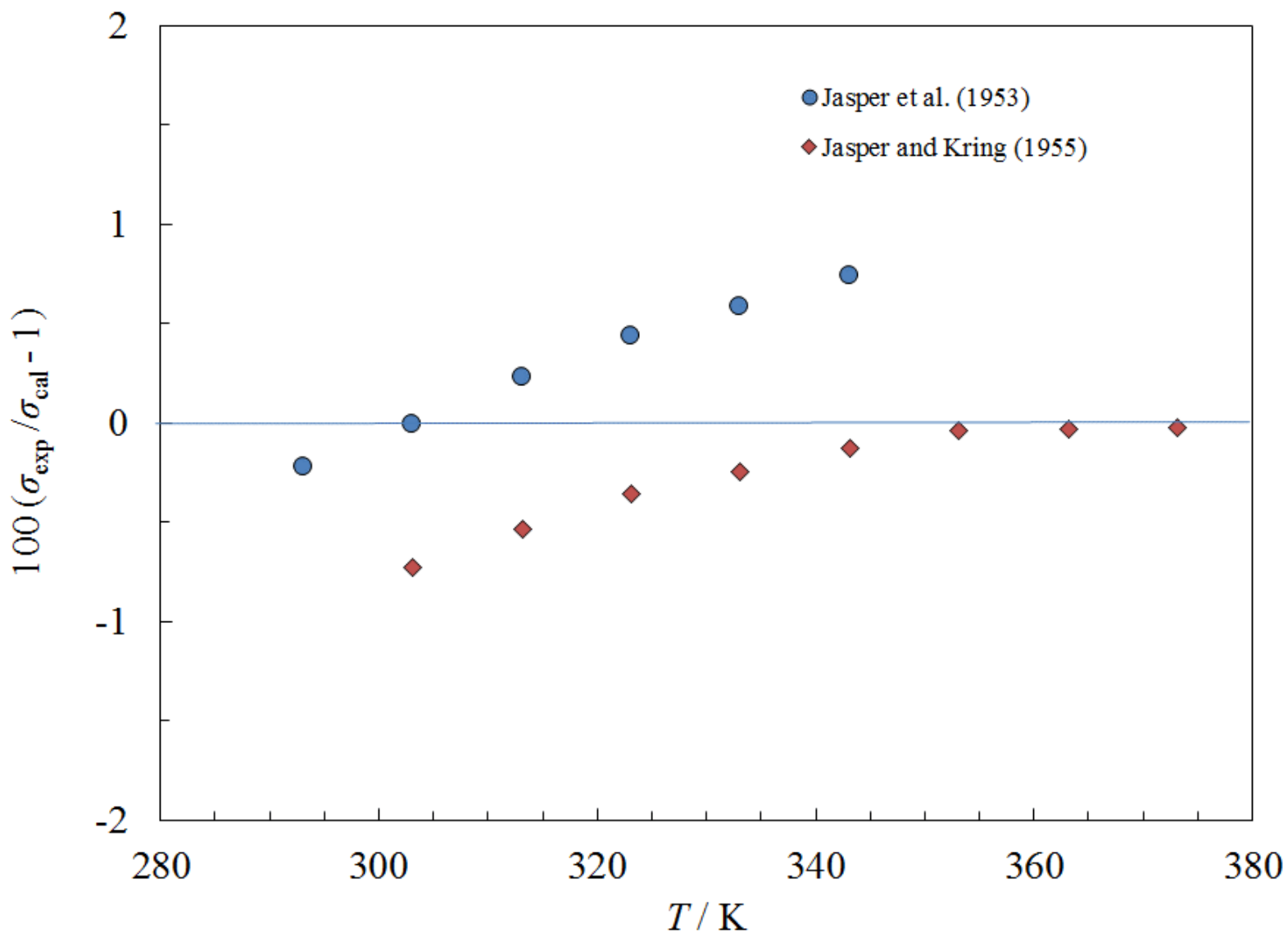

Figure 24. Percentage deviations between the model and the experimental surface tension data for $n$-octadecane.

\subsection{1 n-eicosane}

A Helmholtz equation of state for $n$-eicosane (96) with critical parameters as given in Table 2 was used to provide density. The equation of state is implemented in the REFPROP text file included in Supplementary materials. Lennard-Jones parameters were estimated with a new method developed especially for long-chain alkanes (97). The liquid-phase viscosity data of references $(80,85,87,100,101)$ were used to provide the coefficients in Table 3 , and a deviation plot for data up to $100 \mathrm{MPa}$ is shown in Figure 25. Similar to what was shown for octadecane, there is a lot of scatter in the measurement of Baled et al. (85). Based on comparisons with data, we estimate the uncertainty for the saturated liquid is $5 \%$, rising to $10 \%$ at pressures to $100 \mathrm{MPa}$. 


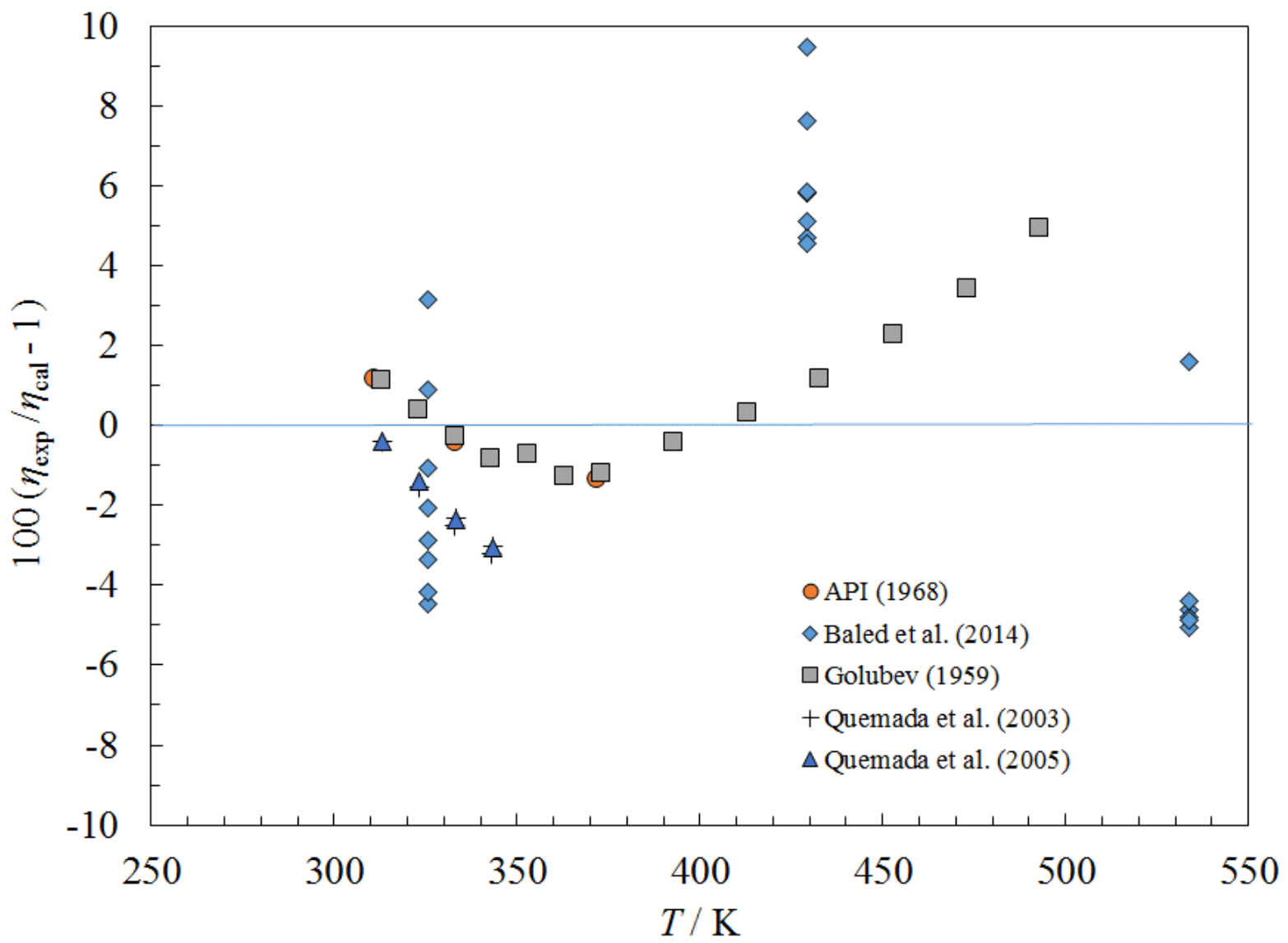

Figure 25. Percentage deviations between the model and the experimental viscosity data for $n$ eicosane.

There were no gas-phase thermal conductivity data available, so we used $1.32 \times 10^{-3}$ for $f_{\text {int }}$ in Eq. (14). Only one source of thermal conductivity data was found (102). The liquid-phase data of Rastorguev et al. (102) obtained with a hot-wire apparatus at pressures up to $50 \mathrm{MPa}$ were used to obtain the coefficients in Table 4, and the deviations are shown in Figure 26. The estimated uncertainty of the correlation for the liquid phase is the same as the uncertainty of the experimental data, $3 \%$. 


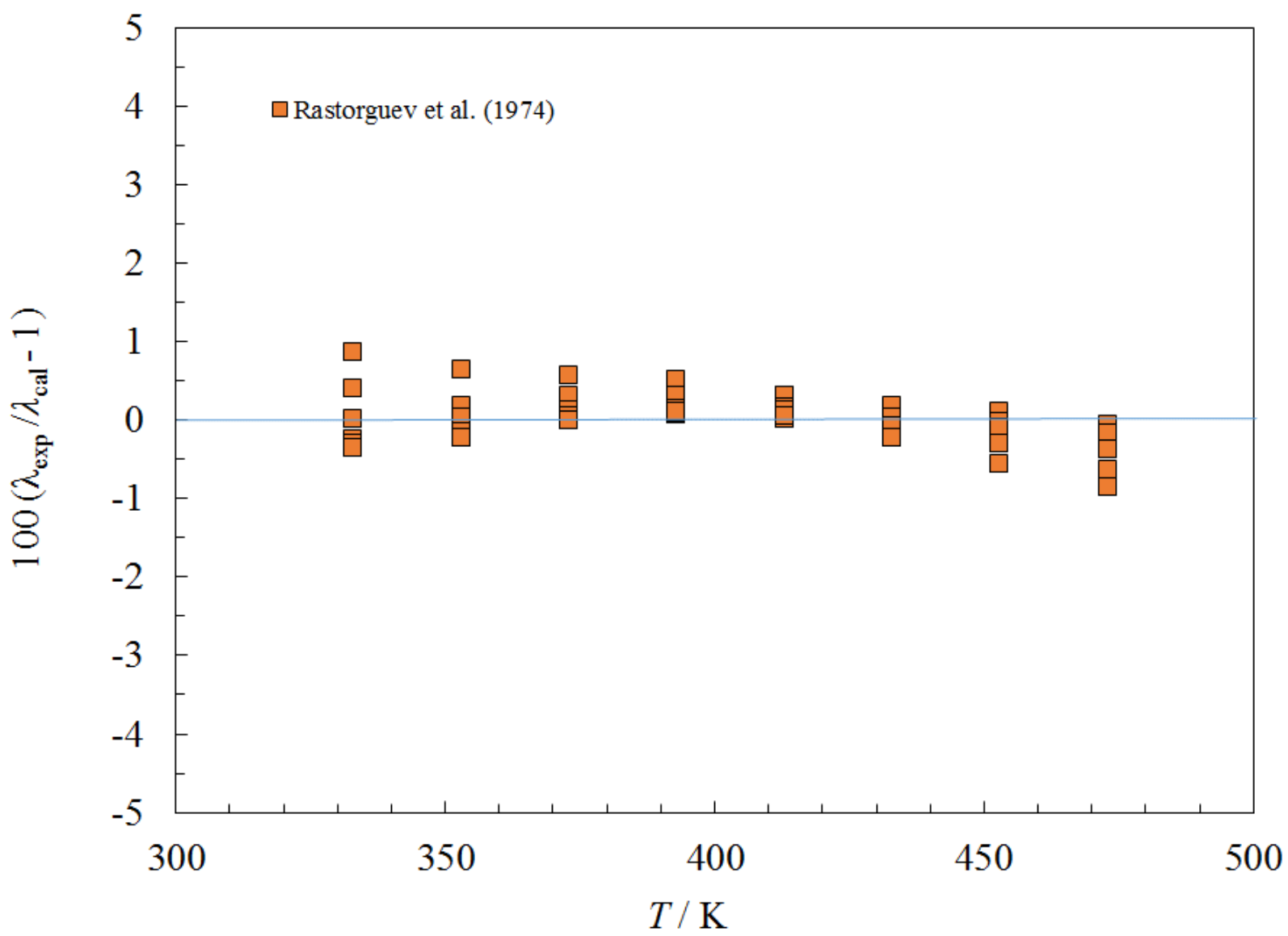

Figure 26. Percentage deviations between the model and the experimental thermal conductivity data for $n$-eicosane.

Surface tension data from Rolo et al. (94) and Quemada et al. $(103,104)$ were used to obtain the coefficients in Table 6 and the deviation plot in Figure 27. The estimated uncertainty of the correlation is approximately the same as the data of Rolo et al. (94), about $2 \%$. 


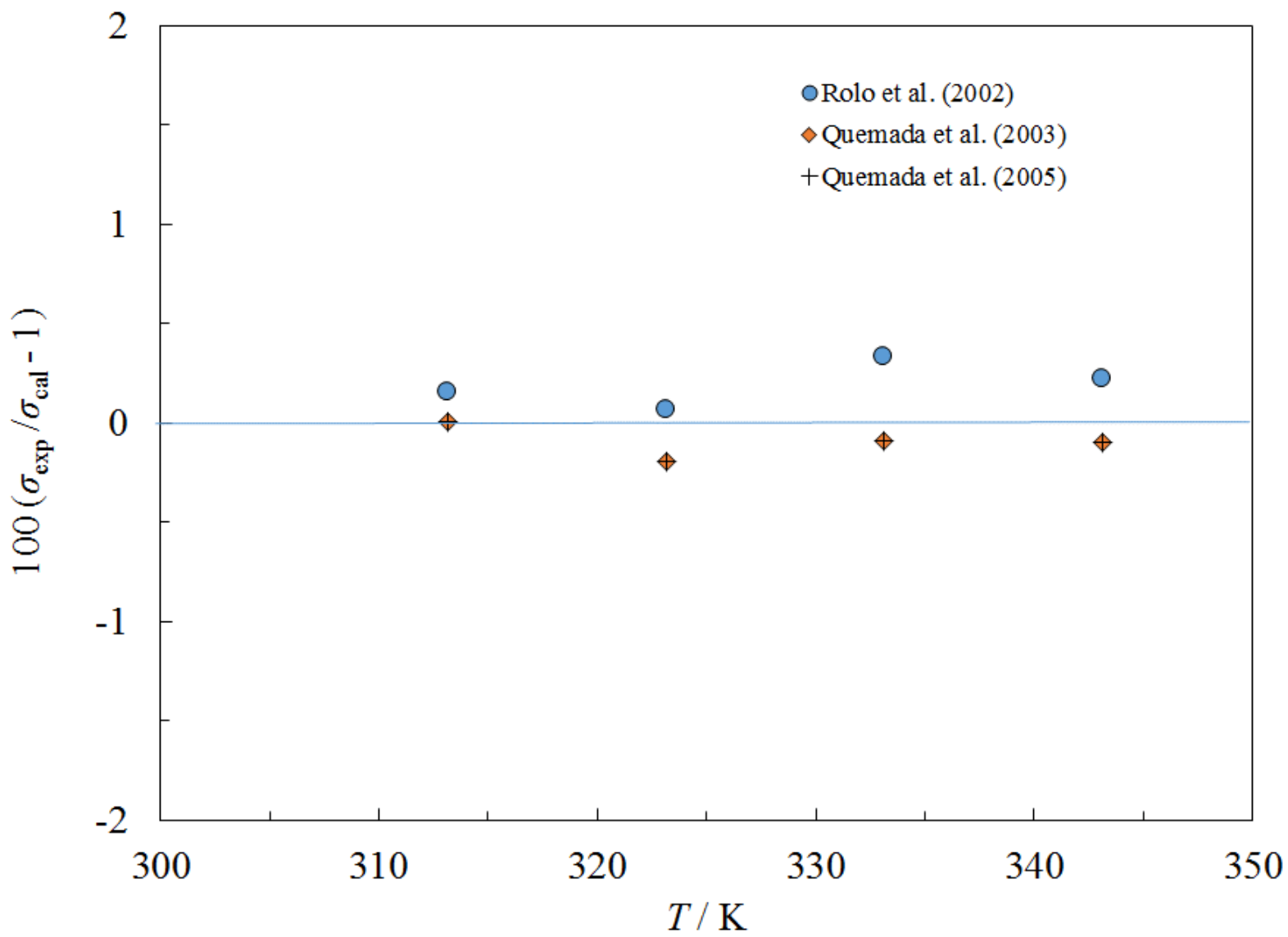

Figure 27. Percentage deviations between the model and the experimental surface tension data for $n$-eicosane.

\subsection{2-methylheptadecane}

The experimental data for this fluid are extremely limited. A Helmholtz equation of state was generated with the equation of state development tool in the NIST TDE software (19). The equation of state is implemented in the REFPROP text file included in Supplementary materials, and was used to provide density in the formulations for viscosity and thermal conductivity. Lennard-Jones parameters were estimated with a new method developed especially for long-chain alkanes (97). This method involves only the molecular weight and the number of carbons, so the LJ parameters for 2-methylheptadecane are the same as $n$-octadecane. The liquid-phase viscosity data of two extremely limited data sets at atmospheric pressure $(80,105)$ were used to provide the coefficients in Table 3, and a deviation plot is shown in Figure 28. Based on comparisons with limited data, the estimated uncertainty for the viscosity of the saturated liquid is $3 \%$. 


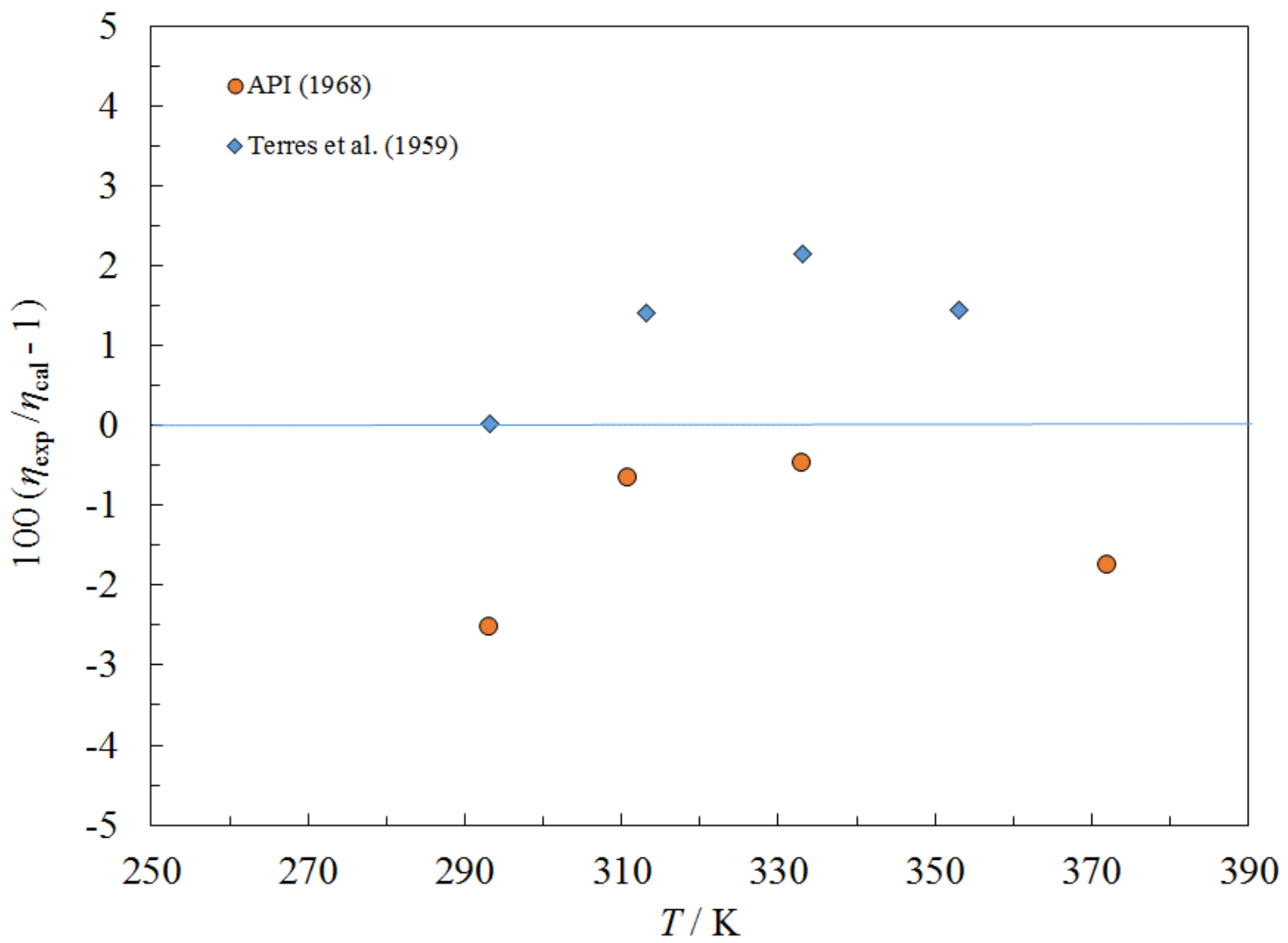

Figure 28. Percentage deviations between the model and the experimental viscosity data for 2methylheptadecane.

There were no gas-phase thermal conductivity data available so we used $1.32 \times 10^{-3}$ for $f_{\text {int }}$ in Eq. (14). There also were no liquid-phase thermal conductivity data available. Watanabe and Kato (25) measured several branched alkanes where it was shown that the branching causes a decrease in the thermal conductivity for isomers of some alkanes. For example, at the same temperature the thermal conductivity of 2,3,4-trimethylpentane is about $9-10 \%$ lower than 2methylheptane (25). Based on this behavior, we estimated the thermal conductivity of 2methylheptadecane should be similar to $n$-hexadecane and obtained the coefficients in Table 4, and estimate the uncertainty of the liquid-phase thermal conductivity correlation is on the order of $30 \%$. Similarly, there were no data available for surface tension. We estimated that the surface tension of 2-methylheptadecane should be in between that of $n$-heptadecane and $n$-octadecane and obtained the coefficients in Table 6 by fitting the average of the value of surface tension value of $n$-heptadecane and $n$-octadecane. Due to the absence of experimental data for 2methylheptadecane, we estimate the uncertainty of the surface tension correlation is $5 \%$. 


\section{$5.132,2,4,4,6,8,8$-heptamethylnonane (isohexadecane)}

A Helmholtz equation of state for isohexadecane (53) with critical parameters as given in Table 2 was used to provide density. The equation of state is implemented in the REFPROP text file included in Supplementary materials. Lennard-Jones parameters were estimated with a new method developed especially for long-chain alkanes (97). Liquid-phase data at pressures up to 50 $\mathrm{MPa}$ (the upper limit of the EOS for isohexadecane) from references (48, 106-109) were fit with $n$-octane as a reference fluid to obtain the coefficients in Table 3 . We found that $n$-octane performed better than $n$-dodecane as a reference fluid, especially at the lowest temperatures. Deviations are shown in Figure 29 for pressures up to $50 \mathrm{MPa}$. The estimated uncertainty for the liquid phase from $293 \mathrm{~K}$ to $373 \mathrm{~K}$ at pressures up to $50 \mathrm{MPa}$ is $4 \%$.

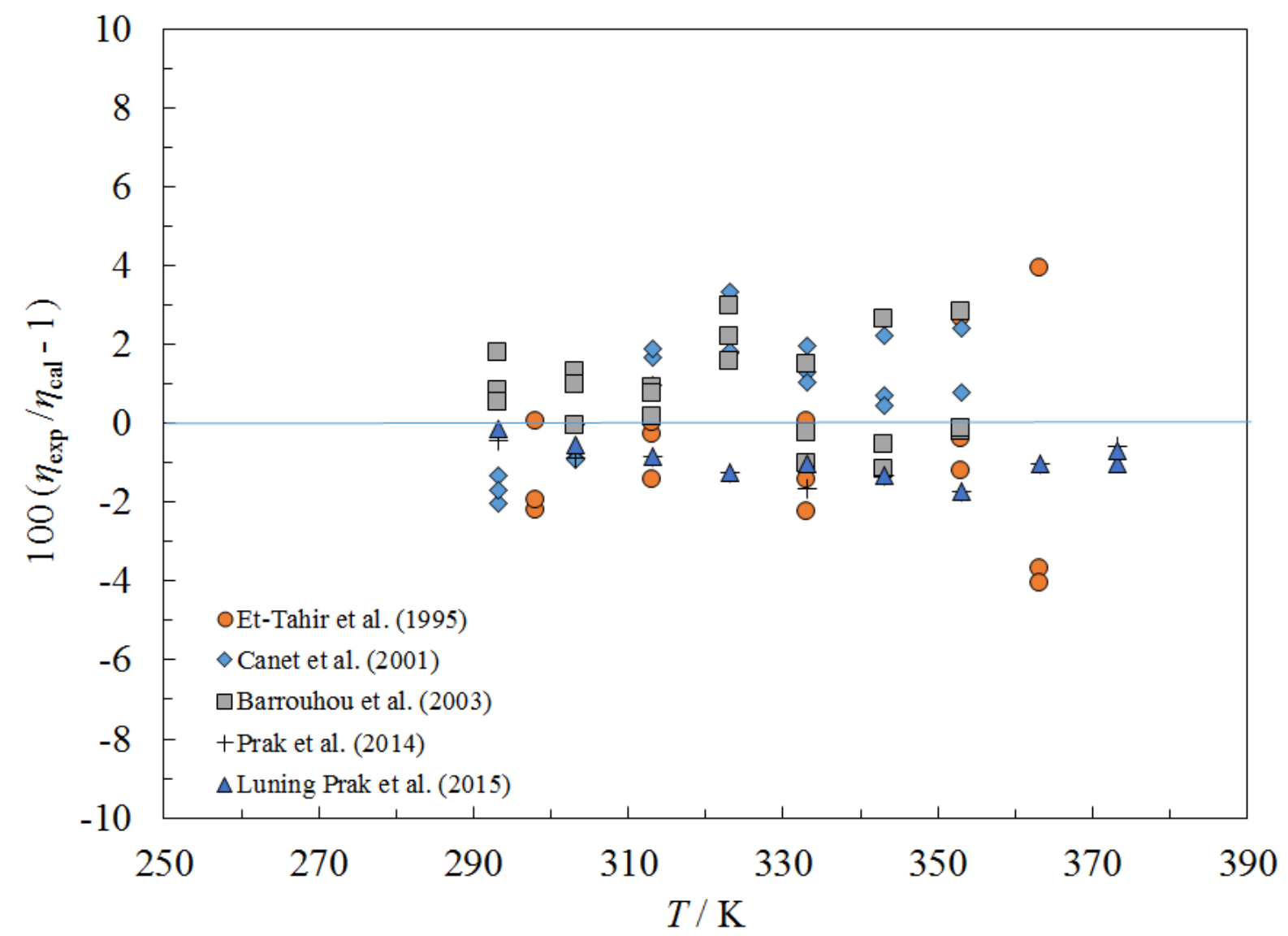

Figure 29. Percentage deviations between the model and the experimental viscosity data for isohexadecane.

There were no gas-phase thermal conductivity data available so we used $1.32 \times 10^{-3}$ for $f_{\text {int }}$ in Eq. (14). There also were no liquid-phase data available, so we used estimated values from the DIPPR program (40) (that were obtained from the method of Pachaiyappan in the Technical Data Book, Petroleum Refining, $4^{\text {th }}$ ed.) to obtain the extended corresponding-states coefficients in Table 4 . The estimated uncertainty of the liquid-phase thermal conductivity is $20 \%$. For surface tension the extremely limited data of references $(108,110)$ were used to obtain the coefficients in 
Table 6 and the deviation plot in Figure 30. Due to the limited data, the estimated uncertainty of the surface tension correlation is $2 \%$.

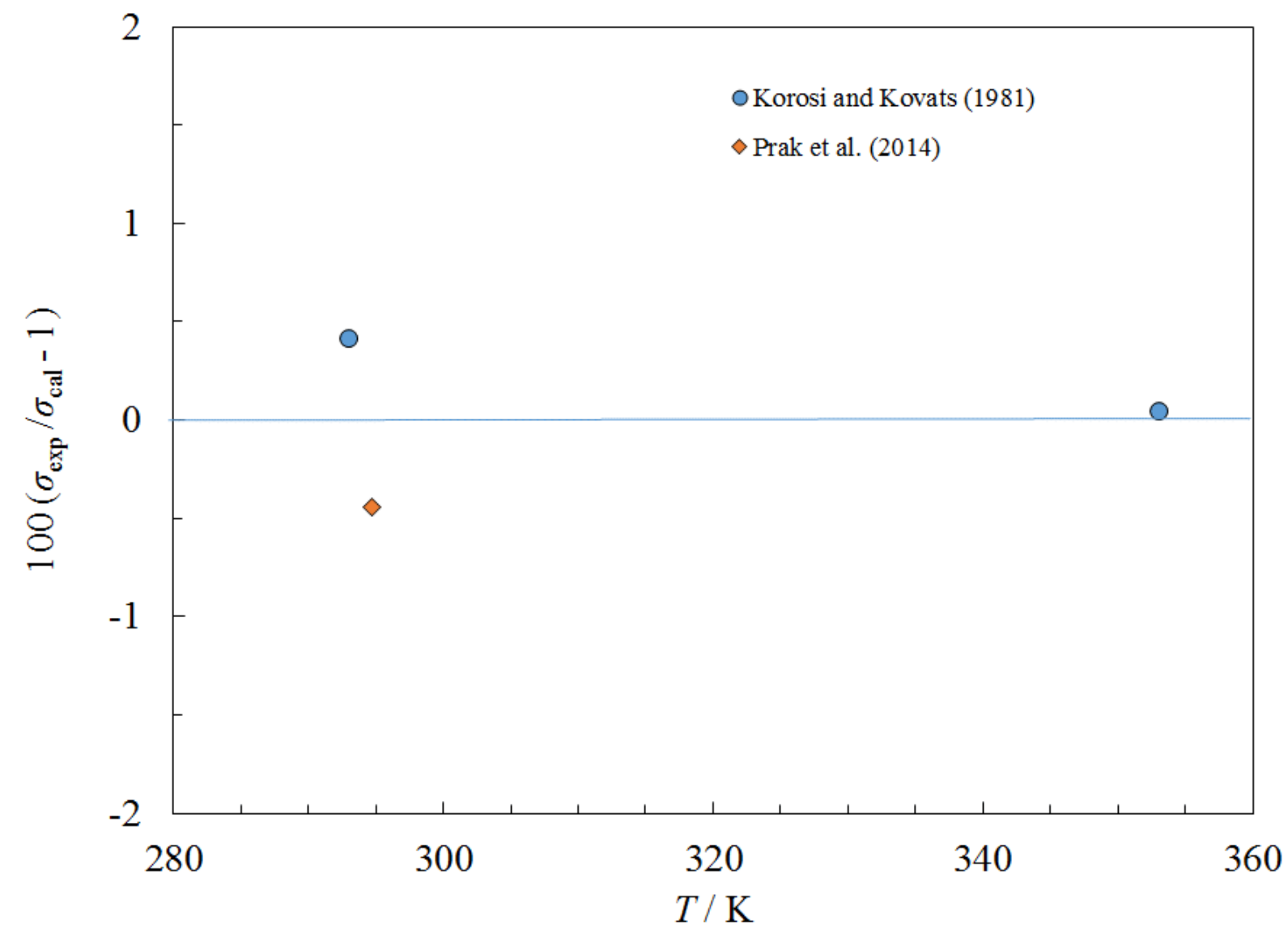

Figure 30. Percentage deviations between the model and the experimental surface tension data for isohexadecane.

\section{Application to the Surrogate Mixtures}

In this section we present thermophysical properties calculated for the four surrogate mixtures developed by Mueller et al. (1-3) to represent low-sulfur diesel fuels. The thermodynamic properties including density, heat capacity, and enthalpy were presented previously $(2,3)$. Here in Tables 7-10 we present the density, viscosity, thermal conductivity, and surface tension of the surrogates along the bubble-point line. The liquid composition along the bubble point is fixed and is the composition given in Table 1. The vapor composition is not the same as the liquid composition, and represents the coexisting vapor phase that is in equilibrium with the liquid at its bubble-point temperature and pressure. The calculations were made with the computer program REFPROP (111) with updated preliminary fluid files containing the transport coefficients developed in this work that are included in the Appendix. The files should be used only with REFPROP versions 9.1.1 (May 11, 2016 Beta, with 9.1304 DLL) or later. They should be considered preliminary and are not part of the official release of the REFPROP computer program. 
The estimated uncertainty for the surrogates is affected by the uncertainty estimates for the properties of the various constituent fluids, as well as uncertainties in the underlying mixture model and any binary interaction parameters. No binary interaction parameters for transport properties have been used here. We estimate that for viscosity of the liquid along the bubble-point line, the uncertainty is $10 \%$ for the surrogates. For liquid thermal conductivity along the bubble-point line, the estimated uncertainty is $15 \%$. For surface tension of the liquid along the bubble-point line, the estimated uncertainty is on the order of $5 \%$. There are very limited data for comparison. We do not have experimental thermal conductivity data, but Mueller et al. $(2,3)$ reported values for kinematic viscosity and surface tension for the four surrogates. Comparisons of the model calculations with the available data are shown in Table 11. Agreement is consistent with the uncertainty estimates given. Figures 31, 32, and 33 show the liquid-phase viscosity, thermal conductivity, and the surface tension for the four surrogate mixtures. 
Table 7. Thermodynamic and transport properties along the bubble-point line for V0a

\begin{tabular}{|c|c|c|c|c|c|c|c|c|}
\hline$t,{ }^{\circ} \mathrm{C}$ & $p, \mathrm{MPa}$ & $\rho_{\mathrm{L}}, \mathrm{kg} \cdot \mathrm{m}^{-3}$ & $\rho_{\mathrm{V}}, \mathrm{kg} \cdot \mathrm{m}^{-3}$ & $\lambda_{\mathrm{L}}, \mathrm{mW} \cdot \mathrm{m}^{-1} \cdot \mathrm{K}^{-1}$ & $\lambda_{\mathrm{V}}, \mathrm{mW} \cdot \mathrm{m}^{-1} \cdot \mathrm{K}^{-1}$ & $\eta_{\mathrm{L}}, \mu \mathrm{Pa} \cdot \mathrm{s}$ & $\eta_{\mathrm{v}, \mu \mathrm{Pa} \cdot \mathrm{s}}$ & $\sigma, \mathrm{mN} \cdot \mathrm{m}^{-1}$ \\
\hline 20. & 0.0000316 & 811. & 0.00187 & 122. & 9.7 & 2995. & 5.7 & 26.6 \\
\hline 30. & 0.0000603 & 804. & 0.00348 & 120. & 10.4 & 2398. & 5.9 & 25.7 \\
\hline 40. & 0.000110 & 797. & 0.00621 & 118. & 11.0 & 1967. & 6.0 & 24.9 \\
\hline 50. & 0.000193 & 790. & 0.0107 & 116. & 11.7 & 1644. & 6.1 & 24.1 \\
\hline 60. & 0.000327 & 783. & 0.0177 & 114. & 12.4 & 1395. & 6.3 & 23.3 \\
\hline 70. & 0.000535 & 776. & 0.0284 & 112. & 13.1 & 1200. & 6.4 & 22.5 \\
\hline 80. & 0.000850 & 769. & 0.0444 & 110. & 13.8 & 1043. & 6.6 & 21.8 \\
\hline 90. & 0.00132 & 762. & 0.0676 & 108. & 14.5 & 916. & 6.7 & 21.0 \\
\hline 100. & 0.00199 & 756. & 0.100 & 106. & 15.2 & 810. & 6.8 & 20.2 \\
\hline 110. & 0.00293 & 749. & 0.146 & 105. & 15.9 & 722. & 6.9 & 19.4 \\
\hline 120. & 0.00424 & 741. & 0.208 & 103. & 16.6 & 647. & 7.1 & 18.7 \\
\hline 130. & 0.00601 & 734. & 0.291 & 101. & 17.3 & 584. & 7.2 & 17.9 \\
\hline 140. & 0.00837 & 727. & 0.400 & 100. & 18.1 & 529. & 7.3 & 17.2 \\
\hline 150. & 0.0115 & 720. & 0.541 & 98. & 18.8 & 481. & 7.5 & 16.4 \\
\hline 160. & 0.0155 & 713. & 0.721 & 97. & 19.6 & 440. & 7.6 & 15.7 \\
\hline 170 . & 0.0205 & 705 . & 0.947 & 95. & 20.3 & 403. & 7.7 & 15.0 \\
\hline 180. & 0.0270 & 698. & 1.23 & 94. & 21.1 & 370 . & 7.8 & 14.3 \\
\hline 190. & 0.0349 & 690. & 1.58 & 92. & 21.9 & 341. & 8.0 & 13.6 \\
\hline 200 . & 0.0447 & 682. & 2.00 & 91. & 22.8 & 315. & 8.1 & 12.9 \\
\hline 210 & 0.0566 & 675. & 2.51 & 89. & 23.6 & 291. & 8.2 & 12.2 \\
\hline 220 & 0.0709 & 667. & 3.13 & 88. & 24.5 & 269. & 8.4 & 11.5 \\
\hline 230. & 0.0880 & 658. & 3.86 & 87. & 25.4 & 250 . & 8.5 & 10.8 \\
\hline 240 & 0.108 & 650. & 4.72 & 85. & 26.3 & 232. & 8.6 & 10.1 \\
\hline 250 . & 0.132 & 642. & 5.74 & 84. & 27.2 & 215. & 8.8 & 9.5 \\
\hline 260. & 0.160 & 633. & 6.92 & 83. & 28.2 & 200 . & 8.9 & 8.8 \\
\hline
\end{tabular}




\begin{tabular}{lllllllll}
270. & 0.192 & 624. & 8.31 & 82. & 29.3 & 186. & 9.0 & 8.2 \\
280. & 0.229 & 615. & 9.92 & 80. & 30.4 & 173. & 9.2 & 7.6 \\
290. & 0.271 & 605. & 11.8 & 79. & 31.5 & 160. & 9.3 & 7.0 \\
300. & 0.319 & 595. & 13.9 & 78. & 32.7 & 149. & 9.4 & 6.4 \\
310. & 0.374 & 585. & 16.4 & 77. & 34.0 & 138. & 9.6 & 5.8 \\
320. & 0.435 & 574. & 19.3 & 76. & 35.4 & 127. & 9.7 & 5.2 \\
330. & 0.504 & 563. & 22.6 & 75. & 37.0 & 118. & 9.8 & 4.7 \\
340. & 0.581 & 551. & 26.4 & 74. & 38.6 & 109. & 10.0 & 4.1 \\
350. & 0.668 & 539. & 30.9 & 73. & 40.5 & 100. & 10.1 & 3.6 \\
360. & 0.763 & 525. & 36.2 & 73. & 42.6 & 91. & 10.3 & 3.1 \\
370. & 0.870 & 511. & 42.3 & 72. & 45.0 & 83. & 10.5 & 2.6 \\
380. & 0.987 & 495. & 49.7 & 71. & 47.8 & 76. & 10.7 & 2.1 \\
390. & 1.12 & 478. & 58.6 & 71. & 51.2 & 68. & 11.0 & 1.7 \\
400. & 1.26 & 458. & 69.8 & 72. & 55.3 & 61. & 11.4 & 1.2 \\
410. & 1.42 & 435. & 84.1 & 72. & 60.5 & 53. & 11.9 & 0.8 \\
420. & 1.59 & 406. & 104. & 75. & 67.6 & 46. & 12.6 & 0.5 \\
430. & 1.78 & 364. & 136. & 82. & 78.5 & 37. & 13.9 & 0.2 \\
\hline
\end{tabular}

Properties along the bubble point (fixed liquid composition, vapor composition variable)

Calculated with REFPROP DLL version 9.1304, preliminary fluid files for components, 6/22/2016

Estimated critical point: $t_{\mathrm{c}}=438.7^{\circ} \mathrm{C}, p_{\mathrm{c}}=1.95 \mathrm{MPa}, \rho_{\mathrm{c}}=239 \mathrm{~kg} / \mathrm{m}^{3}$ 
Table 8. Thermodynamic and transport properties along the bubble-point line for V0b

\begin{tabular}{lllllllll}
\hline$t,{ }^{\circ} \mathrm{C}$ & $p, \mathrm{MPa}$ & $\rho_{\mathrm{L}}, \mathrm{kg} \cdot \mathrm{m}^{-3}$ & $\rho_{\mathrm{V}}, \mathrm{kg} \cdot \mathrm{m}^{-3}$ & $\lambda_{\mathrm{L}}, \mathrm{mW} \cdot \mathrm{m}^{-1} \cdot \mathrm{K}^{-1}$ & $\lambda \mathrm{V}, \mathrm{mW} \cdot \mathrm{m}^{-1} \cdot \mathrm{K}^{-1}$ & $\eta_{\mathrm{L}, \mu \mathrm{Pa} \cdot \mathrm{s}}$ & $\eta_{\mathrm{V},} \mu \mathrm{Pa} \cdot \mathrm{s}$ & $\sigma, \mathrm{mN} \cdot \mathrm{m}^{-1}$ \\
\hline 20. & 0.0000593 & 821. & 0.00305 & 127. & 10.0 & 2536. & 6.1 & 26.4 \\
30. & 0.000112 & 814. & 0.00563 & 125. & 10.7 & 2058. & 6.3 & 25.5 \\
40. & 0.000203 & 807. & 0.00992 & 123. & 11.3 & 1707. & 6.5 & 24.7 \\
50. & 0.000353 & 800. & 0.0168 & 121. & 12.0 & 1441. & 6.6 & 23.9 \\
60. & 0.000590 & 793. & 0.0275 & 119. & 12.7 & 1234. & 6.8 & 23.2 \\
70. & 0.000955 & 786. & 0.0435 & 117. & 13.4 & 1070. & 7.0 & 22.4 \\
80. & 0.00150 & 779. & 0.0669 & 116. & 14.2 & 937. & 7.2 & 21.6 \\
90. & 0.00229 & 772. & 0.100 & 114. & 14.9 & 828. & 7.3 & 20.8 \\
100. & 0.00340 & 765. & 0.146 & 112. & 15.7 & 738. & 7.5 & 20.1 \\
110. & 0.00494 & 757. & 0.209 & 110. & 16.4 & 661. & 7.7 & 19.3 \\
120. & 0.00703 & 750. & 0.293 & 109. & 17.2 & 596. & 7.8 & 18.5 \\
130. & 0.00980 & 743. & 0.402 & 107. & 18.0 & 540. & 8.0 & 17.8 \\
140. & 0.0134 & 736. & 0.543 & 105. & 18.8 & 492. & 8.1 & 17.0 \\
150. & 0.0181 & 728. & 0.722 & 104. & 19.6 & 450. & 8.3 & 16.3 \\
160. & 0.0240 & 721. & 0.946 & 102. & 20.5 & 412. & 8.5 & 15.6 \\
170. & 0.0314 & 713. & 1.22 & 101. & 21.3 & 379. & 8.6 & 14.9 \\
180. & 0.0405 & 706. & 1.56 & 99. & 22.1 & 350. & 8.8 & 14.1 \\
190. & 0.0516 & 698. & 1.97 & 98. & 23.0 & 324. & 8.9 & 13.4 \\
200. & 0.0650 & 690. & 2.47 & 96. & 23.9 & 300. & 9.0 & 12.7 \\
210. & 0.0811 & 682. & 3.06 & 95. & 24.8 & 278. & 9.2 & 12.0 \\
220. & 0.100 & 674. & 3.75 & 93. & 92. & 25.7 & 24. & 9.3
\end{tabular}




\begin{tabular}{lllllllll}
270. & 0.253 & 630. & 9.38 & 86. & 30.6 & 181. & 10.0 & 8.1 \\
280. & 0.298 & 621. & 11.1 & 85. & 31.7 & 168. & 10.1 & 7.5 \\
290. & 0.348 & 61. & 13.0 & 84. & 32.8 & 157. & 10.3 & 6.9 \\
300. & 0.405 & 601. & 15.3 & 82. & 34.0 & 146. & 10.4 & 6.3 \\
310. & 0.469 & 590. & 17.8 & 81. & 35.2 & 136. & 10.5 & 5.7 \\
320. & 0.540 & 579. & 20.7 & 80. & 36.6 & 126. & 10.6 & 5.2 \\
330. & 0.619 & 568. & 24.1 & 79. & 38.0 & 117. & 10.7 & 4.6 \\
340. & 0.706 & 556. & 27.9 & 78. & 39.6 & 108. & 10.9 & 4.1 \\
350. & 0.801 & 543. & 32.3 & 77. & 41.3 & 99. & 11.0 & 3.5 \\
360. & 0.907 & 530. & 37.4 & 76. & 43.3 & 91. & 11.1 & 3.0 \\
370. & 1.02 & 515. & 43.4 & 75. & 45.5 & 84. & 11.3 & 2.6 \\
380. & 1.15 & 499. & 50.4 & 74. & 48.0 & 76. & 11.5 & 2.1 \\
390. & 1.28 & 482. & 58.8 & 74. & 51.0 & 69. & 11.7 & 1.6 \\
400. & 1.43 & 462. & 68.9 & 74. & 54.6 & 62. & 12.0 & 1.2 \\
410. & 1.59 & 440. & 81.5 & 74. & 59.0 & 55. & 12.4 & 0.9 \\
420. & 1.77 & 413. & 97.9 & 76. & 64.7 & 47. & 12.9 & 0.5 \\
430. & 1.95 & 379. & 121. & 79. & 72.5 & 40. & 13.7 & 0.2 \\
440. & 2.14 & 326. & 160. & 88. & 84.9 & 30. & 15.3 & 0.0 \\
\hline
\end{tabular}

Properties along the bubble point (fixed liquid composition, vapor composition variable)

Calculated with REFPROP DLL version 9.1304, preliminary fluid files for components, 6/22/2016

Estimated critical point: $t_{\mathrm{c}}=446.3{ }^{\circ} \mathrm{C}, p_{\mathrm{c}}=2.21 \mathrm{MPa}, \rho_{\mathrm{c}}=232 \mathrm{~kg} / \mathrm{m}^{3}$ 
Table 9. Thermodynamic and transport properties along the bubble-point line for V1

\begin{tabular}{|c|c|c|c|c|c|c|c|c|}
\hline$t,{ }^{\circ} \mathrm{C}$ & $p, \mathrm{MPa}$ & $\rho_{\mathrm{L}}, \mathrm{kg} \cdot \mathrm{m}^{-3}$ & $\rho_{\mathrm{V}}, \mathrm{kg} \cdot \mathrm{m}^{-3}$ & $\lambda_{\mathrm{L}}, \mathrm{mW} \cdot \mathrm{m}^{-1} \cdot \mathrm{K}^{-1}$ & $\lambda_{\mathrm{v}}, \mathrm{mW} \cdot \mathrm{m}^{-1} \cdot \mathrm{K}^{-1}$ & $\eta_{\mathrm{L}}, \mu \mathrm{Pa} \cdot \mathrm{s}$ & $\eta_{\mathrm{v}}, \mu \mathrm{Pa} \cdot \mathrm{s}$ & $\sigma, \mathrm{mN} \cdot \mathrm{m}^{-1}$ \\
\hline 20. & 0.0000610 & 814. & 0.00328 & 124. & 10.3 & 2584. & 6.0 & 26.1 \\
\hline 30. & 0.000115 & 807. & 0.00603 & 122. & 10.9 & 2094. & 6.2 & 25.3 \\
\hline 40. & 0.000208 & 800. & 0.0106 & 120. & 11.6 & 1735. & 6.3 & 24.4 \\
\hline 50. & 0.000360 & 793. & 0.0179 & 118. & 12.3 & 1464. & 6.5 & 23.6 \\
\hline 60. & 0.000600 & 786. & 0.0291 & 116. & 13.0 & 1253. & 6.7 & 22.8 \\
\hline 70. & 0.000968 & 779. & 0.0460 & 115. & 13.7 & 1085 . & 6.9 & 22.0 \\
\hline 80. & 0.00152 & 772. & 0.0705 & 113. & 14.5 & 949. & 7.0 & 21.3 \\
\hline 90. & 0.00231 & 765. & 0.105 & 111. & 15.2 & 838. & 7.2 & 20.5 \\
\hline 100. & 0.00343 & 758. & 0.153 & 109. & 16.0 & 746. & 7.4 & 19.7 \\
\hline 110. & 0.00497 & 751. & 0.218 & 108. & 16.8 & 668. & 7.5 & 18.9 \\
\hline 120. & 0.00706 & 744. & 0.305 & 106. & 17.6 & 602. & 7.7 & 18.2 \\
\hline 130. & 0.00984 & 737. & 0.419 & 104. & 18.4 & 545 & 7.8 & 17.4 \\
\hline 140. & 0.0135 & 729. & 0.564 & 103. & 19.2 & 496. & 8.0 & 16.7 \\
\hline 150. & 0.0181 & 722 . & 0.749 & 101. & 20.0 & 453. & 8.2 & 15.9 \\
\hline 160. & 0.0240 & 715. & 0.981 & 100. & 20.9 & 416. & 8.3 & 15.2 \\
\hline 170 . & 0.0314 & 707. & 1.27 & 98. & 21.7 & 382. & 8.5 & 14.5 \\
\hline 180. & 0.0405 & 699. & 1.62 & 97. & 22.6 & 352. & 8.6 & 13.8 \\
\hline 190. & 0.0515 & 692. & 2.04 & 95. & 23.4 & 326. & 8.7 & 13.0 \\
\hline 200 . & 0.0649 & 684. & 2.55 & 94. & 24.3 & 301. & 8.9 & 12.3 \\
\hline 210. & 0.0809 & 676. & 3.15 & 92. & 25.2 & 279. & 9.0 & 11.7 \\
\hline 220 . & 0.0999 & 668. & 3.87 & 91. & 26.2 & 260. & 9.2 & 11.0 \\
\hline 230. & 0.122 & 660 & 4.70 & 89. & 27.1 & 241. & 9.3 & 10.3 \\
\hline 240 & 0.148 & 651. & 5.68 & 88. & 28.1 & 224 & 9.4 & 9.6 \\
\hline 250 . & 0.178 & 642. & 6.82 & 87. & 29.1 & 209. & 9.6 & 9.0 \\
\hline
\end{tabular}




\begin{tabular}{lllllllll}
260. & 0.213 & 634. & 8.14 & 85. & 30.1 & 195. & 9.7 & 8.4 \\
270. & 0.252 & 624. & 9.65 & 84. & 31.2 & 181. & 9.8 & 7.7 \\
280. & 0.297 & 615. & 11.4 & 83. & 32.3 & 169. & 10.0 & 7.1 \\
290. & 0.347 & 605. & 13.4 & 82. & 33.4 & 157. & 10.1 & 6.5 \\
300. & 0.404 & 595. & 15.7 & 80. & 34.6 & 146. & 10.2 & 6.0 \\
310. & 0.468 & 585. & 18.3 & 79. & 35.9 & 135. & 10.3 & 5.4 \\
320. & 0.539 & 574. & 21.3 & 78. & 37.3 & 126. & 10.5 & 4.8 \\
330. & 0.618 & 562. & 24.8 & 77. & 38.8 & 116. & 10.6 & 4.3 \\
340. & 0.705 & 550. & 28.7 & 76. & 40.4 & 107. & 10.7 & 3.8 \\
350. & 0.801 & 537. & 33.3 & 75. & 42.2 & 99. & 10.8 & 3.3 \\
360. & 0.907 & 524. & 38.6 & 74. & 44.2 & 91. & 11.0 & 2.8 \\
370. & 1.02 & 509. & 44.8 & 73. & 46.5 & 83. & 11.2 & 2.3 \\
380. & 1.15 & 493. & 52.1 & 73. & 49.1 & 75. & 11.4 & 1.9 \\
390. & 1.29 & 475. & 60.9 & 72. & 52.3 & 68. & 11.7 & 1.5 \\
400. & 1.44 & 455. & 71.6 & 72. & 56.0 & 61. & 12.0 & 1.1 \\
410. & 1.60 & 432. & 85.1 & 73. & 60.8 & 53. & 12.4 & 0.7 \\
420. & 1.77 & 404. & 103. & 75. & 66.9 & 46. & 13.0 & 0.4 \\
430. & 1.96 & 366. & 130. & 80. & 75.7 & 37. & 14.1 & 0.2 \\
\hline
\end{tabular}

Properties along the bubble point (fixed liquid composition, vapor composition variable)

Calculated with REFPROP DLL version 9.1304, preliminary fluid files for components, 6/22/2016

Estimated critical point: $t_{\mathrm{c}}=439.5{ }^{\circ} \mathrm{C}, p_{\mathrm{c}}=2.13 \mathrm{MPa}, \rho_{\mathrm{c}}=298 \mathrm{~kg} / \mathrm{m}^{3}$ 
Table 10. Thermodynamic and transport properties along the bubble-point line for V2

\begin{tabular}{|c|c|c|c|c|c|c|c|c|}
\hline$t,{ }^{\circ} \mathrm{C}$ & $p, \mathrm{MPa}$ & $\rho_{\mathrm{L}}, \mathrm{kg} \cdot \mathrm{m}^{-3}$ & $\rho_{\mathrm{V}}, \mathrm{kg} \cdot \mathrm{m}^{-3}$ & $\lambda_{\mathrm{L}}, \mathrm{mW} \cdot \mathrm{m}^{-1} \cdot \mathrm{K}^{-1}$ & $\lambda_{\mathrm{V}}, \mathrm{mW} \cdot \mathrm{m}^{-1} \cdot \mathrm{K}^{-1}$ & $\eta_{\mathrm{L}}, \mu \mathrm{Pa} \cdot \mathrm{s}$ & $\eta_{\mathrm{v}, \mu \mathrm{Pa} \cdot \mathrm{s}}$ & $\sigma, \mathrm{mN} \cdot \mathrm{m}^{-1}$ \\
\hline 20. & 0.0000510 & 840. & 0.00293 & 123. & 11.6 & 2980. & 5.8 & 28.2 \\
\hline 30. & 0.0000964 & 833. & 0.00538 & 121. & 12.2 & 2351. & 6.0 & 27.2 \\
\hline 40. & 0.000174 & 825. & 0.00943 & 119. & 12.9 & 1909. & 6.2 & 26.3 \\
\hline 50. & 0.000303 & 818. & 0.0159 & 117. & 13.7 & 1587. & 6.4 & 25.4 \\
\hline 60. & 0.000508 & 811. & 0.0260 & 116. & 14.4 & 1342. & 6.6 & 24.6 \\
\hline 70. & 0.000823 & 804. & 0.0410 & 114. & 15.2 & 1153. & 6.8 & 23.7 \\
\hline 80. & 0.00129 & 796. & 0.0629 & 112. & 15.9 & 1003. & 7.0 & 22.8 \\
\hline 90. & 0.00198 & 789. & 0.0940 & 111. & 16.7 & 882. & 7.2 & 22.0 \\
\hline 100. & 0.00296 & 782. & 0.137 & 109. & 17.5 & 783. & 7.4 & 21.1 \\
\hline 110. & 0.00431 & 775. & 0.196 & 108. & 18.4 & 700. & 7.6 & 20.3 \\
\hline 120. & 0.00616 & 767. & 0.274 & 106. & 19.2 & 631. & 7.8 & 19.4 \\
\hline 130. & 0.00863 & 760. & 0.377 & 105. & 20.1 & 572. & 8.0 & 18.6 \\
\hline 140. & 0.0119 & 753. & 0.510 & 104. & 21.0 & 521. & 8.2 & 17.8 \\
\hline 150. & 0.0161 & 745. & 0.679 & 102. & 21.9 & 477. & 8.4 & 17.0 \\
\hline 160. & 0.0214 & 738. & 0.890 & 101. & 22.8 & 439. & 8.6 & 16.2 \\
\hline 170 . & 0.0281 & 730 . & 1.15 & 100. & 23.8 & 405. & 8.8 & 15.4 \\
\hline 180. & 0.0364 & 722 . & 1.47 & 98. & 24.7 & 374. & 9.0 & 14.6 \\
\hline 190. & 0.0466 & 714 . & 1.86 & 97. & 25.7 & 347. & 9.2 & 13.9 \\
\hline 200 & 0.0590 & 707. & 2.33 & 96. & 26.7 & 323. & 9.4 & 13.1 \\
\hline 210 & 0.0738 & 699. & 2.89 & 95. & 27.7 & 301. & 9.6 & 12.4 \\
\hline 220 & 0.0915 & 690. & 3.55 & 93. & 28.8 & 281. & 9.7 & 11.6 \\
\hline 230 & 0.112 & 682. & 4.32 & 92. & 29.8 & 262. & 9.9 & 10.9 \\
\hline 240 & 0.137 & 674. & 5.22 & 91. & 30.9 & 245 & 10.1 & 10.2 \\
\hline 250 & 0.165 & 665. & 6.27 & 90. & 32.1 & 229. & 10.3 & 9.5 \\
\hline 260 & 0.198 & 656. & 7.48 & 89. & 33.2 & 215. & 10.5 & 8.8 \\
\hline 270 & 0.235 & 647. & 8.88 & 88. & 34.4 & 201. & 10.6 & 8.2 \\
\hline
\end{tabular}




\begin{tabular}{lllllllll}
280. & 0.278 & 638. & 10.5 & 87. & 35.6 & 188. & 10.8 & 7.5 \\
290. & 0.326 & 628. & 12.3 & 86. & 36.9 & 177. & 11.0 & 6.9 \\
300. & 0.380 & 619. & 14.4 & 85. & 38.2 & 165. & 11.1 & 6.3 \\
310. & 0.441 & 609. & 16.8 & 84. & 39.6 & 155. & 11.3 & 5.6 \\
320. & 0.510 & 598. & 19.5 & 83. & 41.0 & 144. & 11.4 & 5.1 \\
330. & 0.586 & 587. & 22.7 & 82. & 42.6 & 135. & 11.6 & 4.5 \\
340. & 0.670 & 575. & 26.2 & 81. & 44.2 & 126. & 11.8 & 4.0 \\
350. & 0.763 & 563. & 30.3 & 81. & 46.0 & 117. & 11.9 & 3.5 \\
360. & 0.865 & 551. & 35.1 & 80. & 47.9 & 108. & 12.1 & 3.1 \\
370. & 0.978 & 537. & 40.5 & 80. & 50.0 & 100. & 12.4 & 2.6 \\
380. & 1.10 & 522. & 47.0 & 79. & 52.4 & 92. & 12.6 & 2.2 \\
390. & 1.24 & 506. & 54.6 & 79. & 55.2 & 84. & 12.9 & 1.8 \\
400. & 1.38 & 488. & 63.7 & 79. & 58.4 & 76. & 13.3 & 1.4 \\
410. & 1.55 & 468. & 75.0 & 79. & 62.2 & 69. & 13.7 & 1.0 \\
420. & 1.72 & 445. & 89.3 & 80. & 67.0 & 61. & 14.3 & 0.7 \\
430. & 1.91 & 416. & 109. & 83. & 73.4 & 52. & 15.2 & 0.4 \\
440. & 2.11 & 375. & 139. & 88. & 82.7 & 43. & 16.6 & 0.1 \\
\hline
\end{tabular}

Properties along the bubble point (fixed liquid composition, vapor composition variable)

Calculated with REFPROP DLL version 9.1304, preliminary fluid files for components, 6/22/2016

Estimated critical point: $t_{\mathrm{c}}=450.8^{\circ} \mathrm{C}, p_{\mathrm{c}}=2.29 \mathrm{MPa}, \rho_{\mathrm{c}}=239 \mathrm{~kg} / \mathrm{m}^{3}$ 
Table 11. Comparisons of experimental $(2,3)$ and predicted surrogate fuel properties

\begin{tabular}{llllllll}
\hline property & $\begin{array}{l}\text { V0a } \\
\text { experimental }\end{array}$ & $\begin{array}{l}\text { V0a } \\
\text { model }\end{array}$ & $\begin{array}{l}\text { V0b } \\
\text { experimental }\end{array}$ & $\begin{array}{l}\text { V0b } \\
\text { model }\end{array}$ & $\begin{array}{l}\text { V1 } \\
\text { experimental }\end{array}$ & $\begin{array}{l}\text { V1 } \\
\text { model }\end{array}$ & $\begin{array}{l}\text { V2 } \\
\text { experimental }\end{array}$ \\
\hline $\begin{array}{l}\text { Kinematic viscosity } \\
(\mathrm{cSt}) \text { at } 40{ }^{\circ} \mathrm{C}, 0.1 \mathrm{MPa}\end{array}$ & 2.452 & 2.472 & 2.303 & 2.118 & 2.331 & 2.172 & 2.378 \\
$\begin{array}{l}\text { Surface tension }(\mathrm{mN} / \mathrm{m}) \\
\text { at } 23.1^{\circ} \mathrm{C}\end{array}$ & 26.39 & 26.30 & - & - & - & - & - \\
$\begin{array}{l}\text { Surface tension }(\mathrm{mN} / \mathrm{m}) \\
\text { at } 22.8^{\circ} \mathrm{C}\end{array}$ & - & - & 27.41 & 26.14 & - & - & - \\
$\begin{array}{l}\text { Surface tension }(\mathrm{mN} / \mathrm{m}) \\
\text { at } 22.6^{\circ} \mathrm{C}\end{array}$ & - & - & - & - & 27.30 & 25.89 & - \\
$\begin{array}{l}\text { Surface tension }(\mathrm{mN} / \mathrm{m}) \\
\text { at } 22.7^{\circ} \mathrm{C}\end{array}$ & - & - & - & - & - & - & - \\
\end{tabular}




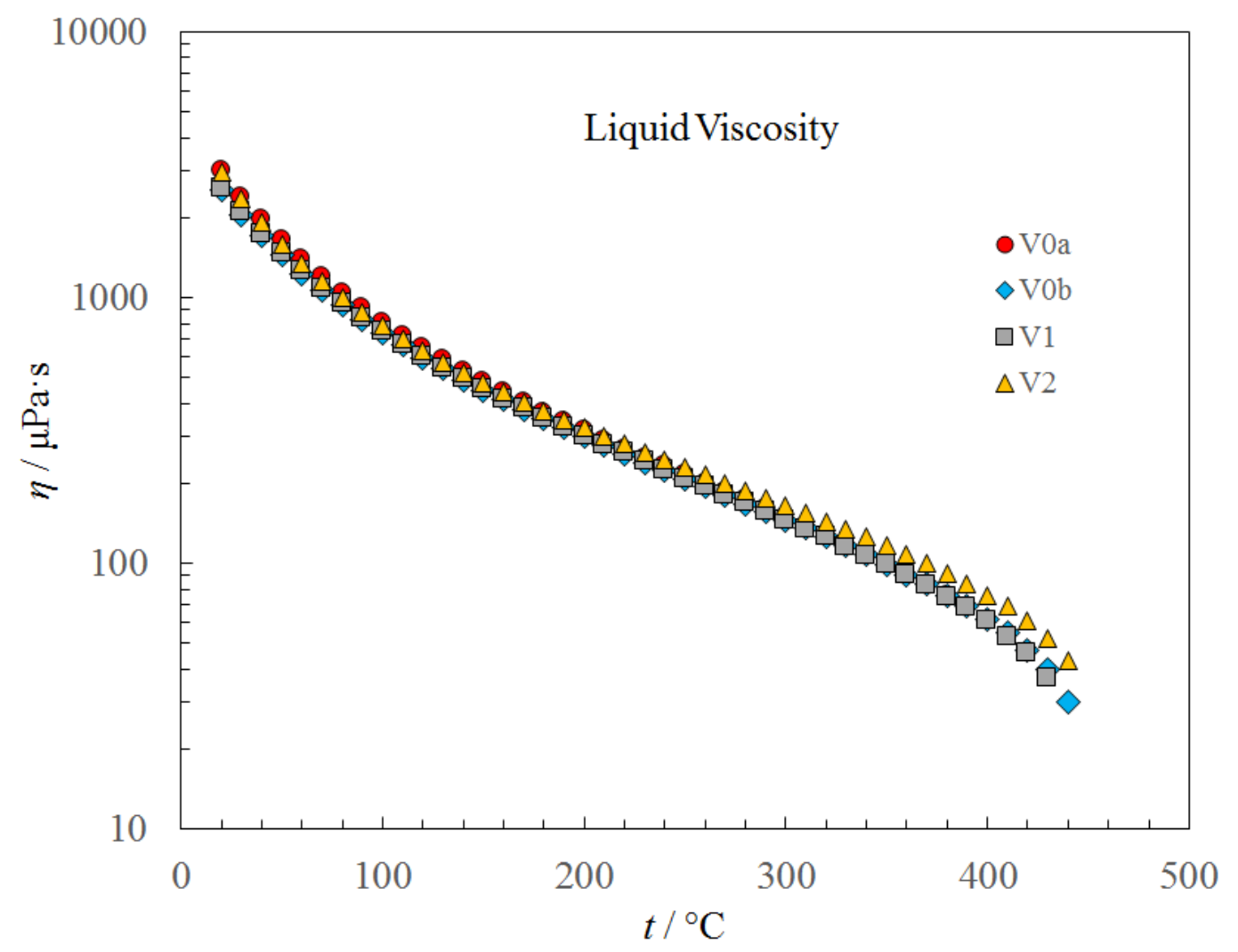

Figure 31. Liquid-phase viscosity along the bubble-point line as a function of temperature 


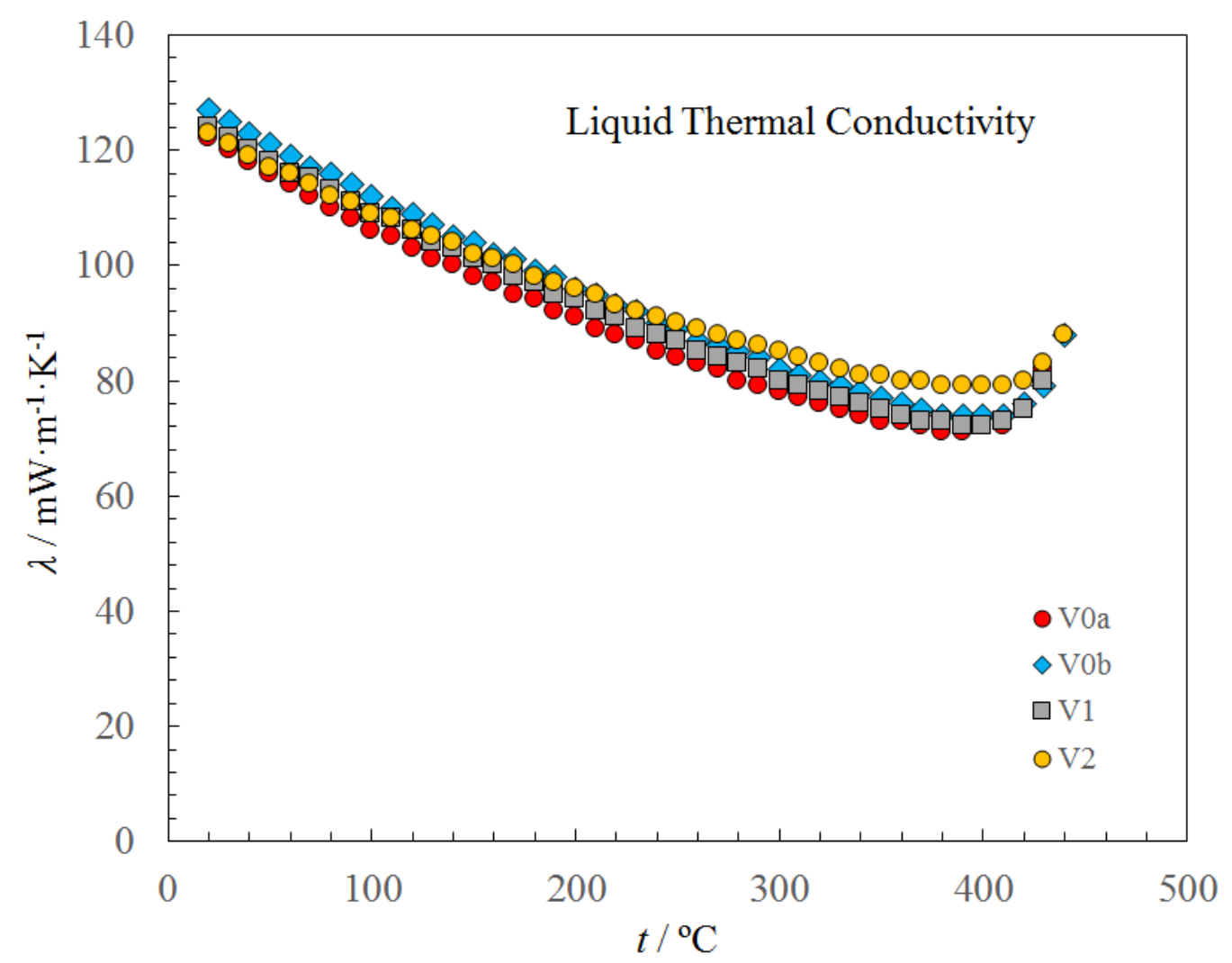

Figure 32. Liquid-phase thermal conductivity along the bubble-point line as a function of temperature 


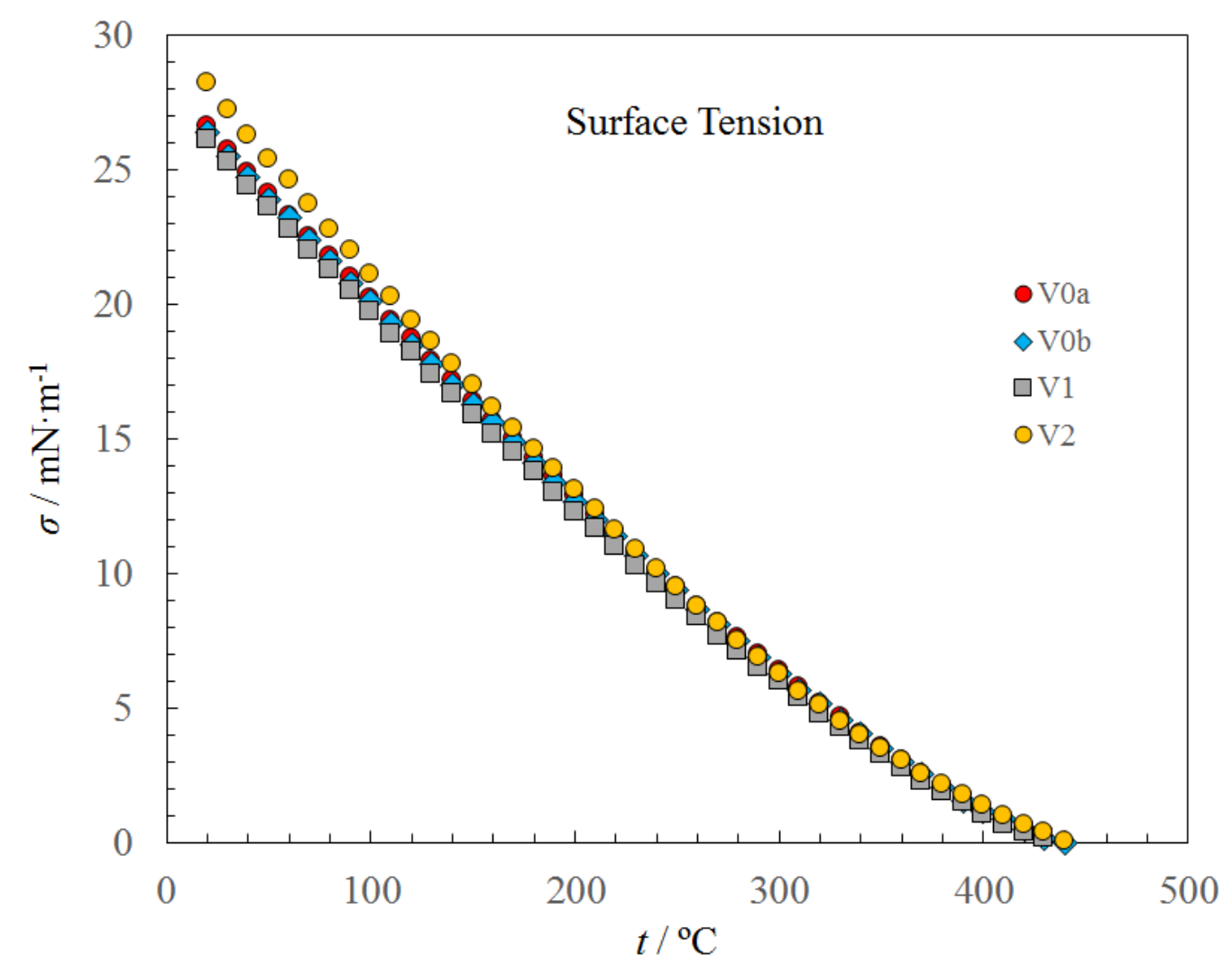

Figure 33. Surface tension along the bubble-point line as a function of temperature

\section{Conclusions}

We present preliminary models for the viscosity, thermal conductivity, and surface tension for thirteen pure fluids used as constituents in four surrogate models (1-3) that can be used to represent the properties of low-sulfur diesel fuels. Comparisons with literature data are given. In many cases the models were developed with little or no experimental data and are subject to large uncertainties, and we recommend that experimental measurements be made to enable more accurate models. For this reason, the models should be considered preliminary. Tables of the viscosity, thermal conductivity, and surface tension of the four surrogates along the bubble-point line are provided that were obtained from using the REFPROP computer program (4) (available from NIST) with the pure fluid transport models developed in this work.

\section{Acknowledgements}

We thank the Coordinating Research Council (CRC) for funding this work. 


\section{References}

1. Mueller CJ, Cannella WJ, Bruno TJ, Bunting B, Dettman HD, Franz JA, Huber ML, Natarajan M, Pitz WJ, Ratcliff MA, and Wright K (2012) Methodology for Formulating Diesel Surrogate Fuels with Accurate Compositional, Ignition-Quality, and Volatility Characteristics. Energy \& Fuels 26(6):3284-3303.

2. Mueller CJ, Cannella WJ, Bays JT, Bruno TJ, DeFabio K, Dettman HD, Gieleciak RM, Huber ML, Kweon CB, McConnell SS, Pitz WJ, and Ratcliff MA (2016) Diesel Surrogate Fuels for Engine Testing and Chemical-Kinetic Modeling: Compositions and Properties. Energy \& Fuels 30(2):1445-1461.

3. Mueller CJ, Cannella WJ, Bays JT, Bruno TJ, DeFabio K, Dettman HD, Gieleciak RM, Huber ML, Kweon CB, McConnell SS, Pitz WJ, and Ratcliff MA (2016) Correction to Diesel Surrogate Fuels for Engine Testing and Chemical-Kinetic Modeling: Compositions and Properties. Energy \& Fuels 30(10):8790.

4. Lemmon EW, Huber ML, and McLinden MO (2013) NIST Reference Fluid Thermodynamic and Transport Properties Database, NIST 23, (REFPROP) (National Institute of Standards and Technology, Gaithersburg, MD), Version 9.1.

5. Chichester JC and Huber ML (2008) Documentation and Assessment of the Transport Property Models for Mixtures Implememented in NIST REFPROP (Version 8.0). in NISTIR 6650 (National Institue of Standards and Technology).

6. Ely JF and Hanley HJM (1981) Prediction of transport properties. 1. Viscosity of fluids and mixtures. Ind. Eng. Chem. Fundam. 20(4):323-332.

7. Ely JF and Hanley HJM (1983) Prediction of transport properties. 2. Thermal conductivity of pure fluids and mixtures. Ind. Eng. Chem. Fundam. 22(1):90-97.

8. Huber ML and Ely JF (1992) Prediction of the Viscosity of Refrigerants and Refrigerant Mixtures. Fluid Phase Equilib. 80:239-248.

9. Huber ML and Ely JF (1992) Prediction of the Thermal Conductivity of Refrigerants and Refrigerant Mixtures. Fluid Phase Equilib. 80:249-261.

10. Huber ML, Laesecke A, and Perkins RA (2003) Model for the viscosity and thermal conductivity of refrigerants, including a new correlation for the viscosity of R134a. Ind. Eng. Chem. Res.42(13):3163-3178.

11. McLinden MO, Klein SA, and Perkins RA (2000) An Extended Corresponding States Model for the Thermal Conductivity of Pure Refrigerants and Refrigerant Mixtures. Int. J. Refrig. 23(1):43-63.

12. Klein SA, McLinden MO, and Laesecke A (1997) An improved extended corresponding states method for estimation of viscosity of pure refrigerants and mixtures. Int. J. Refrigeration 20:208-217.

13. Hirschfelder JO, 1911-, Curtiss CF, and Bird RB (1964) Molecular theory of gases and liquids (Wiley, New York) Corr. print. with notes attached Ed p 1249.

14. Neufeld PD, Janzen AR, and Aziz RA (1972) Empirical Equations to Calculate 16 of the Transport Collision Integrals $\Omega^{(l, s)^{*}}$ for the Lennard-Jones (12-6) Potential. Journal of Chemical Physics 57(3):1100-1102.

15. Mohr PJ, Newell DB, and Taylor BN (2016) CODATA Recommended Values of the Fundamental Physical Constants: 2014. J. Phys. Chem. Ref. Data 45:043102.

16. Olchowy GA and Sengers JV (1989) A simplified representation for the thermal conductivity of fluids in the critical region. Int. J. Thermophys. 10(2):417-426. 
17. Perkins RA, Sengers JV, Abdulagatov IM, and Huber ML (2013) Simplified Model for the Critical Thermal-Conductivity Enhancement in Molecular Fluids. Int. J. Thermophys. 34:191-212.

18. Mulero A and Cachadiña I (2014) Recommended Correlations for the Surface Tension of Several Fluids Included in the REFPROP Program. J. Phys. Chem. Ref. Data 43:023104.

19. Frenkel M, Chirico RD, Diky V, Muzny CD, and Kazakov A (2009) NIST Standard Reference Database 103b, ThermoData Engine (TDE), Version 4.0).

20. Chung TH, Ajlan L, Lee LL, and Starling KE (1988) Generalized multiparameter correlation for nonpolar and polar fluid transport properties. Ind. Eng. Chem. Res.27:671-679.

21. Zambrano JR, Sobrino M, Martin MC, Villamanan MA, Chamorro CR, and Segovia JJ (2016) Contributing to accurate high pressure viscosity measurements: Vibrating wire viscometer and falling body viscometer techniques. J. Chem. Thermo. 96:104116.

22. Lemmon EW and Span R (2006) Short Fundamental Equations of State for 20 Industrial Fluids. J. Chem. Eng. Data 51:785-850.

23. Avgeri S, Assael MJ, Huber ML, and Perkins RA (2015) Reference Correlation of the Viscosity of Toluene from the Triple Point to $675 \mathrm{~K}$ and up to $500 \mathrm{MPa}$. J. Phys. Chem. Ref. Data 44(3):033101.

24. Assael MJ, Mylona SK, Huber ML, and Perkins RA (2012) Reference Correlation of the Thermal Conductivity of Toluene from the Triple Point to $1000 \mathrm{~K}$ and up to 1000 MPa. J. Phys. Chem. Ref. Data 41(2):023101.

25. Watanabe $\mathrm{H}$ and Kato $\mathrm{H}$ (2004) Thermal conductivity and thermal diffusivity of twenty-nine liquids: Alkenes, cyclic (alkanes, alkenes, alkadienes, aromatics), and deuterated hydrocarbons. J. Chem. Eng. Data 49(4):809-825.

26. Bachmann R (1969) Liquid Thermal Conductivities of Derivatives of Benzene Measured By An Unsteady-State Hot Wire Method. Waerme- Stoffuebertrag 2(3):129-134.

27. Rastorguev YL and Pugach VV (1971) Thermal Conductivity of Aromatic Hydrocarbons at High Pressures. Izv. Vyssh. Uchebn. Zaved., Neft Gaz 2:81-84.

28. Mukhamedzyanov GK and Usmanov AG (1968) Thermal Conductivity of Some Classes of Liquid Compounds. Tr. Kazan. Khim.-Tekhnol. Inst. 37:52-63.

29. Donaldson RE and Quayle OR (1950) A study of organic parachors x parachors of american petroleum institute- national bureau of standards hydrocarbons: benzene and homologs of benzene. J. Am. Chem. Soc. 72:35-36.

30. Pan C, Ke Q, Ouyang G, Zhen X, Yang Y, and Huang Z (2004) Excess Molar volumes and Surface Tensions of Trimethylbenzene with Tetrahydrofuran Tetrachloromethane and Dimethylsulfoxide at 298.15 K. J. Chem. Eng. Data 49:1839-1842.

31. Pan CR, Ouyang GF, Lin JL, Rao Y, Zhen XH, Lu GZ, and Huang ZQ (2004) Excess molar volumes and surface tensions of 1,2,4-trimethylbenzene and 1,3,5trimethylbenzene with 1-butanol, 2-methyl-1-propanol, 2-butanol, and 2-methyl-2propanol at 298.15 K. J. Chem. Eng. Data 49(6):1744-1747. 
32. Deng JH, Yang YY, He YM, Ouyang GF, and Huang ZQ (2006) Densities and surface tensions of trimethylbenzene plus dimethyl carbonate or plus diethyl carbonate at 298.15 K and 313.15 K. J. Chem. Eng. Data 51(4):1464-1468.

33. Deng JH, Yang YY, Wang PZ, Ouyang GF, and Huang ZQ (2006) Excess molar volumes and surface tensions of trimethylbenzene plus ethylene glycol ester at 298.15 K and 313.15 K. J. Chem. Eng. Data 51(2):725-729.

34. He YM, Jiang RF, Yang YY, Huang ZQ, and Ouyang GF (2007) Excess molar volumes and surface tensions of 1,2,4-trimethylbenzene and 1,3,5-trimethylbenzene with 1,1-diethoxyethane and 2,2-dimethoxypropane at (298.15, 308.15, and 313.15) K. J. Chem. Eng. Data 52(3):884-888.

35. He YM, Jiang RF, Zhu F, Luan TG, Huang ZQ, and Ouyang GF (2008) Excess molar volumes and surface tensions of 1,2,4-trimethylbenzene and 1,3,5-trimethylbenzene with isopropyl acetate and isobutyl acetate at $(298.15,308.15$, and 313.15$) \mathrm{K} . J$. Chem. Eng. Data 53(5):1186-1191.

36. Yang YY, Deng JH, Yang HL, Zheng XH, Che GQ, and Huang ZQ (2007) Densities, surface tensions, and derived surface thermodynamics properties of (trimethylbenzene plus propyl acetate, or butyl acetate) from $\mathrm{T}=298.15 \mathrm{~K}$ to 313.15 K. J. Chem. Thermo. 39(3):438-448.

37. Fischer J and Weiss A (1986) Transport properties of liquids. V. Self-diffusion, viscosity, and mass density of ellipsoidal shaped molecules in the pure liquid phase. Ber. Bunsen-Ges. Phys. Chem 90:896.

38. Lemmon EW and Huber ML (2004) Thermodynamic Properties of n-Dodecane. Energy \& Fuels 18:960-967.

39. Huber ML, Laesecke A, and Perkins RA (2004) Transport properties of n-dodecane. Energy \& Fuels 18:968-975.

40. (2016) DIPPR DIADEM Professional, Version 8.1.0, Sponsor version (May 2016) (Brigham Young University).

41. (2012) Personal communication from Dr. Eric Lemmon, NIST, 325 Broadway, Boulder, CO 80305.

42. $\quad$ Evans EB (1937) 2 Congr. Mondial Pet., Sect. 2., p 933.

43. Evans EB (1938) The viscosity of hydrocarbons. Parts VII and VIII. J. Inst. Pet. 24:537.

44. Byers CH and Williams DF (1987) Visosities of Pure Polyatomic Hydrocarbons. $J$. Chem. Eng. Data 32:344-348.

45. Caudwell DR, Trusler JPM, Vesovic V, and Wakeham WA (2009) Viscosity and Density of Five Hydrocarbon Liquids at Pressures up to $200 \mathrm{MPa}$ and Temperatures up to 473 K. J. Chem. Eng. Data 54:359-366.

46. Baylaucq A, Boned C, Dauge P, and Lagourette B (1997) Measurements of the Viscosity and Density of Three Hydrocarbons and the Three Associated Binary Mixtures Versus Pressure and Temperature. Int. J. Thermophys. 18:1089-1107.

47. Peleties F and Trusler JPM (2011) Viscosity of Liquid Di-isodecyl Phthalate at Temperatures Between (274 and 373) K and at Pressures up to $140 \mathrm{MPa}$. J. Chem. Eng. Data 56:2236-2241.

48. Canet X, Dauge P, Baylaucq A, Boned C, Zeberg-Mikkelsen CK, Quinones-Cisneros SE, and Stenby EH (2001) Density and Viscosity of the 1-Methylnaphthalene + 
2,2,4,4,6,8,8-Heptamethylnonane System from 293.15 to $353.15 \mathrm{~K}$ at Pressures up to $100 \mathrm{MPa}$. Int. J. Thermophys. 22:1669-1689.

49. Perkins RA, Sloan ED, and Graboski MS (1986) Experimental Study of the Thermal Conductivity of Coal Liquefaction Products and Some Constituent Pure Compounds. Ind. Eng. Chem. Proc. Des. Dev 25:1016-1022.

50. Vogel AI (1948) Physical Properties and Chemical Constitution. Part X V. The Phenyl Group. J. Chem. Soc.:654-658.

51. Fox HW, Hare EF, and Zisman WA (1955) Wetting Properties of Organic Liquids on High-energy Surfaces. J. Phys. Chem. 59:1097.

52. Arrowsmith GB, Jeffery GH, and Vogel AI (1965) Physical properties and chemical constitution. XLI. Naphthalene Compounds. J. Chem. Soc.:2072-2078.

53. (2009) Personal communication from Dr. Eric Lemmon, NIST, 325 Broadway, Boulder, CO 80305.

54. (1978) Tetralin, API Monograph Series, Publication 705, American Petroleum Institute. (Washington, D.C.).

55. Jasper J (1972) The surface tension of pure liquid compounds. J. Phys. Chem. Ref. Data 1(4):841-1009.

56. (2006) Personal communication from Dr. Eric Lemmon, NIST, 325 Broadway, Boulder, CO 80305.

57. Li GQ, Chi H, Guo YS, Fang WJ, and Hu SL (2013) Excess Molar Volume along with Viscosity and Refractive Index for Binary Systems of Tricyclo 5.2.1.0(2.6) decane with Five Cycloalkanes. J. Chem. Eng. Data 58(11):3078-3086.

58. Jiang XD, He GJ, Wu X, Guo YS, Fang WJ, and Xu L (2014) Density, Viscosity, Refractive Index, and Freezing Point for Binary Mixtures of 1,1 '-Bicyclohexyl with Alkylcyclohexane. J. Chem. Eng. Data 59(8):2499-2504.

59. Liu H and Zhu L (2014) Excess Molar Volumes and Viscosities of Binary Systems of Butylcyclohexane with n-Alkanes (C7 to C14) at T=293.15 K to $313.15 \mathrm{~K}$. J. Chem. Eng. Data 59(2):369-375.

60. Zhang C, Li G, Yue L, Guo Y, and Fang W (2015) Densities, Viscosities, Refractive Indices, and Surface Tensions of Binary Mixtures of 2,2,4-Trimethylpentane with Several Alkylated Cyclohexanes from (293.15 to 343.15) K. J. Chem. Eng. Data 60:2541-2548.

61. Perkins RA, Hammerschmidt U, and Huber ML (2008) Measurement and correlation of the thermal conductivity of methylcyclohexane and propylcyclohexane from (300 to 600) K at pressures to $60 \mathrm{MPa}$. J. Chem. Eng. Data 53(9):2120-2127.

62. Bruno TJ, Fortin TJ, Lovestead TM, and Widegren JA (2012) Chemical and Thermophysical Characterization of 1,3,5-Triisopropylcyclohexane. J. Chem. Eng. Data 57(8):2343-2349.

63. (2016) Personal communication from Dr. Eric Lemmon, NIST, 325 Broadway, Boulder, CO 80305.

64. Seyer WF and Leslie JD (1942) The viscosity of cis and trans decahydronaphthalene. Journal of the American Chemical Society 64:1912-1916.

65. Zeberg-Mikkelsen CK, Baylaucq A, Barrouhou M, and Boned C (2003) The effect of stereoisomerism on dynamic viscosity: A study of cis-decalin and trans-decalin versus pressure and temperature. Physical Chemistry Chemical Physics 5(8):15471551. 
66. Span R and Wagner W (2003) Equations of State for Technical Applications. II. Results for Nonpolar Fluids. Int. J. Thermophys. 24(1):41-109.

67. Huber ML, Laesecke A, and Xiang HW (2004) Viscosity correlations for minor constituent fluids in natural gas: n-octane, n-nonane and n-decane. Fluid Phase Equilib. 224:263-270.

68. Huber ML and Perkins RA (2005) Thermal conductivity correlations for minor constituent fluids in natural gas: n-octane, n-nonane and n-decane. Fluid Phase Equilib. 227:47-55.

69. Frezzotti D, Goffredi G, and Bencini E (1995) Thermal-conductivity measurements of cis-decahydronaphthalene and trasn-decahydronaphthalene using a steady-state coaxial cylinders method. Thermochimica Acta 265:119-128.

70. Perkins RA (1983) Development of a Transient Hot Wire Instrument to Measure the Thermal Conductivity of Fluids at High Temperatures and Pressures. PhD PhD (Colorado School of Mines, Golden, CO).

71. Briggs DKH (1957) Thermal conductivity of liquids. Ind. Eng. Chem. 49:418-421.

72. Assael MJ, Mihailidou EK, Huber ML, and Perkins RA (2012) Reference Correlation of the Thermal Conductivity of Benzene from the Triple Point to $725 \mathrm{~K}$ and up to 500 MPa. J. Phys. Chem. Ref. Data 41(4).

73. Assael MJ, Bogdanou I, Mylona SK, Huber ML, Perkins RA, and Vesovic V (2013) Reference Correlation of the Thermal Conductivity of n-Heptane from the Triple Point to $600 \mathrm{~K}$ and up to $250 \mathrm{MPa}$. J. Phys. Chem. Ref. Data 42(2).

74. Mylona SK, Antoniadis KD, Assael MJ, Huber ML, and Perkins RA (2014) Reference Correlations of the Thermal Conductivity of o-Xylene, m-Xylene, pXylene, and Ethylbenzene from the Triple Point to $700 \mathrm{~K}$ and Moderate Pressures. $J$. Phys. Chem. Ref. Data 43(4).

75. Seyer WF and Davenport CH (1941) The densities and surface tensions of cis- and trans-decahydronaphthalene between-30 and 180 degrees. Journal of the American Chemical Society 63:2425-2427.

76. Lemmon EW, McLinden MO, and Wagner W (2009) Thermodynamic Properties of Propane. III. A Reference Equation of State for Temperatures from the Melting Line to $650 \mathrm{~K}$ and Pressures up to $1000 \mathrm{MPa}$. J. Chem. Eng. Data 54:3141-3180.

77. Vogel E, Küchenmeister C, Bich E, and Laesecke A (1998) Reference Correlation of the Viscosity of Propane. J. Phys. Chem. Ref. Data 27:947-970.

78. Marsh K, Perkins RA, and Ramires MLV (2002) Measurement and Correlation of the Thermal Conductivity of Propane from 86 to $600 \mathrm{~K}$ at Pressures to $70 \mathrm{MPa}$. J. Chem. Eng. Data 47(4):932-940.

79. Gudzinowicz BJ, Campbell RH, and Adams JS (1963) Specific Heat Measurements of Complex Saturated Hydrocarbons. J. Chem. Eng. Data 8:201-204.

80. (1968) Properties of hydrocarbons of high molecular weight, American Petroleum Institute Research Project 42, Penn. State University.

81. Boelhouwer JWM, Nederbragt GW, and Verberg GW (1950) Viscosity data of organic liquids. Appl. Sci. Res. 2:249-268.

82. Lusternik VE and Zdanov AG (1973) Viscosity of alkanes, alkenes and alkines in gaseous phase. Teplofiz. Svoistva Veshchestv Mater., Rabinovich, V. A., Ed., Standards Publ.: Moscow 7. 
83. Ducoulombier D, Zhou H, Boned C, Peyrelasse J, Saintguirons H, and Xans P (1986) Pressure (1-1000 bars) and temperature (20-100-degrees $C$ ) dependence of the viscosity of liquid hydrocarbons. Journal of Physical Chemistry 90(8):1692-1700.

84. Rajagopal K, Andrade LLPR, and Paredes MLL (2009) High-Pressure Viscosity Measurements for the Binary System Cyclohexane plus n-Hexadecane in the Temperature Range of (318.15 to 413.15) K. J. Chem. Eng. Data 54(10):2967-2970.

85. Baled HO, Xing D, Katz H, Tapriyal D, Gamwo IK, Soong Y, Bamgbade BA, Wu Y, Liu K, McHugh MA, and Enick RM (2014) Viscosity of n-hexadecane, n-octadecane and n-eicosane at pressures up to $243 \mathrm{MPa}$ and temperatures up to $534 \mathrm{~K}$. J. Chem. Thermo. 72:108-116.

86. Dymond JH and Young KJ (1980) Transport properties of nonelectrolyte liquid mixtures I. Viscosity coefficients for n-alkane mixtures at saturation pressure from 283 to 378 K. Int. J. Thermnophys. 1:331-344.

87. Golubev IF (1959) Viscosity of Gases and Gas Mixtures (Fizmat Press, Moscow).

88. Tarzimanov AA and Mashirov VE (1967) Experimental Investigation of the Thermal Conductivity of Vapours of Normal Saturated Hydrocarbons at Temperatures up to 450 deg C. Teploenergetika 14:67-69.

89. Tarzimanov AA and Mashirov VE (1970) Experimental determination of the thermal conductivity coefficient of n-alkane, alcohol, and acid vapors. Teplofiz. Svoistva Veshchestv Mater., Rabinovich, V. A., Ed., Standards Publ.: Moscow:183-193.

90. Mustafaev RA (1973) Thermal conductivity of high saturated hydrocarbons in the wide temperature and pressure ranges. Inzh.-Fiz. Zh. 24:663-668.

91. Mukhamedzyanov GK, Usmanov AG, and Tarzimanov AA (1963) Experimental determination of the thermal conductivity of saturated hydrocarbons. Izv. Vyssh. Uchebn. Zaved., Neft Gaz 6:75-79.

92. Jasper JJ, Kerr ER, and Gregorich F (1953) The Orthobaric Surface Tensions and Thermodynamic Properties of the Liquid Surfaces of the n-Alkanes, C6 to C28. J. Am. Chem. Soc. 75:5252-5254.

93. Jasper JJ and Kring EV (1955) The isobaric surface tensions and thermodynamic properties of the surfaces of a series of n-alkanes, $\mathrm{c} 5$ to $\mathrm{c} 18,1$-alkenes, $\mathrm{c} 6$ to $\mathrm{c} 16$, and of n-decylcyclopentane, n-decylcyclohexane and n-decylbenzene. J. Phys. Chem. 59:1019-1021.

94. Rolo LI, Caco AI, Queimada AJ, Marrucho IM, and Coutinho JAP (2002) Surface tension of heptane, decane, hexadecane, eicosane, and some of their binary mixtures. J. Chem. Eng. Data 47(6):1442-1445.

95. Mohsen-nia M (2011) Measurement and modelling of surface tensions of systems containing n-hexadecane, n-heptane and n-pentane. Physics and Chemistry of Liquids 49(5):608-614.

96. (2003) Personal communication from Dr. Eric Lemmon, NIST, 325 Broadway, Boulder, CO 80305.

97. Riesco N and Vesovic V (2016, in press) Extended Hard-Sphere Model for Predicting the Viscosity of long-chain n-alkanes. Fluid Phase Equilib.

98. Caudwell DR, Trusler JPM, Vesovic V, and Wakeham WA (2004) The Viscosity and Density of n-Dodecane and n-Octadecane at Pressures up to 200MPa and Temperatures up to 473K. Int. J. Thermnophys. 25:1339-1352. 
99. Naziev YM and Aliev MA (1973) Study of the thermophysical properties of nundecane; n-heptadecane and n-octadecane at various temperatures and pressures. Izv. Vyssh. Uchebn. Zaved., Neft Gaz 16:73-76.

100. Queimada AJ, Quiñones-Cisneros SE, Marrucho IM, Coutinho JAP, and Stenby EH (2003) Viscosity and Liquid Density of Asymmetric Hydrocarbon Mixtures. Int. J. Thermophys. 24:1221-1239.

101. Queimada AJ, Quiñones-Cisneros SE, Marrucho IM, Coutinho JAP, and Stenby EH (2005) Viscosity and Liquid Density of Asymmetric n-Alkane Mixtures:

Measurement and Modeling. Int. J. Thermophys. 26:47-61.

102. Rastorguev YL, Bogatov GF, and Grigov'ev BA (1974) A Study of the Thermal Conductivity of Higher n-Alkanes. Khim. Tekhnol. Topl. Masel 9:54.

103. Queimada AJ, Silva FAE, Caco AI, Marrucho IM, and Coutinho JAP (2003) Measurement and modeling of surface tensions of asymmetric systems: heptane, eicosane, docosane, tetracosane and their mixtures. Fluid Phase Equilib. 214:211221.

104. Queimada AJ, Caco AI, Marrucho IM, and Coutinho JAP (2005) Surface tension of decane binary and ternary mixtures with eicosane, docosane and tetracosane. $J$. Chem. Eng. Data 50:1043-1046.

105. Terres E, Brinkmann L, Fischer D, Huellstrung D, Lorz W, and Weisbrod G (1959) Synthesis and physical property data for some iso-parafins with 11 to 24 atoms. Brennst.-Chem. 40:279-280.

106. Et-Tahir A, Boned C, Lagourette B, and Xans P (1995) Determination of the viscosity of various hydrocarbons and mixtures of hydrocarbons versus temperature and pressure. Int. J. Thermophys. 16:1309-1334.

107. Barrouhou M, Zeberg-Mikkelsen CK, Baylaucq A, and Boned C (2003) HighPressure Viscosity and Density Measurements for the Asymmetric Binary System cisDecalin +2,2,4,4,6,8,8-Heptamethylnonane. Int. J. Thermophys. 24:937-952.

108. Prak DJL, Alexandre SM, Cowart JS, and Trulove PC (2014) Density, Viscosity, Speed of Sound, Bulk Modulus, Surface Tension, and Flash Point of Binary Mixtures of n-Dodecane with 2,2,4,6,6-Pentamethylheptane or 2,2,4,4,6,8,8-

Heptamethylnonane. J. Chem. Eng. Data 59:1334-1346.

109. Luning Prak D, Jones M, Cowart J, and Trulove P (2015) Density, Viscosity, Speed of Sound, Bulk Modulus, Surface Tension, and Flash Point of Binary Mixtures of 2,2,4,6,6-Pentamethylheptane and 2,2,4,4,6,8,8-Heptamethylnonane at (293.15 to 373.15) K and 0.1 MPa and Comparisons with Alcohol-to-Jet Fuel. J. Chem. Eng. Data 60:1157-1165.

110. Korosi G and Kovats E (1981) Density and Surface Tension of 83 Organic Liquids. $J$. Chem. Eng. Data 26:323-332.

111. Lemmon EW, Bell IH, Huber ML, and McLinden MO (2016) NIST Reference Fluid Thermodynamic and Transport Properties Database, NIST 23, (REFPROP), Beta Version v9.1.1 (DLL 9.1304) (National Institute of Standards and Technology, Gaithersburg, MD), Version 9.1.1. 


\section{Appendix}

Seventeen text files (.FLD and .MIX) that can be used with the REFPROP computer program are included here in a zip file archive, Appendix.TN1949.zip that is available from https://doi.org/10.6028/NIST.TN.1949s. The files are designed to be used with versions of REFPROP released after v9.1.1 (May 2016) As improved models and data become available, they will be updated, so these files should be treated as preliminary. The files are named V0a.mix, V0b.mix, V1.mix, V2.mix, C16.FLD, C18.FLD, C20.FLD, ISOC16.FLD, 2MC17.FLD, 135TPCC6.FLD, 135TIPBZ.FLD, TDEC.FLD, TDHP.FLD, C4CC6.FLD, TETRALIN.FLD, 1MNAPH.FLD, and 124MBEN.FLD. 